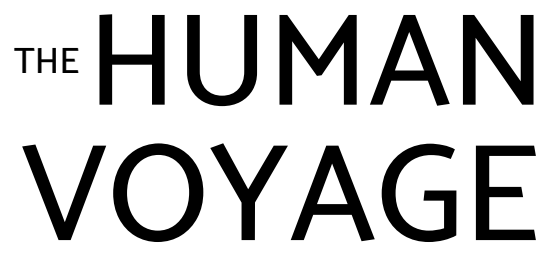

UNDERGRADUATE RESEARCH IN BIOLOGICAL ANTHROPOLOGY 



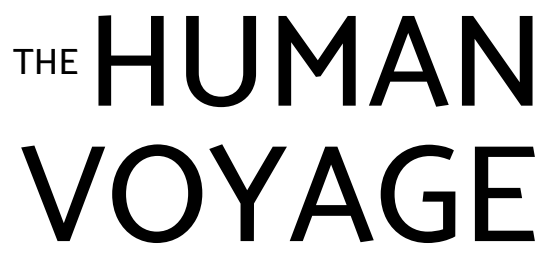

UNDERGRADUATE RESEARCH IN BIOLOGICAL ANTHROPOLOGY

VOLUME 1, 2017

* Australian

National

University

eVIEW 


\section{ANU eVIEW}

Published by ANU eView

The Australian National University

Acton ACT 2601, Australia

Email: enquiries.eview@anu.edu.au

This title is also available online at press.anu.edu.au

ISSN 2208-1984 (print)

ISSN 2208-1992 (online)

All rights reserved. No part of this publication may be reproduced, stored in a retrieval system or transmitted in any form or by any means, electronic, mechanical, photocopying or otherwise, without the prior permission of the publisher.

Cover design and layout by ANU Press.

Front cover photograph by Peter Williams.

Opinions published in The Human Voyage do not necessarily represent those of The Australian National University, or the editors.

This edition (C) 2017 ANU eView 


\section{Contents}

Wind suppresses calling in northern buff-cheeked crested gibbons (Nomascus annamensis). . . . . . . . . . . . . . . . . . . . 1 Jessica Williams

Taking care in prehistoric Latin America: A case study of care giving among hunter-gatherers in the Final Late Holocene . . . . . . . . . . 17 Terri Fisher

Factors affecting energetic regulation of ovulation leading to birth seasonality in tropical and temperate subpopulations . . . . . . . . 31 Tess Johnson

Environmental and health effects of early copper metallurgy and mining in the Bronze Age. . . . . . . . . . . . . . . . . . . . . . 45

\section{Sarah Martin}

Dealing with predators: Vigilance and alarm calling in primates . . . . . . 63 Phoebe Raff

Primate social structure as a predictor of modes of communication and the ability to learn a human language $\ldots \ldots \ldots \ldots \ldots \ldots \ldots 73$

Rebecca Jade Sullivan

Skeletal evidence of torture: How can the past inform the present? . . . . 87 Victoria Tasker

When the forest calls: My experience on the Primate Behavioural Ecology Field School in Cambodia . . . . . . . . . . . . . . . . . . . 97 Cynthia Parayiwa

So that their graves overlooked the sea: Student experience of the Philippines International Archaeological Field School. . . . . . . . . . . . . 105 Melandri Vlok

Author biographies......................... 113 



\title{
Wind suppresses calling in northern buff-cheeked crested gibbons (Nomascus annamensis)
}

\author{
Jessica Williams
}

\begin{abstract}
Communication is multimodal, occurring through many different mediums, and enables relationships to be formed and regulated. As communication is costly to an individual, selection pressures have driven signal formats towards those that maximise the likelihood of success while still being affordable to those producing them. In vocal communication, the acoustic structures of calls and the associated behaviours ensure maximum transmission in an individual's environment, increasing the likelihood that the signal will reach the intended receiver. Nomascus annamensis (northern buff-cheeked crested gibbon), like other gibbon species, is inconspicuous and, as a result, vocalisation surveys are the best way to assess population size and density. I used data produced from vocalisation surveys of three populations of $N$. annamensis in Mondulkiri Province, Cambodia, to assess if wind speed, cloud cover, fog and rain the night before and the morning of surveys impacted calling probability. The findings suggest that wind speed and cloud cover significantly affect calling probability of $N$. annamensis. These findings are relevant for improving the accuracy of population estimates developed from vocalisation surveys.
\end{abstract}

\section{Keywords}

gibbons, communication, wind, calling probability, vocalisation survey 


\section{Introduction}

Communication is extremely important as it enables the creation and regulation of relationships that are essential to the fitness and survival of individuals (Salmi et al. 2013). For primates inhabiting forest environments, vocal signals are the most efficient way of communicating over long distances, as visual and olfactory cues are likely to be obscured (Waser and Waser 1977; Salmi et al. 2013). Predation, habitat and social structure have shaped the vocal repertoire of primate species. For example, Gustison et al. (2012) found a positive correlation between social complexity and the size of a species' vocal repertoire. Vocalisations may function to alert group members to the presence of predators, maintain spatial orientation and advertise resource (mate/ territory) holding ability (Cowlishaw 1996; Sun et al. 2011).

The transmission of acoustic signals is dependent on factors such as the frequency of the sound, the height from which the sound is produced, meteorological conditions and time of day (Waser and Waser 1977; Waser and Brown 1986; Bezerra et al. 2012). The production of vocalisations is energetically costly and can alert predators to the caller's location. As a result, selection pressures have acted on both the acoustic structures of vocalisations and the associated behaviours, driving them towards optimal transmission at minimum cost (Range and Fischer 2004). Range and Fischer (2004) found that the acoustic elements of vocalisations by Cercocebus atys (sooty mangabey) have evolved to minimise distortion while travelling through a forest environment. These acoustic adaptations are particularly important for longdistance calls, which are thought to have species dependent, intragroup and intergroup functions (Oliveira and Ades 2004). Intragroup functions of long calls include spatial coordination and alarm calling, while extragroup functions include mate and/or resource protection and mate acquisition (Oliveira and Ades 2004). Most primate long-distance calls have high amplitudes and low frequencies to minimise attenuation due to atmospheric absorption, scattering and interference from reverberations off the ground (Mitani and Stuht 1998; Oliveira and Ades 2004).

The calling behaviour of animals also reflects selection for optimal message transmission at minimal energetic cost. Mated pairs of Aptenodytes patagonicus (king penguins) take it in turns to hunt and to incubate their offspring (Lengagne et al. 1999). Aptenodytes patagonicus live in colonies composed of several thousand, on sub-Antarctic islands that experience strong winds (Lengagne et al. 1999). The penguins use vocalisations to locate each other on their return from the sea (Lengagne et al. 1999). Lengagne et al. (1999) 
found that the number of calls produced increased with wind speed. Since background noise increases with wind speed, Lengagne et al. (1999) suggests that by increasing the number of calls the penguins are able to increase the probability of their signal reaching the receiver during a window of low-wind speed.

Many animals avoid signal interference by producing vocalisations during a 'sound window' where there is limited interference from ambient noise (Waser and Waser 1977). In a large portion of African savannas, near-surface atmospheric conditions are optimum for sound transmission at dusk and dawn (Larom et al. 1997). These optimal atmospheric conditions may have acted as a selection pressure on the calling behaviour of Panthera leo (lions): Schaller (1972) reported peaks in the number of calls at dusk and dawn. Waser and Waser (1977) studied the long-distance vocalisation of four Old World monkey species living in the Kibale forest: 1) Lophocebus ugandae (grey checked mangabey); 2) Cercopithecus mitis (blue monkey); 3) Cercopithecus ascanius (red-tailed monkey); and 4) Colobus guereza (black-and-white colobus). They found that the male long-range calls of $L$. ugandae were produced between 7-9 am, and those of C. mitis and C. ascanius in the first few hours after dawn, while the calls of $C$. guereza were all produced before dawn at around 5 am (Waser and Waser 1977). By calling in this early morning 'sound window', and using a low frequency, primates living in the forest environments are able to improve communication and reduce the cost of calling (Morrill et al. 2013).

Gibbons are the smallest of the apes and belong to the family Hylobatidae (Mootnick and Fan 2011). They typically live in territorial, socially monogamous family groups consisting of a male-female pair and their offspring (Sun et al. 2011). All gibbon species produce long-distance calls, known as songs, usually in the early morning (Geissmann and Nijman 2006; Sun et al. 2011). The contributions of the male and female in a pair are sex-specific and the song types of mate pairs differ between species (Geissmann and Nijman 2006; Sun et al. 2011). Duets are produced by 10 species (all belonging to the genera Hoolock, Nomascus and Symphalangus), duets and male solo songs are produced by four species (Hylobates agilis, H. lar, H. muelleri and H. pileatus), and female and male solo songs are produced by two species $(H$. klossii and H. moloch; Geissmann and Nijman 2006). The calls of gibbons are thought to have several functions, including spacing among groups, defence of resources, mate attraction and strengthening or advertising pair bond (Geissmann and Nijman 2006). The duets of crested gibbons (Nomascus spp.) are highly stereotyped and male-dominated with a high level of sexual specificity in their songs (Konrad and Geissmann 2006). 
Nomascus annamensis is found east of the Mekong River in northeastern Cambodia, southern Vietnam and possibly southern Laos (Rawson et al. 2009). They primarily inhabit evergreen forests but are also found in semi-evergreen, mixed deciduous and bamboo forests (Rawson et al. 2009). Home ranges of $N$. annamensis are approximately 30 hectare, which is similar to other species of gibbon (Rawson et al. 2009). The diet of $N$. annamensis consists of fruit, leaves and flowers (Traeholt et al. 2006; Rawson et al. 2009). Gibbons are typically inconspicuous and are often hard to find because of their low visibility and unpredictable behaviour in response to humans (Rawson 2004). For this reason, under ideal conditions the long-range duets of gibbons can be heard from up to 3 kilometres away (Rawson 2004), and can be used to locate groups and conduct population surveys.

The aim of this study is to investigate if weather conditions affect calling probability in three populations of $N$. annamensis. This knowledge will help to improve the accuracy of population size and density estimates produced from vocalisation surveys. By using data sets from Rawson (2004) and Rawson et al. (2009) I will assess if rain the night before surveys, rain on the morning of surveys, wind, the presence of cloud or fog affected the likelihood of calling by $N$. annamensis. I predict that wind, which increases ambient noise and prevents the vocal signals from reaching the intended receivers, will reduce calling probability. I also predict that morning rain will decrease calling probability due to raindrops creating increased ambient noise. I will investigate the interaction of wind speed and cloud cover and predict that the effect of the combined presence of these weather conditions will result in decreased calling probability. The findings of my study will help build on those established in Rawson (2004) and assist in more accurately assessing the presence of gibbons and estimating population density.

\section{Methods}

\section{Data sets}

Data were collected from Rawson (2004) and Rawson et al. (2009), who conducted vocalisation surveys of three populations of $N$. annamensis, collecting a total of 115 samples. Data were collected at three different sites and calls were recorded from a total of 19 groups: three groups at Camp 6 and eight groups each at Elephant Rock and Snake Hill (Rawson 2004; Rawson et al. 2009). 
Wind suppresses calling in northern buff-cheeked crested gibbons

\section{Study sites}

The data used in Rawson (2004) were collected at a study area in Mondulkiri Provence, eastern Cambodia, referred to as Camp 6 (C6 in Figure 1). The forest is mixed deciduous and dry deciduous forest with seasonal meadows and is part of a logging concession area (Rawson 2004). The majority of the rainfall at Camp 6 occurs between May and October (Rawson 2004), in line with the wet season in Cambodia. Rawson et al. (2009) further used data collected in the Seima Biodiversity Conservation Area, which is also located in Mondulkiri Provience (Figure 1). Vocalisation surveys were conducted in two nonoverlapping plots referred to as Elephant Rock and Snake Hill (ER and $\mathrm{SH}$ in Figure 1).

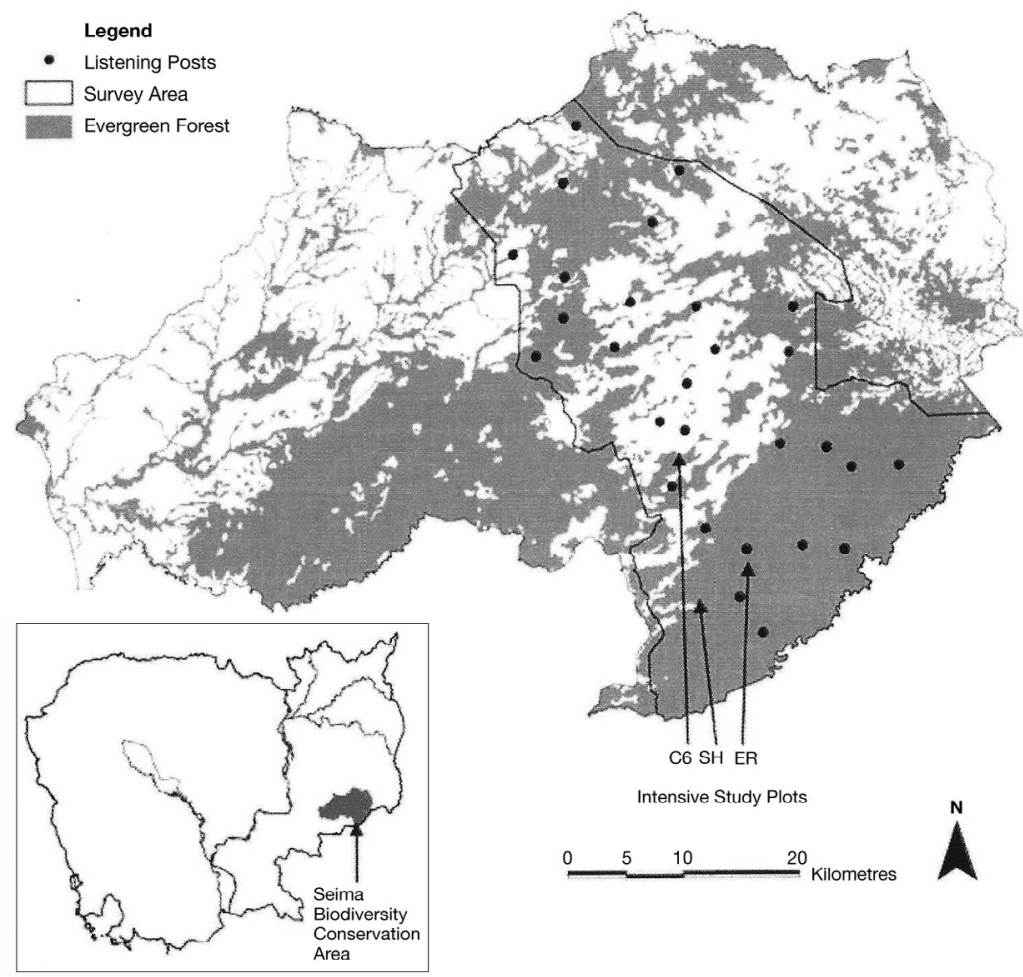

Figure 1: Map of study site locations

Source: Rawson et al. (2009). 


\section{Data collection}

Vocalisation surveys at Camp 6 were conducted for at least five consecutive days per month for 11 months (December 2002 through October 2003) totalling 89 days (Rawson 2004). Surveys were conducted from 30 minutes before sunrise until $7 \mathrm{am}$ from the fixed listening post (Rawson 2004). Duets and solo calls were recorded, as well as vocalisation start times, time of sunrise, duration of call and weather conditions (Rawson 2004). Data were collected at Elephant Rock and Snake Hill in December 2003 and January 2004, to coincide with the driest part of the year (Rawson et al. 2009). At each site, vocal surveys were conducted by the same individual over a total of 27 days: 13 consecutive days in December and 14 consecutive days in January (Rawson et al. 2009). All duet and solo calls heard between a half hour before sunrise and $12 \mathrm{pm}$ were recorded, along with time of call, compass bearing of group, estimated distance and weather conditions (Rawson et al. 2009). In both studies, if a group stopped vocalising for more than five minutes before starting again it was considered a new 'bout' and analysed separately (Rawson 2004; Rawson et al. 2009). Cloud cover, wind and fog were recorded using a subjective scale of $0-3(0=$ absent, $1=$ low, $2=$ medium, $3=$ high: Rawson 2004; Rawson et al. 2009).

\section{Analysis}

In order to increase the statistical power of my results, I combined the data collected from the three sites. As the number of $N$. annamensis groups at each site was known, I was able to conduct my analysis using the proportion of groups that called each day. I used a generalised linear model to assess the impact of wind, cloud, fog, rain and rain the night before on the calling probability of the combined study populations. As the data from Elephant Rock and Snake Hill were collected in the dry season there was no rain, and for this reason I assessed the impact of rain only the night before and morning of vocalisation surveys for Camp 6. I also considered the combination of the presence of wind and cloud for all locations. I adjusted the scale used by Rawson (2004) for cloud cover and wind, combining 'low' and 'medium' into a 'low' category, leaving me with three categories (absent, low and high). 


\section{Results}

The presence of wind had a significant effect on mean calling probability $\left(\chi^{2}=7.014, \mathrm{df}=2, \mathrm{p}=0.03\right)$, which decreased as a function of wind speed (Figure 2).

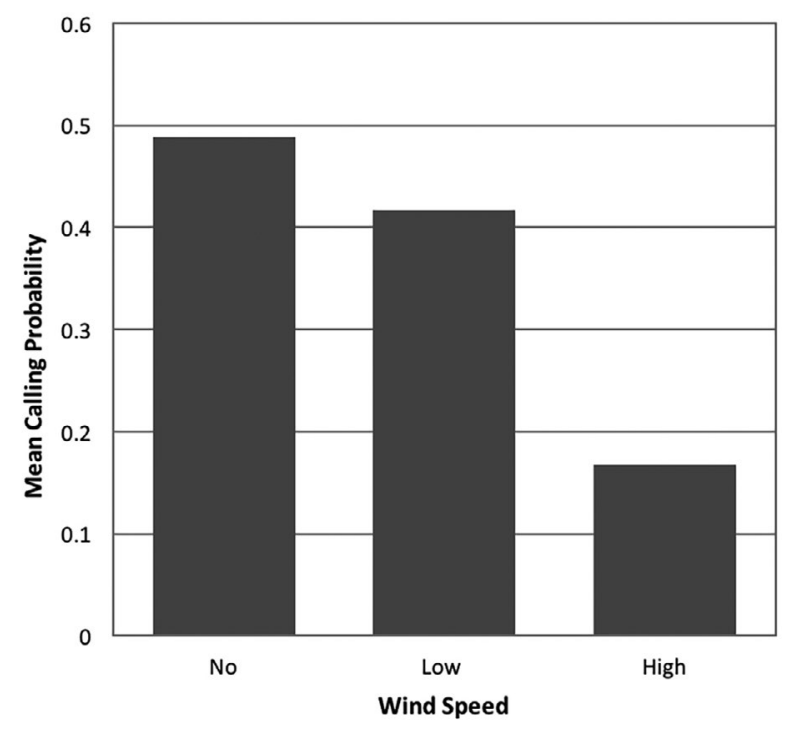

Figure 2: The effect of wind speed on mean calling probability Source: Author.

The amount of cloud cover present had a significant effect on mean calling probability $\left(\chi^{2}=6.020, \mathrm{df}=2, \mathrm{p}=0.049\right)$, with the probability of calling being lower when cloud cover was moderate or heavy compared to when cloud was absent (Figure 3). Mean calling probability increased slightly when cloud cover went from moderate to high (Figure 3). 


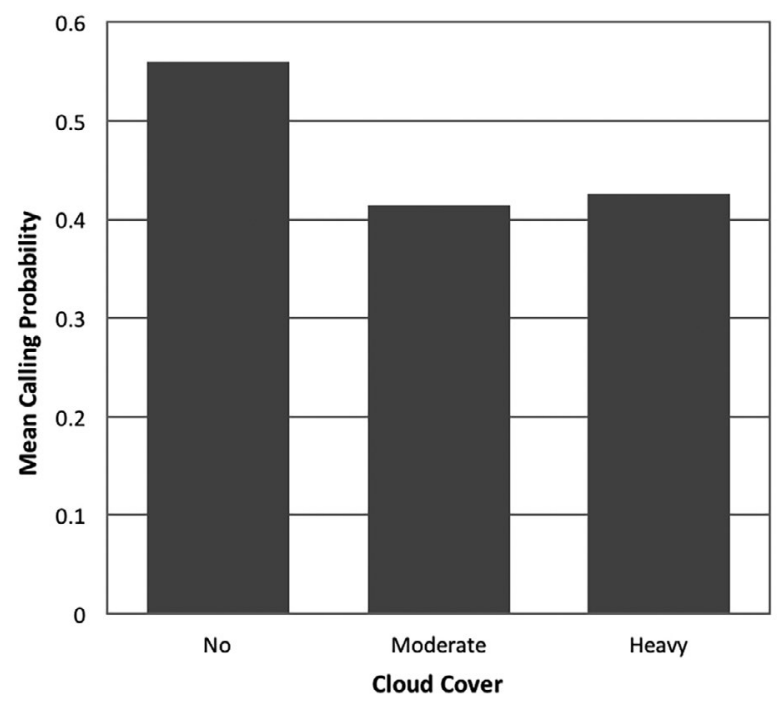

Figure 3: The effect of cloud cover on mean calling probability Source: Author.

Fog was only present on 26.1 per cent of the days data were collected (30 of 115 total days), and did not have a significant effect on the mean calling probability of the sample populations $\left(\chi^{2}=0.922, \mathrm{df}=1, \mathrm{p}=0.337\right)$. On days when fog was absent, the mean calling probability was 0.480 , and on days where fog was present mean calling probability was 0.481 .

When the impact of wind speed and cloud cover on calling likelihood were analysed together, the interaction was found to have a significant effect on mean calling probability $\left(\chi^{2}=4.059, \mathrm{df}=1, \mathrm{p}=0.044\right.$; Figure 4). When wind speed was low, the probability of calling decreased between moderate to heavy cloud cover ( 0.453 and 0.344 , respectively) (Figure 5$)$. When wind speed was high, the probability of calling increased dramatically between moderate to heavy cloud cover ( 0.125 to 0.25 , respectively) (Figure 6). 
Wind suppresses calling in northern buff-cheeked crested gibbons

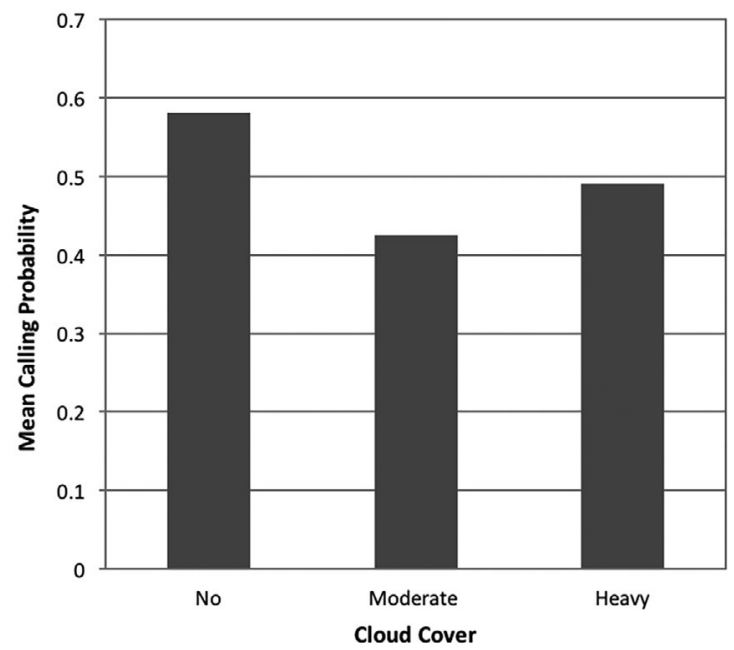

Figure 4: The effect of cloud cover when there is no wind on mean calling probability

Source: Author.

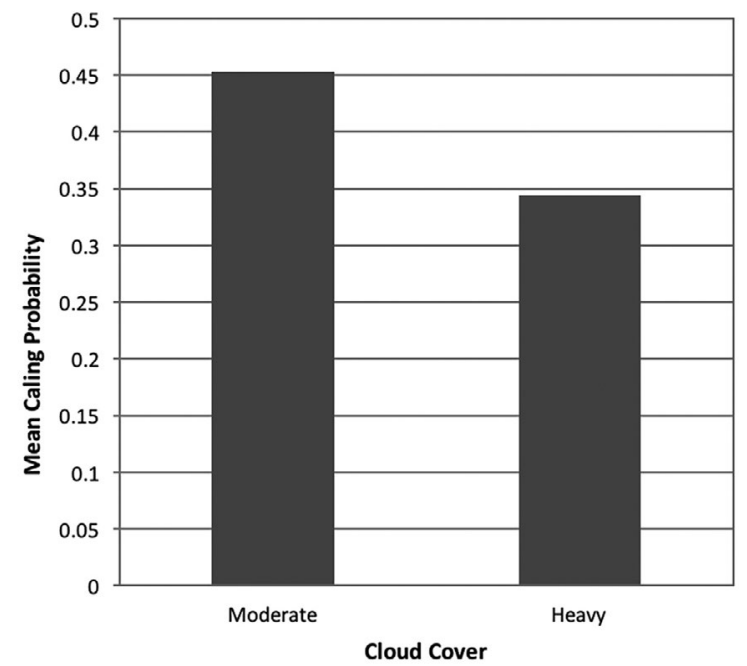

Figure 5: The effect of the interaction of low wind speeds and cloud cover on mean calling probability

Source: Author. 


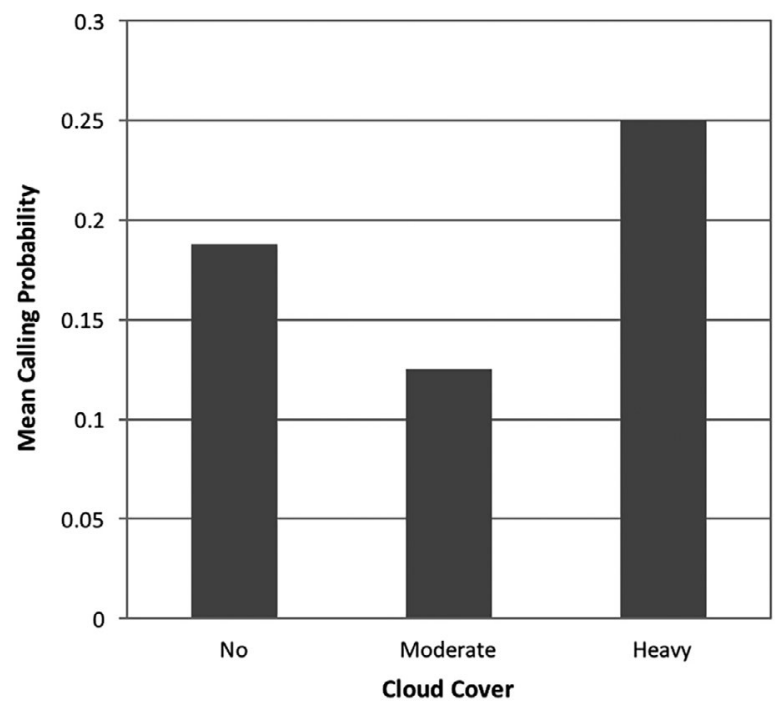

Figure 6: The effect of the interaction of high wind speeds and cloud cover on mean calling probability

Source: Author.

The effect of rain during the morning of surveys and the night before surveys was analysed only for Camp 6 data as there was no rain during the data collection periods at Elephant Rock and Snake Hill. Calls were heard on a total of 65 out of 89 survey days at Camp 6. Neither rain nor rain the night before had any significant effect on the calling probability.

\section{Discussion}

The results suggest that wind speed and the presence of cloud cover have an impact on the calling probability of $N$. annamensis. Wind speed had the largest effect on calling probability, which decreased as wind speed increased. Ambient noise, which prevents the clear transmission of vocal signals, increases with wind speed (Lengagne et al. 1999). The observed decrease in calling probability with increased wind speed may be a reflection of the gibbons being unable to communicate effectively when ambient noise reaches a certain level. If one of the main functions of the gibbon song is to transfer information to neighbouring groups, it is not energetically wise to participate in the costly behaviour if transmission conditions are not optimal (Haimoff 1984; 
Geissmann and Nijman 2006; Cheyne et al. 2007). Wind is known to suppress calling, and a negative correlation between wind speed and calling frequency has been observed in many gibbon species (Brockelman and Ali 1987; Lengagne et al. 1999). It is interesting that the rainfall was not found to significantly impact calling probability, despite rain increasing ambient noise (Lengagne and Slater 2002). Both Hoang et al. (2010) and Rawson (2004) noted that $N$. annamensis were less likely to call on mornings when it rained, or during the wet season. The noise created by falling rain overlaps with the acoustic signals used by birds (Lengagne and Slater 2002); this is a higher frequency than that used by larger primates and may have contributed to rain having no effect on calling probability. It is more likely, however, that the results reflect small sample size as data collection at Elephant Rock and Snake Hill took place only during the dry season.

While cloud cover significantly impacted calling probability, this relationship was not as strong as that between calling probability and wind speed. Due to a lack of literature on the effect of cloud cover on acoustic signals, it is unclear how these results align with calling probabilities in other species. Cloud cover during the day reduces the temperature (Karl et al. 1993), and I suggest that the observed link between morning cloud cover and calling probability may have been caused by temperature variation. When the temperature is cooler, gibbons are required to allocate more energy to thermoregulation, reducing the energy available for behaviours such as calling (Fan et al. 2008). Further investigation into the relationship between temperature and the calling probability of $N$. annamensis is necessary to understand which variable is the cause of the observed variation in calling probability.

The interaction of wind and cloud significantly affected calling probability as predicted, particularly when the wind speed was high. While the presence of cloud cover was found to significantly impact calling probability, I was unable to separate the effects of cloud cover and temperature. It is also therefore unclear whether the observed variation in calling probability was a response to the combined effect of wind speed and cloud, or wind speed and temperature. Regardless, wind speed played the largest role in reducing the calling probability in this interaction.

Rain the night before and the presence of fog during vocalisation surveys had no effect on calling probability. Neither of these variables would interfere with the transmission of the gibbons' morning calls, as they do not create ambient noise during the singing period. The presence of cloud overnight and of morning fog prevents some of the previous day's heat from escaping, maintaining 
warmer temperatures (Karl et al. 1993; Johnstone and Dawson 2010). While this should reduce the energetic cost of thermoregulation, my results suggest that the energy saved is not enough to have an impact on the likelihood of individuals calling.

\section{Conclusion}

In this study, I assessed the impact of wind speed, cloud cover, fog and rain the night before and during vocalisation surveys on the calling probability of $N$. annamensis. I found that wind speed had the most significant impact on calling probability as a result of increased ambient noise preventing the clear transmission of vocal signals. Cloud cover also significantly impacted calling probability, although further research needs to be done to separate the effects of cloud cover and temperature. As $N$. annamensis, like other gibbon species, is inconspicuous, vocalisation surveys are a particularly useful method of assessing populations. As seen in Rawson et al. (2009) and Hoang et al. (2010), vocalisation surveys of the species can be used to estimate population density. The more knowledge there is about the factors that influence calling likelihood, and the extent to which these factors suppress calling, the more accurate the estimates from vocalisation surveys will be.

\section{Acknowledgements}

I would like to thank Dr Alison Behie for her guidance in writing this essay and for facilitating my independent research topic. I would also thank Dr Ben Rawson for allowing me to use his data, Dr Teresa Neeman for assisting with my statistical analysis and the reviewers for their useful feedback.

\section{References}

Bezerra BM, Souto AS, Jones G. 2012. Propagation of the loud 'tchó' call of golden-backed uakaris, Cacajao melanocephalus, in the black-swamp forests of the upper Amazon. Primates. 53(4):317-325. doi.org/10.1007/ s10329-012-0312-8 
Brockelman W, Ali R. 1987. Methods of surveying and sampling forest primate populations. In: CW Marsh, RA Mittermeier, editors. Primate conservation in the tropical rain forest. Canada: John Wiley \& Sons. pp. 23-62.

Cheyne SM, Chivers DJ, Sugardjito J. 2007. Covarvariation in the great calls of rehabilitant and wild gibbons (Hylobates albibarbis). Raffles Bull Zool. 55(1):201-207.

Cowlishaw G. 1996. Sexual selection and information content in gibbon song bouts. Ethology. 102(2):272-284. doi.org/10.1111/j.1439-0310.1996. tb01125.x

Fan PF, Ni QY, Sun GZ, Huang B, Jiang XL. 2008. Seasonal variations in the activity budget of Nomascus concolor jingdongensis at Mt. Wuliang, Central Yunnan, China: Effects of diet and temperature. Int J Primatol. 29(4):1047-1057. doi.org/10.1007/s10764-008-9256-7

Geissmann T, Nijman V. 2006. Calling in wild silvery gibbons (Hylobates moloch) in Java (Indonesia): Behavior, phylogeny, and conservation. Am J Primatol. 68(1):1-19. doi.org/10.1002/ajp.20203

Gustison ML, Le Roux A, Berman TJ. 2012. Derived vocalizations of geladas (Theropithecus gelada) and the evolution of vocal complexity in primates. Phil Trans R Soc B. 367(1597):1847-1859. doi.org/10.1098/ rstb.2011.0218

Haimoff EH. 1984. Acoustic and organizational features of gibbon songs. In: H Preuschoft, DJ Chivers, WY Brockelman, N Creel, editors. The lesser apes: Evolutionary and behavioural biology. Edinburgh (UK): Edinburgh University Press. pp. 333-353.

Hoang MD, Tran VB, Vu L. 2010. Population status of the yellow-cheeked crested gibbon (Nomascus gabriellae) in Ta Dung Nature Reserve, Dak Nong Province, Vietnam. Hanoi (Vietnam): Fauna \& Flora International and Conservation International.

Johnstone JA, Dawson TE. 2010. Climatic context and ecological implications of summer fog decline in the coast redwood region. Proc Natl Acad Sci. 107(10):4533-4538. doi.org/10.1073/pnas.0915062107 
Karl TR, Jones PD, Knight RW, Kukla G, Plummer N, Razuvayev V, Gallo KP, Lindseay J, Charlson RJ, Peterson TC. 1993. A new perspective on recent global warming: Asymmetric trends of daily maximum and minimum temperature. B Am Meteorol Soc. 74(6):1007-1023. doi.org/10.1175/1520-0477(1993)074<1007:ANPORG>2.0.CO;2

Konrad R, Geissmann T. 2006. Vocal diversity and taxonomy of Nomascus in Cambodia. Int J Primatol. 27(3):713-745. doi.org/10.1007/s10764006-9042-3

Larom D, Garstang M, Payne K, Raspet R, Lindeque M. 1997. The influence of surface atmospheric conditions on the range and area reached by animal vocalizations. J Exp Biol. 200(3):421-431.

Lengagne T, Aubin T, Lauga J, Jouventin P. 1999. How do king penguins (Aptenodytes patagonicus) apply the mathematical theory of information to communicate in windy conditions? Proc R Soc Lond B Biol Sci. 266(1429):1623-1628. doi.org/10.1098/rspb.1999.0824

Lengagne T, Slater PJ. 2002. The effects of rain on acoustic communication: Tawny owls have good reason for calling less in wet weather. Proc R Soc Lond B Biol Sci. 269(1505):2121-2125. doi.org/10.1098/rspb.2002.2115

Mitani JC, Stuht J. 1998. The evolution of nonhuman primate loud calls: Acoustic adaptation for long-distance transmission. Primates. 39(2):171182. doi.org/10.1007/BF02557729

Mootnick AR, Fan PF. 2011. A comparative study of crested gibbons (Nomascus). Am J Primatol. 73(2):135-154. doi.org/10.1002/ajp.20880

Morrill RJ, Thomas AW, Schiel N, Suoto A, Miller CT. 2013. The effect of habitat acoustics on common marmoset vocal signal transmission. Am J Primatol. 75(9):904-916. doi.org/10.1002/ajp.22152

Oliveira DA, Ades C. 2004. Long-distance calls in Neotropical primates. Na Acad Bras Cienc. 76(2):393-398. doi.org/10.1590/S0001-37652004 000200031

Range F, Fischer J. 2004. Vocal repertoire of sooty mangabeys (Cercocebus torquatus atys) in the Taï National Park. Ethology. 110(4):301-321. doi.org/10.1111/j.1439-0310.2004.00973.x 
Rawson B. 2004. Vocalisation patterns in the yellow-cheeked crested gibbon (Nomascus gabriellae). In: T Nadler, R Streicher, Ha Thang Long, editors. Conservation of Primates in Vietnam. Hanoi (Vietnam): Fauna \& Flora International and Conservation International. pp. 130-136.

Rawson BM, Clements T, Nut Meng Hor. 2009. Status and conservation of yellow-cheeked crested gibbons (Nomascus gabriellae) in the Seima Biodiversity Conservation Area, Mondulkiri Province, Cambodia. In: S Lappan DJ Whittaker, editors. The gibbons: New perspectives on small ape socioecology and population biology. New York (NY): Springer. pp. 387-408.

Salmi R, Hammerschmidt K, Doran-Sheehy DM. 2013. Western gorilla vocal repertoire and contextual use of vocalizations. Ethology. 119(10):831847. doi.org/10.1111/eth.12122

Schaller GB. 1972. The Serengeti lion: A study of predator-prey relations. Chicago (IL): University of Chicago Press.

Sun GZ, Huang B, Guan ZH, Geissmann T, Jiang XL. 2011. Individuality in male songs of wild black crested gibbons (Nomascus concolor). Am J Primatol. 73(5):431-438. doi.org/10.1002/ajp.20917

Traeholt C, Bunthoen R, Rawson B, Samuth M, Vrak C, Vuthin S. 2006. Status review of pileated gibbon, Hylobates pileatus and yellow-cheeked crested gibbon, Nomascus gabriellae, in Cambodia. Phnom Penh (Cambodia): Fauna \& Flora International-Indochina Programme.

Waser PM, Brown CH. 1986. Habitat acoustics and primate communication. Am J Primatol. 10(2):135-154. doi.org/10.1002/ajp.1350100205

Waser PM, Waser MS. 1977. Experimental studies of primate vocalization: Specializations for long-distance propagation. Z Tierpsychol. 43(3):239263. doi.org/10.1111/j.1439-0310.1977.tb00073.x 



\title{
Taking care in prehistoric Latin America: A case study of care giving among hunter-gatherers in the Final Late Holocene
}

\section{Terri Fisher}

\begin{abstract}
A published case of metastatic cancer from a hunter-gather group in pre-Columbian Argentina analysed the effects this illness would have on group dynamics. This essay uses the published details of the case study to analyse the possibility of care being provided to the dying individual. After a detailed discussion on the skeletal analysis and diagnosis offered by the original authors, this essay proposes that prior to his illness this individual would have been an active contributor to his group, likely involved in the transport and manipulation of stone. The functional impact the individual would have experienced as the result of his illness is discussed including the impact on the rest of his group, i.e. reduced contributions to group subsistence and inability to maintain residential mobility in a nomadic lifestyle. This essay argues that, based on the accommodation of their ill member by continuing to supply food despite his deteriorating state, this group of hunter-gatherers valued their individual members more so than their contribution to the group. This case study provides an insight into the value system of a pre-Columbian hunter-gatherer group outside of the more commonly examined subsistence activities, trading and burial practices.
\end{abstract}

\section{Keywords}

pre-Columbian Argentina, bioarchaeology of care, skeletal analysis, hunter-gatherers 


\section{Introduction}

Luna et al.'s 2008 paper, entitled 'A case of multiple metastasis in Late Holocene hunter-gatherers from the Argentine Pampean region', analysed the impacts individual illness may have had on group dynamics. Yet, the immediate response-specifically, the prospect of interpreting if care would have been provided to the individual — was not considered in the original publication. This was justified by reference to Dettwyler's (1991) well-known publication opposing the interpretation of care in paleopathology. However, this view has since been rebutted by Tilley (2015) opening up the potential to interpret the provision of care in prehistoric times. Seeing as Luna et al. (2008) published prior to Tilley's (2015) rebuttal, it is worth investigating a potential interpretation of the life of that individual while ill. This is important because Luna et al.'s 2008 paper provided an interpretation of the broader concepts of group dynamics even though their analysis was based on a single skeleton case. Establishing if these remains can provide insights into how the group responded to the illness before attempting to theorise how the illness affected group dynamics is an important aspect to consider for the bioarchaeological analysis of this individual. After all, how the group responded to an ill member is a significant factor affecting group dynamics.

In an effort to elaborate on the analysis of these remains, this essay will present an interpretation of the experiences this individual would have endured during the course of his illness. Using a variation on the four stages of Tilley's (2012) 'The bioarchaeology of care' model, this analysis will begin by placing the individual within the context of hunter-gatherer lifestyle in the region. Secondly, the diagnosis provided by Luna et al. (2008) will be expanded on in order to establish the progression of the individual's illness. Finally, a determination of the functional impact of the individual's condition on their daily life will be attempted. Based on this prognosis, and the relevant lifestyle factors, this essay will propose a reconstruction of the immediate response to the illness, including the types of care this individual may have received. Finally, an interpretation of the social and cultural implications of this response will be proposed with reference to the already established social and cultural context of hunter-gatherer groups in the region. 


\section{Context}

The Pampean grasslands covers southern parts of Brazil, all of Uruguay and a large amount of Argentina. Most of that area shares the same flora and fauna with some regional variations, and high winds affect most of the area (Politis 2008; Flensborg 2011). The grassland is intersected by small forested areas located near water sources. Significant evidence of hunter-gatherers has been found throughout the regions including in the isolated hilly regions (Politis 2008). The individual under discussion was excavated at a cemetery called Chenque 1 . Chenque 1 is located in a hilly semi-arid area within Lihue Calel National Park (Flensborg et al. 2015). Cemetery sites such as this one provide some of the strongest insights into the hunter-gatherer lifestyles in the area.

Increasing complexity of burials in the Late Holocene has been seen as indicative of significant socioeconomic changes in the region's hunter-gatherer groups (Martínez et al. 2012). The repeated use of the same sites for burial, along with the more frequent use of secondary burials and inclusions of grave goods, show an increased investment in the dead (Martínez et al. 2012). This change is considered to be the result of 'major changes and reorganisation of cultural systems towards the Final Late-Holocene', ca. 950-1700 CE (Flensborg et al. 2015:816). The aspects of daily life potentially affected by these changes are varied; however, several are likely to have been significant in this case: changes to territoriality, increased resource exploitation and increased social interaction and networking (Politis 2008; Flensborg 2011; Martínez et al. 2012; Flensborg et al. 2015).

The changes to territoriality seem to be signified by a reduction in residential mobility and an increase in networking, including possible trade (Politis 2008). The proposed reduction in residential mobility is consistent with the grave goods found at Chenque 1. Items found were made from raw materials sourced at a great distance: from the Atlantic coast, the trans-Andean region and multiple other areas - the combination of which results in a travel radius of at least 150 kilometres (Luna et al. 2008; Politis 2008; Beron et al. 2009). As this range of group mobility is unlikely, it supports the idea that the circulation of 'exotic material with highly symbolic value' (Politis 2008:254) is evidence of trade between different hunter-gatherer groups inhabiting various areas in the region as opposed to evidence of extended mobility (Beron et al. 2009). 
This capacity to access resources from outside a likely mobility range is also present in research conducted into subsistence practices. Isotopic analysis shows that those buried at Chenque 1 had a continental and marine diet (Luna et al. 2008; Flensborg 2011), despite the distance between the cemetery and the ocean. The presence of marine mollusc remains at archaeological sites throughout the Pampean region would seem to support those results, although Bonomo and Aguirre (2009) question whether these were used as a food source. The Late Holocene changes in resource exploitation are also apparent in the beginnings of horticulture (Politis 2008). This is evidenced by the use of grinding stones (Politis 2008), and the increasing prevalence of caries found in Late Holocene skeletal remains (Flensborg 2011). Flensborg's (2011) analysis of dento-alveolar lesions present in dentition from the region attributed this increase to the rising use of plants as a food source.

Of course, hunting activities of the hunter-gatherer lifestyle is also an important aspect of subsistence. The primary prey of the Pampean hunter-gatherers was the guanaco, a camelid species resembling a llama (Flensborg 2011). It was supplemented by local deer and the rhea, a large flightless bird similar to an emu (Flensborg 2011; Salemme and Frontini 2011). The hunting techniques used to catch these animals are unknown, although a weapon made from two stones attached to each end of some kind of cord, called a bola, was likely used (Politis 2008). These animals are all capable of speeds faster than that of Homo sapiens. Therefore, hunting could presumably have involved tracking, running and throwing. Smaller mammals were also used as food sources (Flensborg 2001); however, traps may have been more effective at gathering these animals.

The final aspect of hunter-gatherer life in the Final Late Holocene that may be relevant is the advent of craftsmanship (Politis 2008; Flensborg 2011). This adaption may have been related to the use of horticulture as subsistence. The standardisation of the design of grinding stones (Flensborg 2011) is an indication of a rise in craftsmanship. Pottery became relatively complex in this period with the development of decorative techniques such as painting and incision; pottery handles and engraved plates are also found (Politis 2008), which indicate a diversity of potential uses. Lithic technology advanced as well, leading to the construction of stone monuments (Politis 2008). 


\section{The burial}

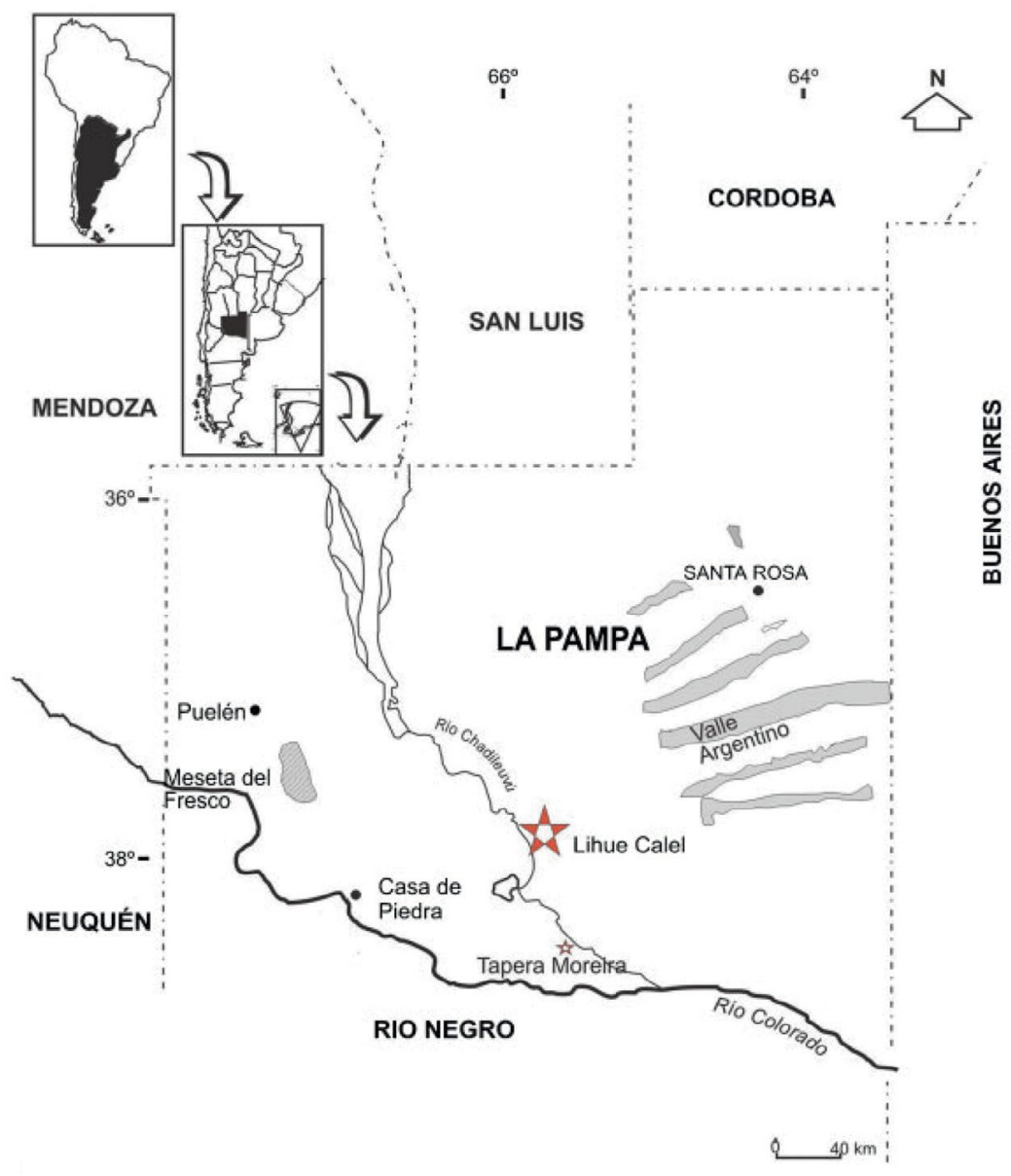

Figure 1: Location of the Lihue Calel National Park, and the Chenque 1 site Source: Luna et al. 2008:493 (Licence no. 4032330886796), reproduced with permission.

Chenque 1 is a prehistoric cemetery site located in the Lihue Calel National Park in the La Pampa province. This is in the Western part of the much larger Pampean Region located mainly in Argentina (Luna et al. 2008; Figure 1). Chenque 1 was in use in the Final Late Holocene 920-1580 CE. The people using this cemetery were hunter-gatherers, and it is theorised that 
multiple groups used this one cemetery (Luna et al. 2008). The cemetery itself is a complex elliptical stone structure with at least two levels of burials (Politis 2008). The upper level is above 30 centimetres and had a minimum number of individuals (MNI) of 53. The lower level had an MNI of 158, including adults, subadults, males and females (Luna et al. 2008). The site had multiple types of burials: primary, secondary and dispositional —in which the anatomical structure of the body is intentionally altered prior to the initial burial (Politis 2008).

The individual in question was found in Burial 12 in the lower level of Chenque 1. The skeleton is that of an adult male aged approximately 40-50 years old at death. He was buried in flexed position at the southwest end of the site (Luna et al. 2008). Luna et al. (2008) noted that two valve beads were associated with Burial 12 however no information was provided regarding whether this was a high or low number of grave goods in the context of this cemetery or this region.

\section{Skeletal analysis}

The skeletal remains of Burial 12 were approximately 70 per cent complete. The authors suggested multiple unspecified taphonomic agents may be the cause of most of the missing bones, although the skull may have been deliberately separated from the body at burial. The cemetery contained several examples of skulls buried in isolation (Luna et al. 2008). Burial 12's remains were missing the cranium, teeth (except for the first right lower premolar), and sternum; the left scapula, clavicle, radius and ulna; the right humerus, patella and tibia, and most of both hands (Luna et al. 2008:494). Burial 12's remains also presented a set of lesions that were spread across the thorax (dorsal arches of vertebrae and diaphyses of ribs), pelvis (os coxae and sacrum), scapula (body and coracoid process), proximal epiphyses of both femora, left humerus and the right ulna (Luna et al. 2008:495). For more information on the remains themselves please see Luna et al.'s (2008) original article, which contains multiple images including those showing the spread and details of the lesions.

Luna et al. (2008) primarily addressed the lesions on the skeleton, but also analysed some exostoses at muscle and ligament attachment sites, which provided some insight into the pre-illness life of this man. The authors 
interpreted repeated strong use of muscles in the neck, pectoral girdle and trunk based on the analysis of multiple exostoses formed at the relevant muscle attachment sites (Mariotti et al. 2007; Luna et al. 2008:498).

In their discussion of the impact a terminal disease might have had on group dynamics, Luna et al. (2008) does not discuss Burial 12's activities prior to his illness. Of course, the lack of detail on this subject does not mean that a thorough skeletal analysis was not completed. As the original article did not discuss Burial 12's activity levels, it would have been superfluous to include additional data that may have resulted from such an analysis. The data that might have been pertinent is the presence or absence of wear on the skeleton, which might have given stronger indications of Burial 12's activities prior to his illness and thus how the loss of his ability to complete these activities may have affected the rest of the group. It is noted that the bones exhibiting lesions were highly fragmented. This is not unexpected as the lesions weaken these bones, making them susceptible to fracture prior to death (Ortner 2003; Aufderheide and Rodríguez-Martin 2011), therefore they would be among the most likely to suffer damage postmortem. The results of analysis on potential antimortem fractures may also have provided an indication of Burial 12's level of activity prior to his death. While it is certainly possible that none of these indicators were present in this instance, Luna et al. (2008) did not include any indication that these aspects were considered when interpreting the impacts of Burial 12's condition. This is unfortunate, as the lack of data on this point leaves a gap in both my own analysis and that provided by Luna et al. (2008).

\section{Diagnosis}

The diagnosis proposed by Luna et al. (2008) is neoplasia that caused secondary manifestations, otherwise known as multiple metastasis or metastases carcinoma (Aufderheide and Rodríguez-Martin 2011). Luna et al. (2008) did provide a differential diagnosis, looking at leukemia and multiple myeloma as possible alternatives, although both were ruled out based on the type and location of the lesions. It is noted that multiple metastasis is a rare diagnosis in paleopathology; however, the diagnosis is reasonable based on the information provided.

It is not possible to determine if the cancer was the cause of death. Although it can be said that, if the cancer was not the cause of death, it would have been fatal if the course of the illness was not interrupted. Multiple metastasis is 
known to be the most common type of cancer that affects the skeleton (Ortner 2003). However, it is not a specific cancer diagnosis. The term multiple metastasis refers to cancer that has spread from one tumour in a specific part of the body to form malignant tumours in multiple areas of the body. In their article, Luna et al. (2008) look at the two most common types of cancer to develop into multiple metastasis-prostate and breast cancer-and ruled out both forms, stating that both prostate and breast cancer result in osteoblastic lesions, which is not consistent with Burial 12. This is not always the case as these conditions can produce either osteolytic or osteoblastic lesions (Ortner 2003; Aufderheide and Rodríguez-Martin 2011). So, while breast cancer is unlikely due to the sex of Burial 12, prostate cancer is still a possibility. Although, as Luna et al. (2008) had access to the remains and were therefore in the best position to analyse the lesions, their dismissal of prostate cancer as a diagnosis is not opposed here. Osteolytic lesions are also indicative of lung, thyroid, kidney or gastrointestinal cancer (Ortner 2003; Luna et al. 2008; Aufderheide and Rodríguez-Martin 2011). This author agrees with Luna et al.'s (2008) conclusion that it is not possible to determine which of the above forms of cancer this individual suffered based on the skeletal evidence.

Osteolytic lesions indicate a slowly progressing illness (Ortner 2003; Aufderheide and Rodríguez-Martin 2011). This concurs with Luna et al.'s (2008) analysis, stating that the presence of both early and late stage lesion development indicates a long-term condition of at least several months. As the initial type of cancer cannot be determined, it is not possible to be exact regarding the symptoms this man would have endured during his final months. Nevertheless, there are some general symptoms that nearly all cancer sufferers experience. Research on modern terminally ill cancer patients shows that the three most constant and debilitating symptoms are pain, weakness and fatigue, with patients also likely to suffer the following symptoms to varying degrees: shortness of breath, anxiety, depression, lack of appetite, memory problems, vomiting, nausea, numbness/tingling, sleeping problems, restlessness, constipation and anorexia (Kwon et al. 2006; Ruijs et al. 2013; Jensen et al. 2014). While it is not possible to know which of these this man suffered, Kwon et al. (2006) found that modern patients had an average of $11 \pm 2.5$ symptoms, so it is likely he had most if not all of the above symptoms. Any combination of these symptoms would have had the obvious effects of reduced physical activity and eventual muscle atrophy. It is important to note, as Luna et al. (2008) did, that at no point is there any 
indication or precedent that this man would have experienced any reduction in cognitive capacity. He would have remained aware of his steadily reducing capabilities throughout his illness.

The research into modern patients has shown a significant increase in the severity of symptoms at an average of four months prior to death. A decline to being bedridden and unable to take care of intimate needs, i.e. toilet, feeding, etc., happen at an average of one month prior to death (Ruijs et al. 2013). This research was conducted in a modern Western medical environment, so it is likely that these patients received treatment that both extended their life and relieved their symptoms to a certain degree. As Burial 12 would not have received such medical aid, it is likely that he progressed through these stages more rapidly with minimal, if any, symptom relief.

\section{Functional impacts}

The functional impacts of this disease may seem self-evident. This illness progressed slowly, likely over at least several months; during which time the individual would have been forced by pain and fatigue to reduce his contribution to his group. It is not possible to be certain of his contribution levels prior to his illness. His involvement in any subsistence practices, particularly hunting, would have been affected to the point where he would not have been capable of participating. However, the assertion by Luna et al. (2008) that this man had a strong trunk, pectoral girdle and neck would indicate that whatever the exact nature of contributions, he regularly performed tasks that required him to be active and strong. As the development of exostoses at muscle attachments requires the build-up of impressive muscle mass (Mariotti et al. 2007), the indications of Burial 12's significant muscularity at the trunk, pectoral girdle and neck —all areas used during heavy lifting — show it is possible that he was involved in the movement and perhaps creation of the stone monuments.

However, pain, weakness and fatigue would have made such activity increasingly difficult, and ultimately impossible to continue as his disease progressed. Burial 12's capacity to travel would have been affected. The reduction in residential mobility of hunter-gatherer groups in the region is significant here as Burial 12's reduced travelling capacity would have had less impact on his group compared to earlier times. As he became more inactive, and as the lack of appetite and weight loss had their effect, his muscles would have begun to atrophy. Luna et al. (2008) considered the muscle atrophy to 
have had the strongest impact on Burial 12, perhaps because it was assumed his strength was his main contribution to the group. The atrophy would have been very visible to both himself and to those around him.

This is not to imply that this man was bedridden or incapable of looking after himself. His capacity would have slowly reduced over time, but it is unlikely he needed constant care until the very end of his life. It is highly possible that this man was capable of taking care of himself for most of the duration of his illness, albeit with increasing difficulty. It is also possible that he remained an active contributor to the group by performing tasks of which he was still capable until very shortly before his death. I will discuss this possibility in more detail in the proposed model of care.

\section{Interpretation of care}

Luna et al. (2008) discussed the functional impacts of Burial 12's conditionand indeed the types of assistance he would have needed during his illness - and yet refused to consider the possible treatment of Burial 12 by his group. This decision was based on Dettwyler's (1991) influential article opposing the interpretation of compassion in paleopathology. As Tilley (2015) pointed out, Dettwyler (1991) conflated the related but separate interpretations of the act of providing care and the motivations for those actions. If evidence indicates that action was taken to extend an individual's life or relieve their suffering, then the provision of care can be a valid interpretation. Although, Dettwyler's (1991) contention that the interpretation of compassion is unjustifiable has some merit. In cases where the provision of care can be reasonably interpreted, any claims that the motivations for, or the manner of, said care was compassionate are unverifiable. Although, this analysis questions whether the current emotional capabilities of our species are so very different from earlier peoples, i.e. it is equally invalid to assume that compassion was absent as it is to assume it was present. Regardless, this essay is not suggesting that Burial 12's treatment was born out of compassion. It is, however, suggesting that Luna et al.'s (2008) refusal to continue analysis beyond Burial 12 's required treatment, and refusal to consider if that treatment was provided, was somewhat shortsighted. 


\section{Model of care}

In 'The bioarchaeology of care', Tilley (2012) divides care into two main categories: direct support or accommodation. Direct support is defined as actual intervening actions to assist the individual such as nursing, medical intervention, etc.; whereas accommodation is the adjustment of activities in order to make provisions for the relevant individual (Tilley 2012). As discussed in the diagnosis, it is likely that Burial 12 only required direct support in his final days (Ruijs et al. 2013). His increasingly severe symptoms would have prevented him from contributing to the group in a physically demanding way. However, it is still likely that he was able to maintain his own hygiene, toilet, eating, etc. For the majority of his illness, Burial 12 probably only required 'accommodation' from his group. His group did not abandon him or refuse to allow him food once he became unable to perform his 'normal' activities. If that had been the case, he would have died well prior to the full spread of the lesions. Burial 12 may have remained a contributing member of the group by adapting to those activities he was still able to complete. This may have included food preparation, making traps or bolas, pottery, conducting trade, etc.; although the level of his continuing contribution to the group, if any, can never be verified. Regardless of Burial 12's level of contribution, his group does appear to have 'accommodated' his illness. This is evidenced by the provision of food during the course of his illness, and by Burial 12 remaining with his nomadic group in spite of his, and therefore the group's, reduced travelling capabilities.

Eventually the course of the disease would have made it impossible for Burial 12 to remain self-sufficient. Since research into timeframes relating to terminally ill cancer patients is conducted on those under modern medical care, it is not possible to determine the exact length of time Burial 12 required direct support prior to his death. Although, based on Ruijs et al. (2013), it was likely only a few weeks at most. At this stage, it is possible that the members of his group simply left him alone once he could not fend for himself. If the assumption of direct support is allowed, then Burial 12 would have needed assistance to toilet and to eat, and if the group was mobile at the time he would have needed to be transported. While there is no hard evidence supporting direct care, accommodation can be argued based on length of time Burial 12 survived as evidenced by the spread of the cancer over the skeleton, as well as long-term nature of the disease itself. 


\section{Interpretation}

The accommodation of Burial 12's deteriorating condition suggests a level of investment in the individuals of that group. Unfortunately, without comparative details it is not possible to situate this within the broader interpretations of increasing social and economic complexity. Nor is it possible to make any interpretations on how Burial 12 responded to his illness. He may have remained an active contributor of the group, or he may have retreated from any human interaction. Regardless of his response, he remained alive long enough for the disease to spread as far across his skeleton as this disease is able. As he would have been restricted from gathering his own subsistence, even while he was still capable of feeding himself, it is likely his group showed enough investment in his life that he was provided with food once he became incapable of gathering his own. Thus, this group of hunter-gatherers valued Burial 12's life above that of his 'normal' contribution to the group.

\section{Conclusion}

The case of Burial 12 is an interesting instance of terminal illness among Latin American hunter-gatherers. This individual lived within a hunter-gatherer society for a significant period while seriously ill. This gives researchers a direct insight into behaviour outside of hunting, farming, fishing, trading or interring. This insight is an intimate one: how they responded to their ill and dying members. It is apparent that this hunter-gatherer group did show adjustment to at least indirectly support an ailing member. The possibility that this was a new adaptation that was brought about by broader social and economic changes is interesting; although it would require further archaeological evidence and research to investigate.

Luna et al.'s (2008) conclusions were remarkably similar to this analysis considering their discussion refused to consider the illness from Burial 12's individual perspective, instead focusing on the inference of 'the consequences that this disease would have had on the dynamics of the group in which this person lived' (Luna et al. 2008:492). It must be noted that the lack of verifiable detail of Burial 12's life during the progression of his illness makes any suggestion of consequences for group dynamics to be highly questionable. Not knowing the level to which the residential mobility of the group was affected-or indeed their subsistence practices or trade capabilities or other unknown factors - any theory would be based on an unsupportable number of assumptions. 
While the case of Burial 12 is a good example of illness within a prehistoric cultural group, unfortunately this insight cannot be expanded to all groups in the region and therefore it does not significantly advance our general knowledge of these hunter-gather groups. It does, however, provide some insight, albeit small, into group values of a single hunter-gatherer society in prehistoric Latin America.

\section{Acknowledgements}

I would like to thank Dr Lorna Tilley and the anonymous reviewers for their comments on earlier drafts of this essay, and John Wiley \& Sons for their permission to reproduce Figure 1. I would also like to acknowledge, with gratitude, Luna et al. (2008) for publishing such an interesting case for our enrichment.

\section{References}

Aufderheide AC, Rodríguez-Martin C. 2011. The Cambridge encyclopaedia of human paleopathology. Cambridge (UK): Cambridge University Press.

Beron MA, Luna LH, Barberena, R. 2009. Isotopic archaeology in the Western Pampas (Argentina): Preliminary results and perspectives. Int J Osteoarchaeol. 19(2):250-265. doi.org/10.1002/oa.1049

Bonomo M, Aguirre ML. 2009. Holocene molluscs from archaeological sites of the Pampean region of Argentina: Approaches to past human uses. Geoarchaeology. 24(1):59-85. doi.org/10.1002/gea.20254

Dettwyler KA. 1991. Can paleopathology provide evidence for "compassion"? Am J Phys Anthropol. 84(4):375-384. doi.org/10.1002/ajpa.1330840402

Flensborg G. 2011. Dento-alveolar lesions and palaeodietary inferences from the Paso Alsina 1 site (Eastern Pampean-Patagonian Transition, Argentina). J Comp Hum Biol. 62(5):335-350. doi.org/10.1016/j.jchb.2011.08.005

Flensborg G, Martínez G, Bayala PD. 2015. Mortality profiles of huntergatherer societies: A case study from the Eastern Pampa-Patagonia transition (Argentina) during the Final Late Holocene. Int J Osteoarchaeol. 25(6):816-826. doi.org/10.1002/oa.2348 
Jensen W, Bialy L, Ketels G, Baumann FT, Bokemeyer C, Oechsle K. 2014. Physical exercise and therapy in terminally ill cancer patients: A retrospective feasibility analysis. Support Care Cancer. 22(5):12611268. doi.org/10.1007/s00520-013-2080-4

Kwon YC, Yun YH, Lee KH, Son KY, Park SM, Chang YJ, Wang XS, Mendoza TR, Cleeland CS. 2006. Symptoms in the lives of terminal cancer patients: Which is the most important? Oncology. 71(1-2):69-76. doi.org/10.1159/000100450

Luna LH, Aranda CM, Bosio LA, Beron MA. 2008. A case of multiple metastasis in Late Holocene hunter-gatherers from the Argentine Pampean region. Int J Osteoarchaeol. 18(5):492-506. doi.org/10.1002/oa.950

Mariotti V, Facchini F, Belcastro MG. 2007. The study of entheses: Proposal of a standardised scoring method for twenty-three entheses of the postcranial skeleton. Coll Antropol. 31(1):291-313.

Martínez G, Flensborg G, Bayala P. 2012. Human corpse manipulation and the body as symbol: A case study from the Eastern Pampa-Patagonia transition (Argentina) during the Final Late Holocene. J Anthropol Archaeol. 31(2):215-226. doi.org/10.1016/j.jaa.2011.12.002

Ortner DJ. 2003. Identification of pathological conditions in human skeletal remains. 2nd ed. San Diego (CA): Academic Press.

Politis G. 2008. The Pampas and Campos of South America. In: H Silverman, WH Isbell, editors. Handbook of South American Archaeology. New York (NY): Springer. pp. 235-260. doi.org/10.1007/978-0-387-74907-5_14

Ruijs CDM, Kerkhof Ad JFM, van der Wal G, Onwuteaka-Philipsen BD. 2013. Symptoms, unbearability and the nature of suffering in terminal cancer patients dying at home: A prospective primary care study. BMC Fam Pract. 14(1):201-201. doi.org/10.1186/1471-2296-14-201

Salemme M, Frontini R. 2011. The exploitation of RHEIDAE in Pampa and Patagonia (Argentina) as recorded by chroniclers, naturalists and voyagers. J Anthropol Archaeol. 30(4):473-483. doi.org/10.1016/j.jaa. 2011.08.001

Tilley L. 2012. The bioarchaeology of care. SAA Archaeol Rec. 12(3):1-6.

Tilley L. 2015. Theory and practice in the bioarchaeology of care. New York (NY): Springer. doi.org/10.1007/978-3-319-18860-7 


\title{
Factors affecting energetic regulation of ovulation leading to birth seasonality in tropical and temperate subpopulations
}

Tess Johnson

\begin{abstract}
This essay details past and current research into the area of human birth seasonality. It focuses on the contrast in the mechanisms affecting the energetic regulation of ovulation $(E R O)$, which leads to birth seasonality between tropical and temperate subpopulations. In doing so, the seasonal nutritional conditions of females in sub-Saharan Africa and Nepal are evaluated, as well as the climatic and cultural factors that affect the hormonal balance that creates ERO. The essay finds that whereas decreased energy intake causes ERO and therefore birth seasonality in tropical agricultural/pastoral populations, it is increased energy expenditure that has the same effect in temperate agricultural/pastoral populations. Finally, current directions in the field of ERO are briefly explored as they relate to birth outcomes that remain unlinked to seasonality in industrialist populations.
\end{abstract}

\section{Keywords}

birth seasonality, ERO, agriculturalist, pastoralist

\section{Introduction}

Although seldom considered a species under seasonal reproductive control, humans in some populations have been shown to conceive and give birth at different rates depending on the season. Thus, around the world, patterns of 
conception rates—and hence birth rates—differ monthly according to seasonal factors, especially in agriculturalist and pastoralist populations (Ellison et al. 1989). This is observed most notably in traditional populations found in subSaharan Africa (e.g. Zairian Lese and Kenyan Turkana populations) and more temperate world regions such as Nepal and Arctic North America (e.g. Nepali Tamang and Arctic Inuit populations) (Ellison et al. 1989; Leslie and Fry 1989; Condon 1991; Panter-Brick 1996). Due to the dependence of tropical populations on both temperature and seasonal rainfall for food production, seasonality can have an immense impact on the energy balance of females in these communities, which in turn affects their fecundity (Bailey et al. 1992). Contrastingly, in temperate climates where crops are less dependent upon rainfall levels, workload generally plays a larger role in determining female energy balance. Although neither mechanism is entirely isolated, a generalisation can be made that environment tends to affect energy balance in tropical regions more, whereas workload tends to affect energy balance in temperate regions more. In both cases, fecundity is affected by changes in monthly ovulation according to energetic hormonal regulation. This energetic regulation of ovulation (ERO) allows women to conserve energy, which may be needed for their own somatic effort (as opposed to reproductive effort) in seasons when there is less food available or more work to be done (Panter-Brick et al. 1993). Thus, ERO is an important cause of birth seasonality, with the effect differing in tropical and temperate areas as a result of the factors of food availability and energy expenditure, respectively. I intend to explicate the contrast in the causes of ERO via comparison of southern African and Nepalese agriculturalist and pastoralist populations, both of which experience dramatic changes in female fecundity according to the above parameters. I will draw primarily from research performed by Ellison et al. (1989), Bailey et al. (1992), Leslie and Fry (1989) and Panter-Brick (1996) on birth seasonality within various subpopulations; however, reference will also be made to more recent literature, which tends to focus on various other subpopulations in industrial societies.

\section{The biology of seasonality}

The first study of birth seasonality dates back to the pioneering investigation of Swedish birth rates by Wargentin in 1767. Since then, an increasingly growing body of research concerning the phenomenon has led to the assertion by Ellison (2003) that birth seasonality is dependent on three categories of factors. These include social factors, such as age at marriage affecting 
intercourse timing; climate-based factors, which affect energy and hence conception probability; and epidemiological factors, which affect pregnancy success. The influence of proximate factors on fertility has been thoroughly investigated in anthropological demography. They are described by Bongaarts' (1978) model as mechanistic processes and anatomical reasons such as age at menarche, ovulatory rate and postpartum infecundability, which determine fertility itself. The mechanism behind ERO as a proximate determinant of fertility has been described by Berga and Naftollin (2012) as failure to ovulate according to alteration of the hypothalamic signals sent to the pituitary gland to cause progesterone and luteinising hormone secretion. While these hormones would ordinarily induce ovulation each month, their secretion is reduced due to the effects of metabolic signals on the hypothalamic processing centre. In addition to this, levels of estradiol are increased, giving negative feedback in the system. This reduces conception rates during periods when women would be less able to self-maintain energetically during pregnancy and lactation due to energy imbalance, which in turn affects birth rates, although intervening social and biological factors such as conceptus loss also contribute to birth rates.

Figure 1 describes the factors affecting energy imbalance in both tropical and temperate populations, and how this affects birth seasonality. The benefits of ERO in relation to the trade-off for somatic effort in place of reproductive effort are evident. Both offspring and, to an even greater extent, parental mortality is greatly increased when parental investment occurs in a sustenance-unstable environment (Rhinehart 2016). In fact, at the latter part of the gestation period, offspring take a full third of the mother's 'metabolic budget' as defined by her energy production and consumption (Ellison 2003). Thus, it is of much more benefit to the mother to invest in somatic effort and future reproduction rather than current reproduction. Under the conditions of natural selection, the ERO trait would have adapted and become more common over time due to the benefits in terms of survival and future reproduction for the parent (Rhinehart 2016). As will be further elucidated below, this has the effect of creating troughs in conception rates during periods of energy imbalance due to decreased rate of ovulation in favour of conserving energy for current somatic effort, and the opportunity to reproduce in future months when this energy imbalance may be later remedied. It should be noted that this effect on conception rates can be distinguished in the literature from the subsequent birth rates, which do not always correlate due to other factors such as conceptus loss. Thus, in the following case studies, emphasis is placed on whether 'seasonality' refers to conception or birth. 


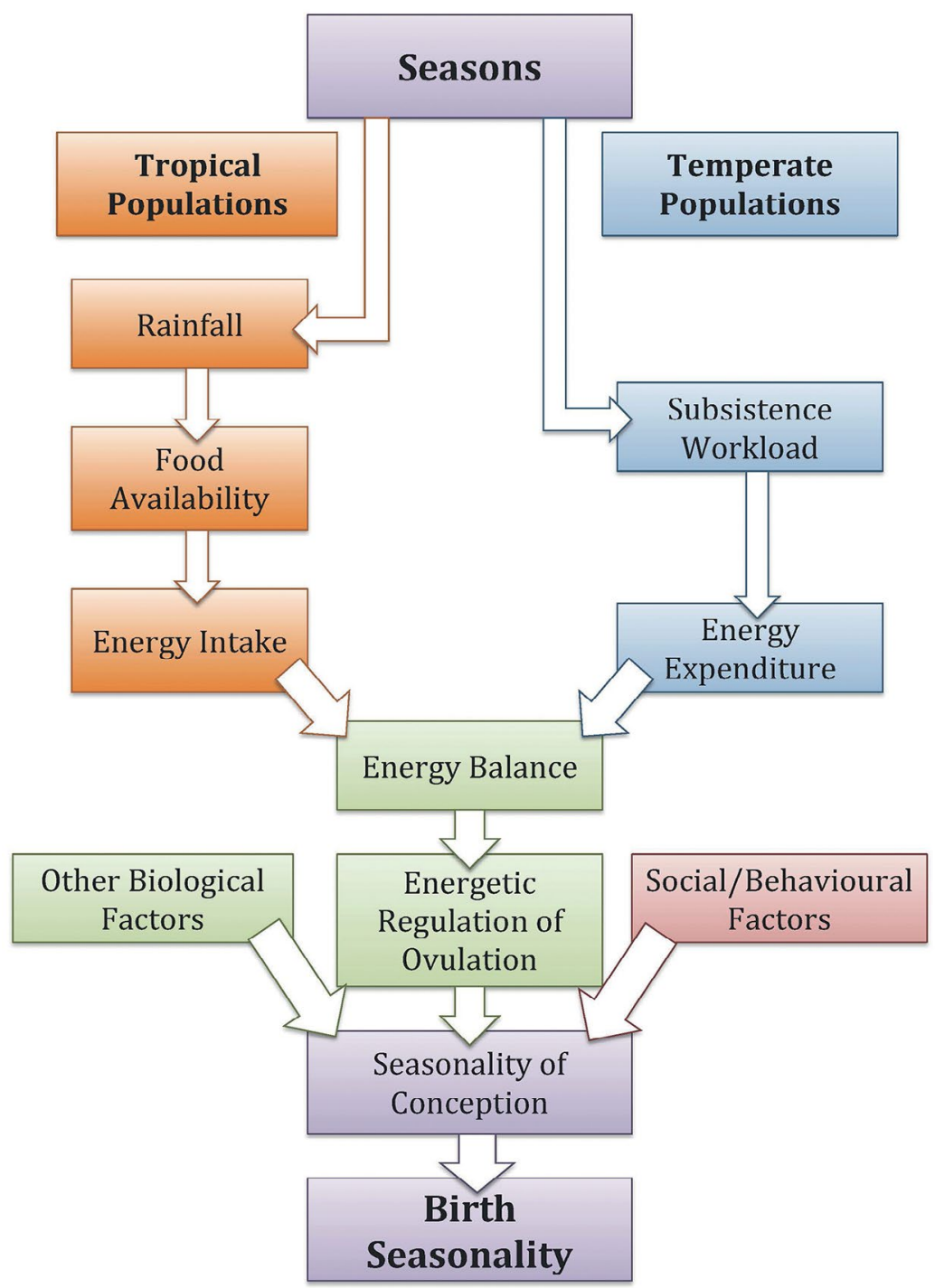

Figure 1: Flow diagram depicting select biological factors affecting birth seasonality in tropical and temperate areas respectively Source: Author. 


\section{Tropical African populations}

Current knowledge regarding energetic regulation of ovulation in tropical sub-Saharan African populations is based on a significant amount of past research. Previous studies have looked at populations from Kenya (Leslie and Fry 1989), Tanzania (Bantje 1987), the Gambia (Moore et al. 1997) and, most notably, former Zaire (Ellison et al. 1989; Bailey et al. 1992). Although a more limited number of recent studies have been conducted, such as Philibert et al.'s (2013) investigation into seasonality in Mali, and Dorélien (2015) and colleagues's (2013) various studies in South Africa, these current applications of birth seasonality focus less on the fundamental causes and occurrences and more on the implications, and are thus of lesser importance here. Of greater note is that seasonality was found to have an effect on the conception rates of all of these sub-Saharan African populations to varying degrees. The most pertinent populations for study in this case are the Lese people of Zaire and the Turkana people of Kenya. These two populations rely on pastoralism and agriculturalism as their means of subsistence in tropical areas, and are therefore the most affected by fluctuation in rainfall (Leslie and Fry 1989; Bailey et al. 1992).

Studies performed on the Lese agriculturalists date from Ellison's work from 1986 to 1989, which centred around the seasonality of births, and a comparison between these ovulatory rates and those of a standard Western population. Bailey et al.'s (1992) later work built upon this scaffold in a more biological context. He investigated hormonal levels and ovulation during the peak and trough months of conception rate, and related this to female energy balance. In this context, energy balance is defined as net energy intake over expenditure. Together, these studies found that in the population of Lese agriculturalists, monthly ovulatory frequency fluctuated dramatically. Troughs occurred reliably during the hunger season, sometime between January and June each year. During this time, seasonal rainfall was low and food availability decreased until the harvest in late June. After this point, food availability was greatly increased and ovulatory frequency rose again. In Bailey et al.'s (1992) later study, it was determined that the ovulatory frequency decrease was due to a marked reduction in ovarian hormone levels, including progesterone, which prevented ovulation from occurring during the hunger season. Hormone levels correlated directly with energy balance, which became negative during the hunger season due to a decrease in energy intake, shown by a decrease in weight of 2 kilograms on average compared to the seasons of plenty (Ellison et 
al. 1989). Contrastingly, after the harvest ovulatory frequency reached a peak with progesterone levels rising as female energy balance became positive due to increased food availability. The subsequent increase in weight correlated with an increase in conception rate from the period late July to November (Bailey et al. 1992). Energy balance was also to some extent affected by higher energy expenditure due to the winter workload; however, this had a milder effect. Thus, emphasis here is placed on the effects of lower energy intake on ERO in this and other African populations.

Study of ERO in the pastoralist Turkana population of Kenya was performed in a similar manner and time period to that of Ellison et al. (1989) and Bailey et al. (1992) by Leslie and Fry (1989). Their findings concerning the seasonality of conception patterns in the population corroborated the findings described above. In fact, in their study fluctuations in conception rates were found to be even more extreme. Leslie and Fry's work (1989) showed a positive correlation between conception rates and rainfall, but with a lag time of a couple of months. Peak conception rates occurred July-August, with a clear trough shown (with less than 5 per cent of all conceptions occurring) MarchApril. These data, as they correlate with (adjusted) rainfall and livestock milk production, are expressed in Figure 2.

Evidence that falls contrary to the above is shown in studies of the Efe people of Zaire and of !Kung San people in Namibia (Bentley 1985; Ellison et al. 1989). Compared to the above populations, these showed a highly reduced birth seasonality, with a lack of hormonal or ovulatory frequency fluctuation, despite their parallel geographic location. This contradiction highlights an important parameter of seasonality: subsistence type. The more constant birth rates of the Efe and !Kung populations can be explained by their forage-based subsistence type. With no dependence on rainfall for crop productions or livestock health, ERO in these populations is much less prominent, as female energy balance is not as affected by food availability according to rainfall (Bentley 1985). This evidence thus reinforces the following conclusions: 1) ERO is the result of energy imbalance due to food availability as affected by rainfall and 2) ERO has a significant impact on seasonality of conception, and thus birth rates. It can thus be seen that ERO in sub-Saharan tropical African agriculturalist and pastoralist populations is caused by fluctuations in rainfall, which affect food availability. 


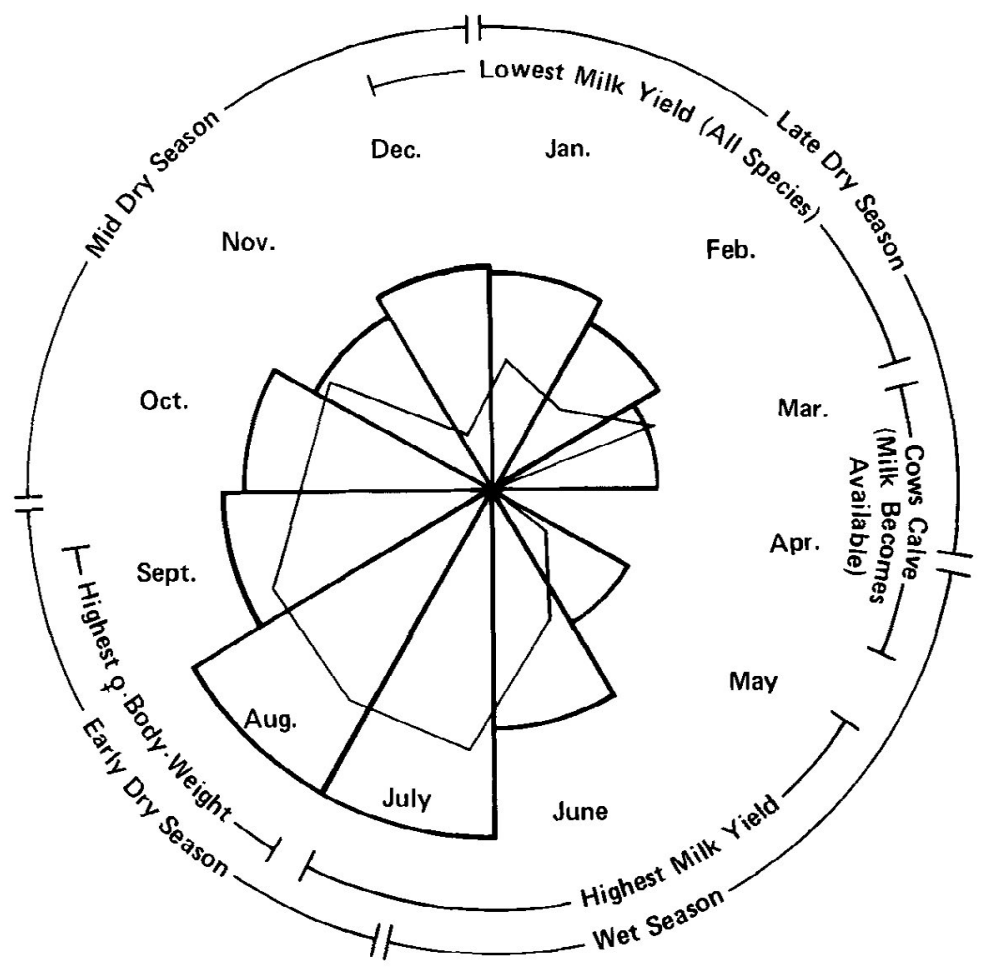

Conceptions
Rainfall Rotated $109^{\circ}$ (3.6 Month Lag)

Figure 2: Circle graph showing conception rates (bars) according to rainfall (line) in a calendar year, as correlated with seasons and milk production in Turkana pastoralist population

Source: Leslie and Fry 1989:108, Fig. 4 (License no. 3897990628417), reproduced with permission.

\section{Temperate Nepali populations}

In the foothills of the Himalayas live the native Nepalese Tamang people. With the temperate climate in this region, they subsist via agriculturalism with aspects of pastoralism, growing mainly root vegetables and other hardy plants that are not dependent on rainfall. Studies performed on energetic regulation 
of ovulation in the population were performed in collaboration by PanterBrick and Ellison over a period of several years, and followed Ellison's previous research in former Zaire on the Efe and Lese (Panter-Brick et al. 1993). Research here revolved around the significance of food availability in this more temperate, food-constant region. In their studies, Panter-Brick et al. (1993) and Panter-Brick (1996) proposed that an observed energetic imbalance seen in Tamang women would be, for the most part, the result of a different factor-namely increased energy expenditure rather than decreased energy intake. The studies found that ovarian hormone suppression and consequent reduced ovulatory frequency occurred in the population with an increase in workload. When energy expenditure related to subsistence (e.g. harvesting potato crops) increased two-fold, a parallel reduction in Body Mass Index (BMI) occurred. With an increased workload from October to December, Tamang women showed hormonal suppression, which resulted in a 33 per cent decrease in ovulatory frequency (Panter-Brick 1996). Contrastingly, it was found that during periods of hunger, when BMI was also reduced due to reduced energy intake occurring in tandem with reduced workload, ovulatory frequency did not decrease as dramatically (Panter-Brick 1996). Confirming this were data indicating that women in the Tamang population who gained weight during the usual work-heavy monsoon months did not have reduced progesterone levels. As weight is the main indicator of energy balance, these data demonstrate that hormone suppression was not dependent upon nutritional status as such, but energy balance: when energy balance was maintained (and therefore weight was maintained), hormonal levels did not change (Panter-Brick 1996). This observation was crucial in determining that it is not merely reduced nutritional status, but actual negative energy balance that causes ERO in agriculturalist/pastoralist populations, as well as indicating the greater effect of energy expenditure compared to energy intake on ERO in the temperate population.

One important factor to note regarding the study of the Nepali population is the confounding effect of culture and behaviour. A conception trough from October to December was predicted by the ERO, which occurred due to negative energy balance during this period. However, another birth trough seen from March to May was not anticipated by the purely biological model, as maximal weight occurred in the population during this winter period. This second trough is instead explained by behavioural factors, which have an added effect upon the biological factors influencing birth seasonality. To cover them briefly, in the Tamang population, men and women are traditionally separated between the months of March and May. This is because their subsistence work 
takes them to different areas, with the men often out-migrating temporarily for wage-earning work in other regions, while the women undertake the winter agricultural work (Panter-Brick 1996). This fact is acknowledged simply as a footnote: that the birth seasonality seen in the study populations was not wholly the result of biological factors involving ERO.

Overall, the study of the Tamang population shows: 1) ERO resulting in decreased conception rate during particular months occurs as a result of increased energy expenditure leading to negative energy imbalance for women and 2) nonbiological factors also have an influence on this seasonality, and should not be discounted in broader research.

\section{Further directions and current applications}

The area of birth seasonality has recently branched out into more crossdisciplinary fields, and has looked more at consequences of seasonality than causes. These current applications are fundamentally based on the causes of birth seasonality such as the energetic regulation of ovulation, which is this essay's focus. Although it is the author's belief that more recent, thorough research into the various causes of birth seasonality is required, the leap forward caused by the extrapolation of birth seasonality in various other fields is undoubtable. In areas as diverse as epidemiology, sociology, evolutionary biology and wider demography, large-scale birth seasonality models have been found to offer accurate predictions of later outcomes.

In a paper published recently, Dorélien (2016) links the subpopulation results found in studies of sub-Saharan African birth seasonality to larger-scale demographic data, as well as producing aggregate measures across countries and ecological zones to summarise scaled birth rates over the seasons. For epidemiology, this is because of the dependency of infectious disease dynamics upon seasonal mechanisms, which depend on birth seasonality, such as the number of susceptible individuals in a given winter (Dorélien 2016). This is further explored in Martinez-Bakker et al.'s (2014) recent study of childhood disease dynamics in the USA - in this case, measles-according to month of birth.

ERO is a cause of conception seasonality-and therefore to some extent birth seasonality-not only in the case of infectious disease, but in the expression of genes linked with diseases such as diabetes, obesity and eating disorders. This was discussed in Schneider et al. (2012). As indicated therein, the 
differences in hormone secretion, which are caused by the metabolic signals sent during ERO, are shown to have an effect even when conception is successfulthe alteration in hormone levels results in different gene expression.

In wider demography, birth seasonality is important for understanding future mortality and fertility patterns. Supporting this, Dorélien (2015) refers to mortality among young adults in the Gambia, which was found to be increased in those born in the hunger season (Moore et al. 1997), and her own research investigating child mortality in sub-Saharan Africa according to birth month.

As shown, the future direction of this field lies in further investigation into population-characteristic birth seasonality and the resulting demographic trends. The importance of birth seasonality studies is marked by their applicability to a wide range of linked areas. This said, it should be noted that applying biological models of birth seasonality to many current large-scale populations is inappropriate, especially in the developed world. As mentioned, ERO was seen in the referenced agriculturalist and pastoralist populations; though not in populations with different means of subsistence. In many developed countries, the industrial subsistence type means that energy balance remains more constant. For example, with crops transported and grown globally or in temperature- and water-controlled environments, rainfall and seasonality is not a parameter limiting food availability in developed industrialist populations. Similarly, as noted by Panter-Brick (1996) when introducing her study of Tamang women, with much of an industrialist population undertaking no subsistence workload whatsoever, the seasonality of energy expenditure is greatly reduced. However, this does not mean that studies of ERO are useless in such populations. Here, studying ERO is valuable on a more individual or subcultural level. The energy-heavy workloads of elite athletes and, in particular, the combination of this with low energy intake in ballerinas has been increasingly studied recently (Louks 2013; Fontana and della Torre 2016), and poses some interesting questions regarding the limits to fecundity in these subcultures, offering another context and direction that this aspect of birth seasonality may take in the future.

\section{Conclusions}

Comparing birth seasonality as a result of ERO in temperate and tropical subpopulations highlights the complexity of mechanisms regulating birth seasonality. In terms of the effects of ERO, the following trends were seen. 
In the tropical African populations, the effect of ERO is seen as troughs in conception rates during their respective preharvest months, when low rainfall and crop maturity reduces food availability. The resulting negative energy balance caused by reduced energy intake is clearly correlated to reduced frequency of ovulation and conception. This can be compared to peaks in these rates after successful harvest in late July to September, when an increase in energy intake results in positive energy balance and hence increased ovulatory frequency (Bailey et al. 1992).

Contrastingly, in the temperate Nepali population, workload increase during the harvest creates an energy imbalance that results in a trough in conceptions from October to December, as the increased energy expenditure tips the energy balance to negative. The expected subsequent peak in conception rates later in the year is somewhat mitigated by nonbiological factors, although it is evident that, biologically speaking, the reduction in workload results in energetic rebalance. Thus there is a return to regular ovulatory patterns, with seasonality of conception being due to behavioural factors only (Panter-Brick 1996).

The wide-ranging impacts of birth month on population health and mortality are evidently linked to many different fields, as has been further investigated recently. This underlines the importance of understanding the biological mechanisms such as the energetic regulation of ovulation that cause birth seasonality, and how these differ between populations. Through gaining a fundamental understanding of the causes of birth seasonality, its consequences can be investigated from a more nuanced perspective.

\section{Acknowledgements}

I would like to take the opportunity to acknowledge the editing contributions of my lecturer and editor, Dr Geoff Kushnick, and to thank him for his advice.

\section{References}

Bailey RC, Jenike MR, Ellison PT, Bentley GR, Harrigan AM, Peacock NR. 1992. The ecology of birth seasonality among agriculturalists in central Africa. J Biosoc Sci. 24(3):393-412. doi.org/10.1017/ S0021932000019957 
Bantje H. 1987. Seasonality of births and birth weights in Tanzania. Soc Sci Med. 24(9):733-739. doi.org/10.1016/0277-9536(87)90110-9

Bentley GR. 1985. Hunter-gather energetics and fertility: A reassessment of the !Kung San. Hum Ecol. 13(1):71-109. doi.org/10.1007/BF01531090

Berga S, Naftollin F. 2012. Neuroendocrine control of ovulation. Gynecol Endrocrinol. 28(1):9-13. doi.org/10.3109/09513590.2012.651929

Bongaarts J. 1978. A framework for analysing the proximate determinants of fertility. Popul Deve Rev. 4(1):105-132. doi.org/10.2307/1972149

Condon RG. 1991. Birth seasonality, photoperiod, and social change in the Central Canadian Arctic. Hum Ecol. 19(3):287-321. doi.org/10.1007/ BF00888980

Dorélien AM. 2015. Effects of birth month on child health and survival in sub-Saharan Africa. Biodemography Soc Biol. 61(2):209-230. doi.org/10 $.1080 / 19485565.2015 .1032399$

Dorélien AM. 2016. Birth seasonality in sub-Saharan Africa. Demographic Res. 34:761-796. doi.org/10.4054/DemRes.2016.34.27

Dorélien AM, Ballesteros S, Grenfell BT. 2013. Impact of birth seasonality on acute immunizing infections in sub-Saharan Africa. PLoS ONE. 8(10):e75806. doi.org/10.1371/journal.pone.0075806

Ellison PT. 2003. Energetics and reproductive effort. Am J Hum Biol. 15(3):342-351. doi.org/10.1002/ajhb.10152

Ellison PT, Peacock NR, Panter-Brick CM. 1989. Ecology and ovarian function among Lese women of the Ituri forest, Zaire. Am J Phys Anthropol. 78(4):159-526. doi.org/10.1002/ajpa.1330780407

Fontana R, della Torre S. 2016. The deep correlation between energy metabolism and reproduction: A view on the effects of nutrition for women's fertility. Nutrients. 8(2):87-121. doi.org/10.3390/nu8020087

Leslie PW, Fry PH. 1989. Extreme seasonality of births among nomadic Turkana pastoralists. Am J Phys Anthropol. 79(1):103-115. doi.org/ 10.1002/ajpa.1330790111 
Louks AB. 2013. Exercise training in the normal female: Effects of low energy availability on reproductive function. In: M Constantini, A Hackney, editors. Endocrinology of physical activity and sport. 2nd ed. New York (NY): Humana Press. pp. 185-205. doi.org/10.1007/978-1-62703-314$5 \_11$

Martinez-Bakker M, Bakker K, King A, Rohani P. 2014. Human birth seasonality: Latitudinal gradient and interplay with childhood disease dynamics. Proc R Soc B. 281(1783): 20132438. doi.org/10.1098/ rspb.2013.2438

Moore SE, Cole TJ, Poskitt EM, Sonko BJ, Whitehead RG, McGregor IA, Prentice AM. 1997. Season of birth predicts mortality in rural Gambia. Nature. 388(6641):434. doi.org/10.1038/41245

Panter-Brick C. 1996. Proximate determinants of birth seasonality and conception failure in Nepal. J Pop Stud. 50(2):203-220. doi.org/10.1080/ 0032472031000149306

Panter-Brick CM, Lotstein DS, Ellison PT. 1993. Seasonality of reproductive function and weight loss in rural Nepali women. Hum Reprod. 8(5):684690. doi.org/10.1093/oxfordjournals.humrep.a138120

Philibert A, Tourigny C, Coulibaly A, Fournier P. 2013. Birth seasonality as a response to a changing rural environment (Kayes region, Mali). J Biosoc Sci. 45(4):547-565. doi.org/10.1017/S0021932012000703

Rhinehart E. 2016. Mechanisms linking energy balance and reproduction: Impact of prenatal environment. Horm Mol Biol Clin Investig. 25(1):1868-1883. doi.org/10.1515/hmbci-2016-0004

Schneider J, Klingerman C, Abdulhay A. 2012. Sense and nonsense in metabolic control of reproduction. Front Endocrinol. 3:26. doi.org/ $10.3389 /$ fendo.2012.00026

Wargentin P. 1767. Uti hvilka Manader flera Maniskor arligen foda och do i Sverige. Mem Sci Acad Sweden. 27:249-258. 



\title{
Environmental and health effects of early copper metallurgy and mining in the Bronze Age
}

\section{Sarah Martin}

\begin{abstract}
Copper was a vital metal to the development of the Bronze Age in Europe and the Middle East. Many mine locations and mining techniques were developed to source the copper and other elements needed for the production of arsenic or tin bronze. Mining came with many associated health risks, from the immediate risk of collapse to eventual death from heavy metal poisoning. Severe environmental pollution from mining and smelting occurred, affecting the local mining community with effects that can still be felt today. This essay aims to establish that copper mining and manufacture had dramatic effects on the environment and health of people living in Europe and the Middle East during the Bronze Age. It goes on to speculate that heavy metal poisoning may have contributed to the increase in fractures seen between the Neolithic and Bronze Age.
\end{abstract}

Keywords

copper, Bronze Age, mining, health, environment

\section{Introduction}

The Bronze Age in the Middle East and Europe occurred approximately 3200-600 BCE. During this period, the importance of copper and its alloys grew to dominate society. The earliest uses of copper occurred in the Neolithic Period before its use in tools or weapons. Copper and its ores were used for colouring in ointments and cosmetics such as the vibrantly coloured 
oxide malachite. The trading and manufacturing of bronze weapons quickly became essential for the survival of Bronze Age societies in times of warfare. Bronze weapons were superior-in terms of sharpness, durability, weight and malleability - to other materials available at the time. They could be easily repaired and resharpened, or even melted down and made into another object (De Jesus 1980).

Although copper was easily found in surface outcrops, it would not have performed as well as tools or weapons fashioned from stone or flint, as the pure metal is considerably softer. The importance of copper began to rise with increased knowledge, such as the formation of harder copper compounds when combined with arsenic or tin. Pure copper can be hardened into smelted copper by the process of beating and quenching the meal to harden it (De Jesus 1980). Due to increasing demand for copper, native copper supplies became rare and other sources had to be found, as well as the development of more effective ways of processing the desired materials from the slag (stony waste material). The process of mining, smelting and roasting to separate out the desired metals released poisonous gases into the environment and resulted in a lot of physical waste in the form of slag piles. The released fumes and discarded materials affected not only the people in direct contact with them, but also the environment around them. The consequences of this environmental pollution can still be seen today in areas such as Wadi Faynan in Jordon, where waste from ancient copper mines continues to pollute the surrounding environment (Pyatt et al. 2000; Grattan et al. 2007).

This essay will focus on the dramatic effects that copper mining and manufacture had on the environment and health of people in Europe and the Middle East during the Bronze Age, 3200-600 BCE. It will examine where copper was sourced and how it was extracted in Europe and the Middle East, the important properties of tin and arsenic copper alloys, and dangers associated with mining. The environmental and health effects of copper mining will then be explored, focusing on the toxicity of the metals involved. A case study of the Wadi Faynan (also spelt Feynan, Fuynan, Feinan) in southern Jordan will be used to highlight the effects of metal manufacturing on the environment. Potential effects from increased levels of metal pollution across the ancient world will be proposed. 


\section{Copper mining: Locations, metal extraction and dangers}

The major Middle Eastern and European copper sources utilised in the ancient world were located in Spain, Anatolia (now known as Turkey), Jordan and Egypt. The production and use of copper and its alloys began earliest in Anatolia and the Near East by 8000 BCE, and spread from east to west through the Mediterranean, with the earliest sites dating from 5500 BCE (Kassianidou and Knapp 2008).

Copper naturally occurs in three main forms: as native metal, an oxide or a reduced sulphide ore. The ores, in turn, are associated with other metals and the concentration of these metals can dramatically fluctuate depending on geographical location. In Turkey, the most common form in which copper is found is chalcopyrite, a copper sulphide. It is frequently found in association with lead and zinc, and when this occurs all three metals can be mined and smelted from the same source (De Jesus 1980). Copper ores could be identified using a number of methods. Some are brightly coloured, and are often found in association with other, less vibrantly coloured, ores. The taste of water and presence of copper tolerating plants such as Silene inflate can also be used to identify copper ores (De Jesus 1980; Kassianidou and Knapp 2008).

Active mining for metals most likely started on a small scale, with limited numbers of local people and simple 'open cast' pit mines, where material is removed directly from an open pit. As soon as tunnelling techniques were adopted, many more people were required (250-300 men according to estimates from De Jesus 1980). This included jobs outside of directly tunnelling, which would be needed to support the operation such as smelting, prospecting and food provision (De Jesus 1980). Another mining technique that was used was trench mines, which followed the vein of ore into the ground. These were only as wide as the ore vein itself. An example of this approach is seen in a tin mine in Karnab, Uzbekistan. It shows that women and children must have been involved in excavations, as in some places the mine was so narrow that no grown man could have worked in it (Cierny and Weisgerber 2003).

Once the ore is found, the desired metal must be separated. The ore was often first roasted to oxidise the copper and to get rid of components with lower melting points, such as water and sulphur (Erb-Satullo et al. 2014). The metal itself is removed by smelting, a process of heating the ore beyond the melting point of the desired metal. This is often done in the presence of either reducing 
or oxidising agents such as elements found in air. To get the high temperatures required to do this, furnaces and bellows had to be developed. Examples of these were discovered at the Wadi Faynan site and are thought to have been wind driven (Kassianidou and Knapp 2008).

There were many dangers associated with mining, in particular the toxic byproducts, risk of collapse, lack of ventilation and dust inhalation. Open furnaces that allowed air to circulate also enabled the toxic byproducts (such as the poisonous and foul-smelling gas sulphur dioxide) to escape into the environment (Thompson Rowling 1967), reducing inhalation by workers, but increasing environmental pollution. In extreme cases, the environmental pollution can lead to decreased crop productivity, increasing the risk of famine and food shortages. It also causes bioaccumulation of metals in plants and animals that is passed on to the humans consuming them, and leaves them severely physically weakened by the contaminates consumed (Pyatt et al. 1999, 2000). The specific effect of the contaminates would depend on the kind - for example lead or copper-and the concentration consumed over a period of time.

Collapse is always one of the biggest risks of tunnel and trench mining (Figure 1). In the trench mines of Karnab, not all of the ore vein was extracted, with miners leaving bridges of the original ore as support structures (Cierny and Weisgerber 2003). In tunnel mines, pillars made from wood or stones were very common, with many examples from all over the world being found. Other approaches to supporting tunnels were to support the roof with wood and to fill in old, unused tunnels with stones or debris. Nevertheless, collapses seem to have been very common in many ancient mines, as the remains of buried miners have been discovered inside. The danger of further collapse must have been clear to their fellows, as in many of these cases there does not appear to be a huge amount of effort made to free the trapped miners (De Jesus 1980). This can be seen in the discovery of more than 50 miners who had been trapped about 3,000 years ago by a collapsed tunnel entrance in Koniah, Turkey (Sharpless 1908). 


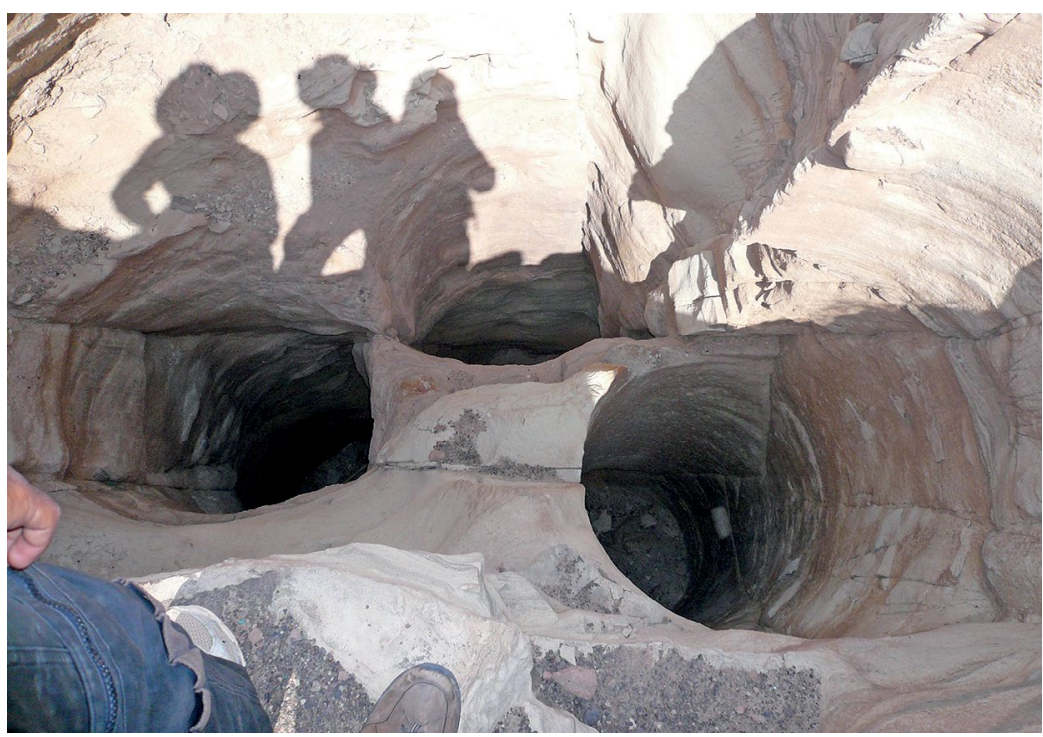

Figure 1: Three vertical copper mine shafts in Wadi Faynan

Source: Volker Umpfenbach 2011, reproduced with permission.

Another major problem in long tunnel or shaft mines was ventilation. Oxygen was used up by the miners themselves and ventilation was necessary to overcome the effects of dust and heat buildup. This issue was exacerbated when fire had to be used to break the rock, as this used up all of the oxygen in the mine. Without adequate ventilation, work had to be abandoned until the fumes naturally left and oxygen levels were restored to a level supporting life. Aside from this, options included digging small parallel holes that joined the working tunnel at intervals to create a draft, or piercing air holes from above when the tunnel depth allowed for ventilation. Two other methods used to increase ventilation by creating a draft were lighting a fire under an air hole and shaking a linen cloth. While these methods would have partially worked, the mines would still have been incredibly unpleasant places to work in, being hot and stuffy with minimal oxygen and a large amount of dust (De Jesus 1980). The large levels of dust present in mines can lead to anthracosis, a condition resulting from long-term exposure to dust particles containing silicon, quartz or carbon (Thompson Rowling 1967; De Jesus 1980; Ghanei et al. 2011). However, it is difficult to definitively determine the cause of anthracosis in ancient cases as it can be caused by active tuberculosis or previous infection with Mycobacterium tuberculosis (Ghanei et al. 2011). 


\section{Properties of arsenic and tin bronze}

Arsenic bronze, the addition of arsenic to copper, was the first kind of bronze to be made, followed by the addition of tin to copper to create tin bronze. Arsenic bronze is the most widely used metal alloy of the Bronze Age, being found at all important sites from this time period in the Middle East and Europe. Arsenic bronze was the first form of bronze to be created and widely used, later followed by tin bronze. There are two main theories about how arsenic came to be alloyed with copper: the copper deposits mined already had arsenic present or arsenic was mined separately and co-smelted (Merideth 1998; Oudbashi and Davami 2014). It is likely that both of these events occurred as copper ores containing arsenic do occur, and so could have been accidentally incorporated this way. However, these ores are a less common form of copper ore and are often associated with lead (De Jesus 1980). Tin bronze was introduced later than arsenic bronze and both alloys continued to be used, though the amount of arsenic bronze decreased over time (De Jesus 1980; Kassianidou and Knapp 2008). Interestingly, tin and arsenic bronze appear to have been kept actively separated, and not melted together, in either scrap form or after smelting, despite examples of both being used in the same object (De Jesus 1980).

Smelted copper was also used in the ancient world and is produced by a process of working and annealing, in which the copper is hammered and stretched towards the desired shape. It is then heated to a specific temperature and allowed to slowly cool to retain its ductility (Merideth 1998). Bronze never completely supplanted smelted copper, and items made from smelted copper have been found that date to the Bronze Age (Birmingham 1977).

Theories as to why the amount of arsenic bronze decreased include that tin was favoured for safety, given the highly poisonous nature of arsenic (Birmingham 1977; De Jesus 1980), or that tin ores were more readily available. Another theory proposes that arsenic bronze was harder to create with appropriate levels of arsenic as losses are high during roasting, smelting and refining. However, there is conflicting support for this theory (McKerrell and Tylecote 1972; Branigan 1974). It is likely that a combination of the poisonous nature, rarity of arsenic ores and difficulties in manufacturing led to the reduction in the amount of arsenic bronze produced after the middle Bronze Age approximately 1600 BCE (Birmingham 1977; Kassianidou and Knapp 2008). 
Different ratios of tin or arsenic in copper change the characteristics of the bronze they produce. The addition of tin or arsenic results in a harder metal that is easily cast and hammered. However, the amount of metal (either tin or arsenic) that needs to be added to achieve the desired harder bronze is unclear. The optimal per cent of arsenic desired in bronze is not consistent across the literature. An intentional alloy is defined as one with more than 2 per cent arsenic or tin, as they could otherwise just be the result of impurities in the copper ore (Merideth 1998). Branigan (1974) states that more than 2 per cent arsenic makes the bronze brittle. This is in contrast to Merideth (1998), who establishes that ideal arsenic content is 5-7 per cent, which will result in a much harder and more durable metal than smelted copper when cold worked at under $300^{\circ} \mathrm{C}$. The desired amount of tin in bronze is also inconsistent across sources, with proposed optimal amounts of 7-8 per cent (Primas 2003), 10 per cent (Cierny and Weisgerber 2003) and 18 per cent (Oudbashi and Davami 2014).

Another metal that is sometimes added to tin and arsenic bronze is lead. This is often found in association with copper ores and the effects that it has on bronze are disputed. Branigan (1974) maintains that lead is insoluble in copper and weakens it by forming globules in the copper matrix as the phases solidify at different rates. Merideth (1998) states that lead was added to tin bronze as it allowed better flowing capacities for casting objects. Morr and Modlinger (2014) add that while they are not sure that lead improved the castability of the metal, there is an association found between cast items and leaded alloys. This is elaborated on further in that the addition of lead was detrimental to copper alloys if they were then hammered. Another suggestion they propose for why lead was added is that it was used in areas with fuel shortages to reduce the melting temperature and therefore the amount of fuel needed. Primas (2003) concluded that lead was added for sound technical reasons rather than to save tin. This conclusion was reached using the grave goods of a bronze smith that date to $1100 \mathrm{BCE}$. These goods were technologically advanced compared to older examples and included items made of a copper-tin-lead alloy.

\section{Toxicity and bioaccumulation of heavy metals}

Copper is an essential element in human health; it is used in certain enzymes and for other bodily functions such as melanin transformation and forming links between collagen and elastin for the maintenance of connective tissue (Sandford 1993). As copper cannot be made in the body, it must be absorbed 
from the diet. Because of this, the body is also very effective at getting rid of excess copper; therefore many times more copper than required must be absorbed to produce adverse effects in the body. When this occurs, the symptoms include diarrhea, nausea, vomiting, coma, increased rates of lung and liver tumours and eventually death (Pyatt et al. 2005).

Tin is similar to copper in that it is an essential element (Sandford 1993); excess is poorly absorbed and 95 per cent is excreted. The remaining 5 per cent is absorbed in the gastrointestinal tract and circulates through the body before extraction through the kidneys. A small amount is deposited in the bones and lungs. For amounts in excess of 130 milligrams (mg) per day, buildup also occurs in the kidneys and liver. Effects begin as skin and eye irritation, progressing to nerve, liver and immune system damage (Winship 1988).

Lead and arsenic are much more toxic in smaller doses and are also carcinogenic, suppress enzyme activity and accumulate in bone (Flessel 1979; Aufderheide and Rodriguez-Martin 2006; Aufderheide 2011). Lead and arsenic are not essential in the human body and have a very slow excretion rate, so exposure results in cumulative effects (Aufderheide 1989).

There appears to be no minimal level of lead exposure for its toxic effects to be felt upon metabolism and neurophysiology (Needleman 1991) as it attaches to and inhibits enzymes (Bishop et al. 2013). As a result, acute (shortterm) and chronic (long-term) poisoning can occur, showing slight variation in symptoms (Pyatt et al. 2000). General symptoms of lead poisoning are brain damage, anaemia, convulsions, nerve paralysis, osteoporosis and eventually death (Aufderheide 1989; Pyatt et al. 2005). At a minimum, blood levels should be below 0.05 parts per million (ppm) (4.2 ppm in bone from Martínez-García et al. 2005), as even at $0.1 \mathrm{ppm}$ permanent intellectual and hearing defects can occur (Bishop et al. 2013). Lead retention in different areas of the body vary: the brain has a lead retention time of weeks while the bones retain lead for years. Bone is one of the most common places that lead builds up over time after being absorbed and transported in the soft tissue (Pastorelli et al. 2014). Lead can be taken up in a variety of ways, including eating contaminated food (especially cereals), animal products or water (Pastorelli et al. 2014), or inhaled after release from smelting lead containing ores (Grattan et al. 2002).

Arsenic toxicity is well established by Aufderheide (2011), Aufderheide and Rodriguez-Martin (2006), Flessel (1979) and Branigan (1974). Aufderheide and Rodriguez-Martin (2006) directly refer to mining of copper ores as 
a possible source of arsenic poisoning, and the smelting of said ores resulting in the production of highly toxic arsine gas. Poisoning can be either acute or chronic. In high enough acute doses, brain stem failure can occur, leading to coma and eventually death. At lower acute doses, damage to the kidneys, liver and gastrointestinal tract occur. After chronic exposure, symptoms are often peripheral neuropathy, skin changes, respiratory inflammation, increased risk of lung and skin cancer and blood clot formation (Aufderheide and RodriguezMartin 2006).

Lead and arsenic have detrimental long-term effects upon bone, which can be seen in the skeletal record. They both cause osteoporosis and increase the risk of fractures and breaks. Lead can also affect osteoblast cell number, leading to decreased bone formation (Beier et al. 2013). Arsenic poisoning has been associated with an increased cancer risk, particularly lung cancer (Järup 2003); but cancers caused specifically by arsenic are difficult to identify in the skeletal record (Ortner 2003; Aufderheide and Rodriguez-Martin 2006). If the level of arsenic is high enough to lead to cancer, the exposure would have been long term and result in arsenic deposited in the bones, which can be easily tested (Järup 2003).

The manifestations of high levels of heavy metal exposure in the skeletal record are varied. The main indication of heavy metal poisoning is assessed through analysis of the metal content of the bones and teeth. Care must be taken with this method as the leaching of metals from the soil into bone (and vice versa) can influence results so soil samples should be taken for comparison. Contamination can also occur from metallic grave goods and postexcavation exposure (Pastorelli et al. 2014). When comparing populations, samples should be taken from the same area of the skeleton, as heavy metal load in bone changes throughout the body. Some areas can have a much higher metal level than others (Martínez-García et al. 2005).

\section{Environmental effects of widespread heavy metal pollution}

The release of heavy metals from ancient mining and smelting offered an immediate danger to those extracting and processing them. On top of this, the released metals built up in the environment in a form that was easily accessible to plants, leading to bioaccumulation when they are eaten. This led to high levels of heavy metals in the soil surrounding processing and extraction areas, 
as well as being released into the atmosphere and spreading large distances around the world. This can be seen in high altitude mires of Switzerland, where accumulating concentrations of lead over natural levels began 5,500 years ago - the same time that more intensive mining methods began to be used (Grattan et al. 2007). The high levels of heavy metal pollution that are still present in ancient mining sites can also provide an insight into the effects that mining had on the immediate environment. By studying the impact of heavy metal loads on modern plants, animals and people, we are given insight into the impact of these loads on Bronze Age people (Pyatt et al. 1999, 2005).

Recent studies attempting to establish the effect of heavy metals on the ancient world have begun to focus on the environmental state of the modern sites. Wadi Faynan, a site of particular interest, is located in Southern Jordan and has been mined extensively for copper, iron and other ores from $6000 \mathrm{BCE}$ through the Bronze Age and Roman-Byzantine times. The main metals polluting the site are lead and copper. It includes the site of the ancient Roman city of Phaino and consists of over 250 copper mines, associated spoil tips and extensive slag heaps, as well as a large field system used for food production (Pyatt et al. 1999, 2005).

The extensive mining that occurred in this location has left more marks than the obvious debris. Pyatt et al. $(1999,2005)$ studied this site, focusing on the current environmental impact of mining. In particular, they observed the animals that use the area, the growth rate of crops, and investigated the difference in heavy metal load between ancient and modern skeletons. The heavy metal load of the site is likely to be lower today than it would have been when mining ceased, as there has been time for extensive environmental weathering to occur. This weathering includes leaching, and atmospheric, sheet and gulley erosion. These processes ultimately pollute the areas surrounding them by redistributing the metal contamination (Pyatt et al. 1999, 2005).

Metals would have been slowly released into the soil and taken up by plants. To test the effects of heavy metals on plant growth, barley was grown on areas with varying pollution levels. Barley has been grown in this area for millennia, with wild barley still growing at the site. It would have been used as one of the primary cereals supporting the mining community and their animals. No difference in plant height was found between the polluted spoil tip and the control site; however, the number of viable seeds produced were almost doubled at the control site. At a more heavily polluted site, plant height was dramatically reduced from $13-15$ to $6-10$ centimetres. Seed potential 
was also adversely affected in the area of higher pollution, dropping to nine seeds per 20 plants. Because of the decrease in production effectiveness, food shortages would have been common. A much larger area would have needed to be dedicated to food production than at uncontaminated sites to compensate for the loss in production. Furthermore, workers would have been severely physically weakened from consuming contaminated food and direct inhalation of pollutants (Pyatt et al. 1999).

Herbivorous animals have few options for food in the Wadi Faynan, and had to eat contaminated material. Goats and sheep are the main domestic grazers in the area because when horses and cattle are grazed on grass grown in soils containing these levels of metal pollution (1,000 ppm lead detected) they die or become seriously ill. The bodies of goats and sheep grazed in the Wadi Faynan today were analysed for their heavy metal content. Goats have a higher resistance to copper and lead poisoning, but both species are able to tolerate higher levels of copper than lead. The highest concentration of metals was in the faecal matter, demonstrating that the metals could be excreted, and continue to be recycled into the soil. Despite this, the heavy metal content of the modern animals' bones was very high $(293 \mathrm{mg} / \mathrm{kilogram}(\mathrm{kg})$ of lead and $46.5 \mathrm{mg} / \mathrm{kg}$ of copper from 24 goat skeletons), and all products such as milk and meat were contaminated. This has dangerous implications for the local Bedouin population, who rely on these animals (Pyatt et al. 2000). Contaminated animal products would have also adversely affected people working in this area in the Bronze Age, providing another source of heavy metal poisoning.

Pyatt et al. (2005) conducted a study comparing ancient human skeletal remains from the Bronze Age to modern copper and lead levels in human bone. The copper load of the Bronze Age sample was 27 times the typical amount of copper in human bone, and the lead load was also massively enhanced. It is unlikely that the ancient samples were contaminated from the grave environment as the heavy metal levels in the surrounding soil were considerably lower than the levels found in the bone (Pyatt et al. 2005). 


\section{Wider implications of increased heavy metal load}

Higher levels of lead in bone have been noted across the ancient world after the intensification of mining practices. This is perhaps from atmospheric circulation spreading particles throughout the world's atmosphere (GonzálezReimers et al. 2005; Pastorelli et al. 2014).

A study by Erdal and Erdal (2012) provides an overview of the injuries sustained to skeletons dating from the Neolithic and Bronze Age in Anatolia (modern Turkey). They discovered that the number of fractures seen doubled from the Neolithic to the Bronze Age, and concluded that this was as a result of increasing interpersonal violence. However, they also added that these kinds of injures can also be attributed to accidents and daily activity.

A speculative explanation for the increase in fracture rates is heavy metal poisoning as a result of the increased mining in Anatolia. Heavy metal poisoning could both directly and indirectly lead to an increase in fracture rates. The direct effects of heavy metal poisoning by lead and arsenic is accumulation in bone and osteoporosis (Aufderheide 1989; Pyatt et al. 2005; Aufderheide and Rodriguez-Martin 2006; Aufderheide 2011), increasing the risk of fractures and breaks (Beier et al. 2013). The consequence of this decreased bone strength would be an increased likelihood of fractures or breaks occurring from accidents, daily activity or interpersonal violence.

Heavy metal pollution leads to an increased heavy metal load in the environment, which could have indirect effects on fracture rates. This increase can also affect locally grown crops, decreasing seed production the more polluted the site and increasing the amount of land needed to grow crops (Pyatt et al. 1999). It can also detrimentally affect or even kill grazing animals such as cattle or horses as the metals accumulate in their tissues. While sheep and goats are less affected by high metal loads, they still experience bioaccumulation of heavy metals through ingestion of contaminated feed or water (Pyatt et al. 2000). The effects of heavy metal accumulation on both plants and animals would have led to increased heavy metal loads in humans consuming the contaminated food. There would have also been reduced food productivity and an increased risk of famine and food shortages (Pyatt et al. 1999), placing stress on the local populations and potentially increasing interpersonal violence as people fight over resources. 
The skeletal population from Titris Hoyuk studied by Erdal (2012) was in close proximity to mines used at that time. In particular, the silver and lead mines Keban and Pirajman, the lead and zinc mine Deri, and the copper mines Keydak, Ergani and Karabek were within 150 kilometres of the city (De Jesus 1980). This city was also reported to be experiencing resource stress and environmental deterioration during the Late Bronze Age because of both climate change and the overexploitation of the surrounding area (Erdal 2012). This is consistent with the environmental effects of heavy metal pollution detailed above. Further research, such as the heavy metal levels in the skeletons from Titris Hoyuk and the soil in which they were found, is required to add support to this theory.

\section{Conclusion}

This essay aimed to establish the dramatic effects that copper mining and manufacture had on both the environment and health of people in Europe and the Middle East during the Bronze Age. It detailed how and where copper was sourced and extracted, how bronze was made and the dangers to people conducting this work, both from injury during the work and the heavy metal poisoning they experienced. It was determined that the environmental pollution by heavy metals and the effect of this on people using the affected land was dramatic and can still be seen in areas such as Wadi Faynan today. It was speculated that heavy metal poisoning may have contributed to the increase in fractures seen between the Neolithic and Bronze Age.

The development of bronze and the mining associated with its production have had many unintended consequences. The miners were exposed to many dangers from the physical dangers of mining and the very real possibility of heavy metal poisoning during mining and bronze production. Arsenic bronze was eventually primarily supplanted by tin bronze, most likely because of the adverse health effects of arsenic and the increased availability of tin.

The release of heavy metals into the environment had detrimental effects upon the plants and animals living there, and the humans who depended on them for food. This can be clearly seen in Wadi Faynan, where the pollution levels are still very high and affect the living organisms there today. Heavy metals were spread around the world through the atmosphere and inhaled by the ancient population, resulting in increased heavy metal levels in bone. Lead and arsenic are particularly dangerous and may have caused the resource 
stress and increase in trauma injures seen throughout Bronze Age Anatolia. The discovery of bronze and its associated consequences paved the way for the development of modern life as we know it today. Our world has been greatly affected by it, and will never be the same.

\section{Acknowledgements}

I would like to thank Mr Rodney Studdert for his continual enthusiasm for and encyclopaedic knowledge of ancient history, Dr Ekatarina Pechenkina for her fascinating biological anthropology subject that sparked my interest in this area and for helping direct my focus, my long-suffering roommate and friends for keeping me fed and sane during the writing process, and my parents for proofreading drafts, listening to my rants and being so incredibly supportive.

\section{References}

Aufderheide AC. 1989. Chemical analysis of skeletal remains. In: MY Işcan, KAR Kennedy, editors. Reconstruction of life from the skeleton. New York (NY): Wiley-Liss. pp. 238-260.

Aufderheide AC. 2011. Soft tissue taphonomy: A paleopathology perspective. Int J Paleopathol. 1(2):75-80. doi.org/10.1016/j.ijpp.2011.10.001

Aufderheide AC, Rodriguez-Martin. 2006. The Cambridge encyclopedia of human paleopathology. 3rd ed. Cambridge (UK): Cambridge University Press.

Beier E, Maher J, Sheu T, Cory-Slechta D, Berger A, Zuscik M, Puzas J. 2013. Heavy metal lead exposure, osteoporotic-like phenotype in an animal model, and depression of Wnt signaling. Environ Health Perspect. 121(1):97-104. doi.org/10.1289/ehp.1205374

Birmingham J. 1977. Spectrographic analyses of some middle Bronze Age metal objects. Levant. 9(1):115-120. doi.org/10.1179/lev.1977.9.1.115

Bishop ML, Fody EP, Schoeff LE. 2013. Clinical chemistry: Principles, techniques, and correlations. 7th ed. New York (NY): Lippincott Williams \& Wilkins. 
Branigan K. 1974. Aegean metalwork of the early and middle Bronze Age. London (UK): Oxford University Press.

Cierny J, Weisgerber G. 2003. Bronze Age tin mines in Central Asia. In: A Giumlia-Mair, F Lo Schiavo, editors. The problem of early tin. Oxford (UK): Archaeopress BAR International Series 1199. pp. 23-31.

De Jesus PS. 1980. The development of prehistoric mining and metallurgy in Anatolia. Oxford (UK): British Archaeological Reports.

Erb-Satullo NL, Gilmour BJJ, Khakhutaishvili N. 2014. Late Bronze and early Iron Age copper smelting technologies in the South Caucasus: The view from ancient Colchis c. 1500-600 BC. J Archaeol Sci. 49:147159. doi.org/10.1016/j.jas.2014.03.034

Erdal ÖD. 2012. A possible massacre at Early Bronze Age Titriş Höyük, Anatolia. Int J Osteoarchaeol. 22(1):1-21. doi.org/10.1002/oa.1177

Erdal YS, Erdal ÖD. 2012. Organized violence in Anatolia: A retrospective research on the injuries from the Neolithic to Early Bronze Age. Int J Paleopathol. 2(2):78-92. doi.org/10.1016/j.ijpp.2012.09.014

Flessel CP. 1979. Metals as mutagenic initiators of cancer. In: N Kharasch, editor. Trace metals in health and disease. New York (NY): Raven Press. pp. 109-122.

Ghanei M, Aslani J, Peyman M, Asl MA, Pirnazar O. 2011. Bronchial anthracosis: A potent clue for diagnosis of pulmonary tuberculosis. Oman Med J. 26(1):19-22. doi.org/10.5001/omj.2011.05

González-Reimers E, Arnay-de-la-Rosa M, Velasco-Vázquez J, GalindoMartín L, Santolaria-Fernández F. 2005. Bone cadmium and lead in the ancient population from El Hierro, Canary Islands. Biol Trace Elem Res. 105(1-3):37-51. doi.org/10.1385/BTER:105:1-3:037

Grattan J, Huxley S, Abu Karaki L, Toland H, Gilbertson D, Pyatt B, al Saad Z. 2002. 'Death ... more desirable than life'? The human skeletal record and toxicological implications of ancient copper mining and smelting in Wadi Faynan, southwestern Jordan. Toxicol Ind Health. 18(6):297-307. doi.org/10.1191/0748233702th153oa 
Grattan JP, Gilbertson DD, Hunt CO. 2007. The local and global dimensions of metalliferous pollution derived from a reconstruction of an eight thousand year record of copper smelting and mining at a desertmountain frontier in southern Jordan. J Archaeol Sci. 34(1):83-110. doi.org/10.1016/j.jas.2006.04.004

Järup L. 2003. Hazards of heavy metal contamination. Br Med Bull. 68(1):167-182. doi.org/10.1093/bmb/ldg032

Kassianidou V, Knapp AB. 2008. Archaeometallurgy in the Mediterranean: The social context of mining, technology, and trade. In: E Blake, AB Knapp, editors. The archaeology of Mediterranean prehistory. Cornwall (UK): Blackwell Publishing. pp. 215-251.

Martínez-García MJ, Moreno JM, Moreno-Clavel J, Vergara N, GarcíaSánchez A, Guillamón A, Portí M, Moreno-Grau S. 2005. Heavy metals in human bones in different historical epochs. Sci Total Environ. 348(1):5172. doi.org/10.1016/j.scitotenv.2004.12.075

McKerrell H, Tylecote RF. 1972. The working of copper-arsenic alloys in the Early Bronze Age and the effect on the determination of provenance. Proc Prehist Soc. 38:209-218. doi.org/10.1017/S0079497X00012111

Merideth C. 1998. An archaeometallurgical survey for ancient tin mines and smelting sites in Spain and Portugal: Mid-central western Iberian geographical region, 1990-1995. Oxford (UK): British Archaeological Reports.

Morr ZE, Modlinger M. 2014. Middle Bronze Age metal artifacts and metallurgical practices at the sites of Tell Arqu, Mougharet el-Hourryieh, Yanouh and Khariji in Lebanon. Levant. 46(1):27-42. doi.org/10.1179/0 075891413Z.00000000033

Needleman HL. 1991. Human lead exposure. Boca Raton (FL): CRC Press.

Ortner DJ. 2003. Identification of pathological conditions in human skeletal remains. 2nd ed. San Diego (CA): Academic Press.

Oudbashi O, Davami P. 2014. Metallography and microstructure interpretation of some archaeological tin bronze vessels from Iran. Mater Charact. 97:74-82. doi.org/10.1016/j.matchar.2014.09.007 
Pastorelli AA, Campanella L, Coppa A, Stacchini P. 2014. Exposure to cadmium and lead in an agropastoral Iron Age population. Int J Osteoarchaeol. 26(1):132-140. doi.org/10.1002/oa.2403

Primas M. 2003. Bronze Age tin mines in Central Asia. In: A Giumlia-Mair, F Lo Schiavo, editors. The problem of early tin. Oxford (UK): Archaeopress BAR International Series 1199. pp. 87-91.

Pyatt FB, Barker GW, Birch P, Gilbertson DD, Grattan JP, Mattingly DJ. 1999. King Solomon's miners-starvation and bioaccumulation? An environmental archaeological investigation in southern Jordan. Ecotoxicol Environ Saf. 43(3):305-308. doi.org/10.1006/eesa.1999.1795

Pyatt FB, Gilmore G, Grattan JP, Hunt CO, Mclaren S. 2000. An imperial legacy? An exploration of the environmental impact of ancient metal mining and smelting in southern Jordan. J Archaeol Sci. 27(9):771-778. doi.org/10.1006/jasc. 1999.0580

Pyatt FB, Pyatt AJ, Walker C, Sheen T, Grattan JP. 2005. The heavy metal content of skeletons from an ancient metalliferous polluted area in southern Jordan with particular reference to bioaccumulation and human health. Ecotoxicol Environ Saf. 60(3):295-300. doi.org/10.1016/j. ecoenv.2004.05.002

Sandford MK. 1993. Investigation of ancient human tissue: Chemical analysis in anthropology. Philadelphia (PA): Gordon and Breach Science Publishers.

Sharpless FF. 1908. Mercury mines at Konia, Asia Minor. Eng Min J. 86(13):601-603.

Thompson Rowling J. 1967. Respiratory disease in Egypt. In: DR Brothwell, AT Sandison, editors. Diseases in antiquity: A survey of the diseases, injuries, and surgery of early populations. Springfield (IL): C.C. Thomas. pp. 489-493.

Umpfenbach V. 2011. Travelogue Jordan 2011 Feynan. Retrieved from volker. umpfenbach.de/en/reisen/2011jordanien/2011jordanien09.htm

Winship KA. 1988. Toxicity of tin and its compounds. Adverse Drug React Acute Poisoning Rev. 7(1):19-38. 



\title{
Dealing with predators: Vigilance and alarm calling in primates
}

\author{
Phoebe Raff
}

\begin{abstract}
Predation is considered one of the most important selective pressures on animals. Evidence of predation on primates is particularly rare; however, it is thought that it has been a major selective force for many species in the primate order. This can be seen through the occurrence and application of vigilance and alarm calling in many primate species. Studies of vigilance have shown that animals have a tendency to decrease individual vigilance as group size increases. However, it has been found that primates do not fit this model, and either maintain or increase their individual vigilance as group size increases. A likely reason for the maintenance of individual vigilance is that primates utilise this behaviour as both a form of antipredation behaviour and social monitoring; thus it largely depends on the social structure of the species and the environmental conditions of the ecosystem being occupied by a primate group. Another antipredator behaviour that occurs in primates is alarm calling, which may be to deter predators. The studies presented here show that primates have the ability to distinguish between predators, between and within predator classes and also predator hunting styles. It is believed that the development of these behaviours in the primate order shows that these animals have evolved in environments where predation is a threat.
\end{abstract}

\section{Keywords}

primates, predators, vigilance, alarm calling, social monitoring, aggregation 


\section{Introduction}

While witnessed accounts are rare, predation on primates has been observed. For example, chimpanzees (Pan troglodytes) have been known to strategically hunt and kill red colobus monkeys (Procolobus badius) (Treves 1999), and howler monkeys (Alouatta seniculus) have been documented to be eaten by jaguars (Panthera onca) (Peetz et al. 1992) and harpy eagles (Harpia harpyja) (Sherman 1991). However, as such witnessed accounts are rare, it seems that the presence of antipredator behaviours may be a better way to understand the level of threat posed to primates by predators. Given their widespread nature within the primate order, the presence of antipredator behaviours may in fact indicate that primates have evolved behavioural adaptations to deal with the selection pressure of predation threats.

Antipredator behaviours come in many forms and can be utilised in different ways within and across species. While such behaviours include concealment, active defence and flight, the two forms of antipredator behaviour that will be the focus of this research essay are vigilance and alarm calling. These two antipredator behaviours are highlighted here because they are important to predator-prey studies due to their wide use among primates to deter potential threats, and they are often used to initiate further responses within primate groups. The foundations of vigilance studies have been laid out and the benefits and costs associated with individual and group vigilance have been discussed in previous works. However, it is generally thought that primates do not fit the usual models for the function of vigilance when compared to other animals because their individual alertness does not decrease as group size increases (Treves 1999, 2000). This is contradictory to the 'many eyes' and 'dilution effect' hypotheses so common in vigilance studies that suggest that with increasing group size there should be a decrease in individual vigilance (Roberts 1996; Beauchamp 2003).

Alarm calling is also an extremely important tool used by primates to signal predator threats. This behaviour is employed differently across primate species and can be used to signal threats to the group, including predator classification and to deter predators (Seyfarth et al. 1980; Zuberbuhler et al. 1997; Ramakrishnan et al. 2005). It is thought that vigilance and alarm calling have both positive and negative effects on groups and individuals, and are utilised differently across primate species. However, they primarily serve as indicators that primates have evolved with the adaptations necessary to deal with predators. 
In this research essay, I will describe both the positive and negative impacts of vigilance and alarm calling on primate groups. With respect to vigilance studies, I will discuss how primates differ from each other and the foundational hypotheses in their employment of vigilance, and how social structure, aggregational living and environment are important contributors to primate vigilance. Alarm calling is also shown to be a technique employed by primates to deter potential predators, and, like vigilance, many species use this technique differently. It is concluded that the use of vigilance and alarm calling in primates, specifically the species discussed throughout this essay, is evidence that primates have evolved in environments with predation threats and have incorporated these responses into their group structures to deal with predators and other potential threats.

\section{Vigilance}

Vigilance is defined as the visual scanning of the surrounding environment by animals, and is often assumed to be a behaviour aimed at predators. However, its employment can also be associated with the social structure of a species and their environmental conditions (Treves 2000; Beauchamp 2003). In many animal studies, it has been exemplified that increases in group size lead to decreases in individual vigilance (Treves 2000). This is known as 'the group size effect' and, according to Roberts (1996), there are two main hypotheses and associated benefits to explain the theory.

The first hypothesis is termed the 'many eyes' hypothesis, which states that individuals in larger groups should enjoy the same rate of predator detection, despite being less vigilant, because they can rely on the vigilance of others, allowing them to reduce their own alertness in order to maximise feeding time (Roberts 1996). For this hypothesis to work, collective detection must lower the individual risk of predation because if nonvigilant animals gain nothing from associating with vigilant ones, then individual vigilance should not be reduced in larger groups (Roberts 1996; Treves 2000). This is supported by Roberts' (1996:1077) suggestion that 'if vigilance depends on predation risk and if that risk declines with increasing group size, vigilance should also decline with increasing group size'.

The second hypothesis, often referred to as the 'dilution effect', suggests that an individual's risk of predation becomes diluted by living in larger groups with more potential predation targets than just themselves. Thus, under this 
hypothesis, it is expected that with increasing group size comes a decreased individual risk of being targeted by predators (regardless of vigilance rates); thus individual vigilance should decrease (Beauchamp 2003). This theory is based upon the assumption that animals in larger groups would exert the same effort into individual vigilance as animals in smaller groups if the probability of being attacked by a predator were the same (Treves 2000). For this hypothesis to work, increasing group vigilance must improve the detection of predators; otherwise individual vigilance would not vary according to risk (Treves 2000).

While the two aforementioned hypotheses present benefits to increased group vigilance against predation with increasing group sizes, there are two other things that need to be considered-both of which stem from the aggregation required for group vigilance to work. One such cost is the increased scramble competition associated with living in large groups that results from animals having to increase foraging speed and risky behaviours to maintain food intake (Beauchamp 2003). Models of scramble competition assume that resources are limited and that foragers will jostle each other and try to increase feeding rates to gain access to a greater portion of the food supply (Lima et al. 1999). Thus, when faced with increased competition, an animal will have to forage faster and as such may make riskier decisions, such as decreasing individual vigilance or searching for food further away from the protection of the group (Beauchamp 2003). This implies that reduced foraging efficiency is a key trade-off for increased vigilance.

However, many agree that primates do not conform to the trends set out by these theories. This may be due to the fact that individual vigilance in larger groups of primates may reflect both predation pressure and the needs of their complex social systems (Treves 1999). Primates will thus often remain observant even with increasing group size to increase social monitoring, whereby primates monitor the actions of their neighbours within the group (Treves 1999; Hirsch 2002), which may be needed as intragroup competition is often associated with larger groups. This may occur irrespective of predation pressure.

The idea that primates maintain individual vigilance with increasing group size due to a combination of both social monitoring and antipredation has been supported in brown capuchin monkeys (Cebus apella), where a positive correlation between the number of individuals in a group and vigilance levels has been found (Hirsch 2002). Hirsch (2002) established that within the group he studied, social monitoring was the primary driver for vigilance as 
neighbour density and predation pressure were lower in this region. He found that the time spent vigilant correlated with time spent social monitoring, in that it was more infrequent than the time spent monitoring for predators outside the groups (Hirsch 2002). However, it was also reported that in other populations of brown capuchin monkeys, predator detection is the primary driver of vigilance as predation pressure and the time spent vigilant in these areas is higher (Hirsch 2002). Whether used for social monitoring or predator detection, brown capuchins show that a positive correlation exists between group size and vigilance. Furthermore, long-tailed macaques (Macaca fascicularis) in larger groups are better at detecting potential human predators, and as a result spend more time in the lower canopies than smaller groups where access by terrestrial predators is more prevalent (Isbell 1994). This suggests that primates in larger groups, by either maintaining or increasing their individual vigilance, are better able to detect predators.

Treves (1999) studied the effect that group size has on social monitoring in red colobus monkeys and red-tailed monkeys (Cercopithecus ascanius) in Uganda. The maintenance of vigilance levels here was due to the need to both detect predators and to monitor associates. During mating periods, he found that males glance at associates more often, while females survey associates more often at times when infants are young or out of contact (Treves 1999). His study showed no evidence for an increase of within-group surveillance associated with an increase in group size, but that these primates tended to remain vigilant. This vigilance pattern likely reflected reproductive strategies within the group associated with social monitoring, as well as serving as a predator response (Treves 1999). Vigilance here was thus associated with both antipredation and social monitoring for infant protection and mate selection.

Another study done on white-faced capuchins (Cebus capucinus) found that the time spent vigilant within the group was not expressively correlated with group size, but was actually more closely associated with the number of males in each group (Rose and Fedigan 1995). In the groups studied, alpha males were the most vigilant, and applied this vigilance when the group was accessing resources and around waterholes, in areas of overlapping range and when female protection was necessary (Rose and Fedigan 1995). Male vigilance appeared to be directed at males from outside groups, rather than towards group associates and potential predators (Rose and Fedigan 1995). This, combined with the previous studies, suggests that the application of vigilance is highly dependent on the group structuring and environment of the species. Like Treves (1999), 
Hirsch (2002) and Isbell (1994), Rose and Fedigan (1995) found that group size had no effect on the vigilance of an individual primate; a primate will remain vigilant despite the size of the group (Rose and Fedigan 1995).

However, there is a negative correlation seen between group size and individual vigilance in a study done by Ducheminsky et al. (2014), who suggested that the large group size of vervet monkeys (Chlorocebus pygerythrus) led to less predator-appropriate evasion and vigilance than expected. It is thought that the differences seen between primate species in their utilisation of vigilance occurs due to the separate social grouping needs and environmental conditions of the primates being studied. These reports also show that primates are distinct from other animals in their use of vigilance, as individual alertness does not usually decrease with increasing group size, as suggested by other animal vigilance studies (Roberts 1996; Beauchamp 2003). Importantly, these studies of vigilance in primates show that they have evolved the trait to deal with both predation and potential threats within the group. The behaviour thus is associated with both primate sociality and predator avoidance, suggesting selective pressures acting from both social and predatory forces.

\section{Alarm calling}

Alarm calling as an antipredator behaviour has evolved to alert group members to the presence of possible predators. Here, I define alarm calling as any vocalisation used to alert a group to the presence of a predator, which may then lead to other antipredator behaviours and precautions, such as concealment or flight. The use of alarm calling by individuals can have numerous positive and negative effects on both the individual and the group. Alarm calling may benefit the signaller directly by initiating a protective response within the wider group, which may include concealment, flight or defence (Zuberbuhler et al. 1999). In addition, there may be an indirect benefit to the signaller by enhancing the survival chances of close kin and by facilitating social transmission to inexperienced offspring of predator knowledge (Zuberbuhler et al. 1999). This is likely why Wheeler (2008) and Zuberbuhler et al. (1999), state that kin selection and parental care are likely causes for the evolution of alarm calling. By signalling the presence of a predator, individuals can protect potential mates and they can increase their direct fitness by protecting others, and, thus, reap the benefits of reciprocal altruism (Wheeler 2008). The caller may also benefit by causing group members to coalesce around the caller, creating a potentially dangerous mob for the predator (Wheeler 2008). Therefore, there are many potential benefits for an individual to use alarm calls. 
However, there is also one main negative consequence of alarm calling. By alerting a group to the presence of a predator, that individual may identify themselves as a potential target by making themselves known to the predator (Hollen and Radford 2009). This creates a paradox in which behaving in an altruistic way when a predator is nearby results in very costly behaviour being exhibited (Zuberbuhler et al. 1999). Due to the potentially high costs of alarm calling for the signaller, the potential benefits must have outweighed the costs in many situations, otherwise we would not expect it to have evolved as a common antipredatory behaviour. The evolution of alarm calls in primates clearly shows that they have adapted to deal with conditions in which predators are threats. Studies done on numerous species of primates, including vervet monkeys, bonnet macaques (Macaca radiata) and Diana monkeys (Cercopithecus diana diana), have shown that although they are quite adept at dealing with the threats posed before them, there are slight similarities and differences in the way primates employ alarm calls.

Vervet monkeys are amongst the most extensively studied primates with regards to their alarm calling system. Seyfarth et al. (1980) observed that adult vervet monkeys have the knowledge to not only identify predator types, but also to distinguish between predator species within classes (for example, between martial eagles (Polemaetus bellicosus) and other birds). By using specific alarm calls, vervet monkeys respond according to the threat and hunting style they believe they were faced with (Seyfarth et al. 1980). Similarly, Ramakrishnan et al. (2005) found bonnet macaques can distinguish between venomous, nonvenomous and predatory snakes. The macaques responded with caution to all snake species, but pythons (Python molurus), the only snakes known to consume bonnet macaques, were the only species that elicited alarm calls (Ramakrishnan et al. 2005). This shows that bonnet macaques have the ability to distinguish between snake species, as their main predator prompted the most active response.

Likewise, male Diana monkeys are also capable of distinguishing between predators. However, their use of alarm calls is slightly different in that males only call in response to leopards (Panthera pardus) and crowned hawk eagles (Stephanoaetus coronatus), but not in response to chimpanzees and humans who will pursue the caller in the canopy. This indicates the monkeys are not only able to differentiate the species of predator, but also their hunting behaviour (Zuberbuhler et al. 1997). Furthermore, Zuberbuhler et al. (1997) also find that once the Diana monkeys made an alarm call, the males would 
approach the predator as a group. It was concluded that their calls are used to signal to the predators that rely on stealth that they had been detected. This 'perception advertisement hypothesis' is supported by observations that the pursuit of crowned hawk eagles by male Diana monkeys results in the predator's departure, and that leopards tend to abandon their hunt once they had been detected by the group (Zuberbuhler et al. 1997).

This recognition of hunting style makes Diana monkeys different from vervet monkeys and bonnet macaques, which seem to mainly identify predator type. These experiments show that many primates are adept at using alarm calls as a form of antipredator behaviour. The presence of this behaviour in these species shows that primates have adapted uniquely to deal with the specific predators they face in their environments.

\section{Conclusion}

Predation has been an important selective force for the behaviours of primates, which has been exemplified through the evolution of vigilance and alarm calling in these animals. While vigilance does not follow the same trend in primates that it does in other foraging mammals, due to their need to monitor associates, the fact that it is also associated with predators suggests it likely evolved in the company of predators. Further, primates all employ vigilance to varying degrees but, in general, they rely on each other for the detection of predators. They also monitor their associates should threats arise within the group. Alarm calling is further evidence that primates evolved in the presence of predators, and is also employed differently from species to species. It was shown that vervet monkeys and bonnet macaques have the ability to define species within classes of predators (Seyfarth et al. 1980; Ramakrishnan et al. 2005), while Diana monkeys also respond differently based on predator hunting style (Zuberbuhler et al. 1997). This is evidence that each species has evolved specific mechanisms that are likely suited to the specific needs of their own environments. Antipredator behaviours come with ecological trade-offs. For example, does one initiate an alarm call and draw attention to themselves and save possible mates and kin; or does one remain vigilant, but lose access to resources? Whether primates are conscious of the decisions they make is up for debate; however, the presence of antipredator behaviours in primates shows that they have evolved in complex social groupings and in environments alongside predators making these ecological trade-offs necessary for their survival. 


\section{Acknowledgements}

I would like to thank Alison Behie and Rebecca Hendershott, who were my course convenor and tutor for the 'Primate Ecology and Behaviour' course. Your enthusiasm for and love of primates helped to fuel my own interest in this area and in wider topics of conservation.

\section{References}

Beauchamp G. 2003. Group-size effects of vigilance: A search for mechanisms. Behav Process. 63(3):141-145. doi.org/10.1016/S0376-6357(03)00011-1

Ducheminsky N, Henzi SP, Barrett L. 2014. Responses of vervet monkeys in large troops to terrestrial and aerial predator alarm calls. Behav Ecol. 25(6):1474-1484. doi.org/10.1093/beheco/aru151

Hirsch BT. 2002. Social monitoring and vigilance behaviour in brown capuchin monkeys (Cebus apella). Behav Ecol Sociobiol. 52(6):458-464. doi.org/10.1007/s00265-002-0536-5

Hollen LI, Radford AN. 2009. The development of alarm call behaviour in mammals and birds. Anim Behav. 78(4)791-800. doi.org/10.1016/j. anbehav.2009.07.021

Isbell LA. 1994. Predation on primates: Ecological patterns and evolutionary consequences. Evol Anthropol. 3(2):61-71. doi.org/10.1002/evan. 1360030207

Lima SL, Zollner PA, Bednekoff PA. 1999. Predation, scramble competition, and the vigilance group size effect in dark-eyed juncos (Junco hyemalis). Behav Ecol Sociobiol. 46(2):110-116. doi.org/10.1007/s002650050599

Peetz A, Norconk MA, Kinzey WG. 1992. Predation by jaguar on howler monkeys (Alouatta seniculus) in Venezuela. Am J Primatol. 28(3):223228. doi.org/10.1002/ajp.1350280307

Ramakrishnan U, Coss RG, Schank J, Dharawat A, Kim S. 2005. Snake species discrimination by wild bonnet macaques (Macaca radiata). Ethology. 111(4):337-356. doi.org/10.1111/j.1439-0310.2004.01063.x

Roberts G. 1996. Why individual vigilance declines as group size increases. Anim Behav. 51(5):1077-1086. doi.org/10.1006/anbe.1996.0109 
Rose LM, Fedigan LM. 1995. Vigilance in white-faced capuchins, Cebus capucinus, in Costa Rica. Anim Behav. 49(1):63-70. doi.org/ 10.1016/0003-3472(95)80154-5

Seyfarth RM, Cheney DL, Marler P. 1980. Monkey responses to three different alarm calls: Evidence of predator classification. Science. 210(4471):801-803. doi.org/10.1126/science.7433999

Sherman PT. 1991. Harpy eagle predation on a red howler monkey. Folia Primatol. 56(1):53-56. doi.org/10.1159/000156528

Treves A. 1999. Within-group vigilance in red colobus and redtail monkeys. Am J Primatol. 48(2):113-126. doi.org/10.1002/(SICI)1098-2345(1999) 48:2<113::AID-AJP3>3.0.CO;2-K

Treves A. 2000. Theory and method in studies of vigilance and aggregation. Anim Behav. 60(6):711-722. doi.org/10.1006/anbe.2000.1528

Wheeler BC. 2008. Selfish or altruistic? An analysis of alarm call function in wild capuchin monkeys, Cebus apella nigritus. Anim Behav. 76(5):14651475. doi.org/10.1016/j.anbehav.2008.06.023

Zuberbuhler K, Jenny D, Bshary R. 1999. The predator deterrence function of primate alarm calls. Ethology. 105(6):477-490. doi.org/10.1046/j.14390310.1999.00396.x

Zuberbuhler K, Noe R, Seyfarth RM. 1997. Diana monkey long-distance calls: Messages for conspecifics and predators. Anim Behav. 53(3):589604. doi.org/10.1006/anbe.1996.0334 


\title{
Primate social structure as a predictor of modes of communication and the ability to learn a human language
}

\section{Rebecca Jade Sullivan}

\begin{abstract}
For little over five decades, scientists have attempted to teach nonhuman hominids to communicate using human languages. The decision to utilise nonhuman hominids for this area of research is often attributed to their close genetic relatedness and similarly complex social structures to humans (Gardner and Gardner 1978). However, there has been minimal explanation in the literature as to why more complex social group structures allow for successful human language acquisition. Furthermore, there has been no investigation into whether other nonhominid primates, who may be more genetically dissimilar to humans but share similar social group complexity, could also be good candidates for human language acquisition. The following essay will argue that nonhuman hominids are likely successful at human language acquisition as a result of the social complexity hypothesis - a theory that states there is a positive association between social group and communication complexity (Freeberg et al. 2012). It will be proposed that the social complexity hypothesis may also be useful for identifying potential nonhominid candidates for future primate language acquisition research. However, future research should also analyse language acquisition in genera that do not appear to follow the social complexity hypothesis, to determine whether learning human languages requires only social complexity or communication complexity, and not both in combination.
\end{abstract}

\section{Keywords}

primate, social structure, social complexity hypothesis, language, great ape 


\section{Introduction}

The potential for nonhuman primates to learn human languages has both intrigued and baffled scientists for decades. Chimpanzees (Pan troglodytes) and gorillas (Gorilla gorilla) have often been the species of choice in studies of primate language acquisition, with researchers usually attributing this decision to both their close genetic relatedness to humans and the social complexity of the species (e.g. Gardner and Gardner 1969; Patterson 1978). However, there has been little explanation by researchers as to why social complexity in nonhuman hominids ${ }^{1}$ makes them suitable candidates for learning visual human languages, nor is there any indication in the literature as to why nonhominid primates ${ }^{2}$ with equal levels of social complexity are not chosen for these studies. According to the social complexity hypothesis, as social group styles increase in complexity, so too do the modes of communication (Freeberg et al. 2012). This mostly holds true in nonhuman hominids, with those species that have similarly complex social systems to humans also exhibiting highly complex methods of communication. For example, both chimpanzees and human hunter-gather societies form highly complex social groups, whereby a larger community will often temporarily split into smaller subgroups for various social benefits. As a result, complex forms of communication, such as gesturing and facial expressions, are required in order to communicate over long distances and re-establish relationships with other individuals when the groups reconvene (Dunbar 1993; Aureli et al. 2008). This relationship between social and communicative complexity offers a potential explanation for the exclusive use of hominid species in primate language acquisition research. However, nonhominid primate species with complex social groups may be equally receptive to learning human languages, and could be identified for future research opportunities based on the similarity of their social structures to that of humans. In turn, primate species that are socially dissimilar to humans could be identified as poor candidates for learning a human language through this method, as their modes of communication are predicted to be incompatible with human languages.

This essay aims to investigate the potential effectiveness of the social complexity hypothesis in predicting successful human language acquisition, by exploring the link between social complexity and communicative complexity in both

1 A primate family consisting of chimpanzees, bonobos, gorillas and orang-utans (i.e. great apes).

2 Any primate species that is not a great ape. 
human and nonhuman primates. Additionally, this essay aims to identify suitable and unsuitable candidate species for future language acquisition research in nonhuman primates.

\section{The differences between communication and language}

Before delving into the research question, an understanding of the relationship and differences between communication and language is needed. Primates use communication to relay a message, and this can occur in four forms. Olfactory communication relies on the use of chemical signals from scent gland excretions, saliva or mucus to relay information regarding female receptivity, territorial boundaries (Heymann 2006), dominance status (Roberts 2012) and mate attraction (Heymann 2006; Scordato and Drea 2007). Tactile communication is intimate, involving skin-to-skin contact such as allogrooming and embracing (Weber 1973) and is used to maintain social structure, strengthen bonds between individuals, relieve stress and social agitation and maintain mother-infant attachments (Hertenstein et al. 2006). Auditory communication can occur through vocalisations, as well as acoustic gestures such as tree buttress drumming (Arcadi et al. 1998), branch shaking (Zhao 1997), chest-beating or hand-clapping (Kalan and Rainey 2009), and is used to express social status (Remedios et al. 2009), defend territory, assist in agonistic confrontations and advertise alliances and group strength (Hagen and Hammerstein 2009). Finally, visual communication can involve the use of brachiomanual gestures such as arm-raising (Pollick and de Waal 2007) and beckoning (Hobaiter and Byrne 2011), facial expressions (Micheletta et al. 2015) and body language/posture (Smith and Delgado 2015) to convey messages about an individual's internal state such as emotions and desires (Pika et al. 2003; Parr et al. 2005).

Human language is a subcategory of communication, aligning with either auditory (i.e. speech) or visual (e.g. American Sign Language (ASL), or reading and writing) communication. While all primates are capable of communicating using sounds, human language is unique in that it is recursive, uses words and semantics and involves hierarchical syntax (Hauser et al. 2002; Berwick et al. 2013; Bolhuis et al. 2014). That is, there is an infinite combination of sentence structures and lengths in human language, producing limitless expressive power. 
While nonhuman primates naturally do not communicate using human-like language, a number of experiments have attempted to teach human languages to other hominid species. Early attempts to induce speech in chimpanzees and orang-utans (Pongo spp.) proved unsuccessful, due to morphological constraints of breathing control apparatus in the species only allowing for short, unmodulated utterances (Bryan 1963; Gardner and Gardner 1969; MacLarnon and Hewitt 1999). Subsequent research focused heavily on teaching nonhuman hominids to communicate using human visual languages, with greater success. Chimpanzees (e.g. Washoe and Nim Chimpsky), gorillas (e.g. Koko) and orang-utans (e.g. Chantek) have been taught over 100 signs in ASL (Gardner and Gardner 1969, 1978; Patterson 1978; Terrace et al. 1979; Miles 1990). Bonobos (Pan paniscus) such as Kanzi have also learned to read and communicate using hundreds of lexigrams - geometric symbols that function similarly to written language (Savage-Rumbaugh et al. 1985).

\section{The link between social structure and mode of communication}

The question remains: why are nonhuman hominid species successful at learning visual human languages like ASL and lexigrams? One of the most compelling and popular ideas, the social complexity hypothesis, suggests that complex social systems require complex modes of communication (Freeberg et al. 2012). With the exception of gorillas, all nonhuman hominids live in individual-based fission-fusion societies-one of the most complex social systems of any animal (van Schaik 1999; Ramos-Fernández 2005; Amrein et al. 2014; Bergman and Beehner 2015; Classen et al. 2016). These fissionfusion societies consist of large communities that often divide into smaller, temporary parties that provide various social benefits to in-group members, such as reducing in-group feeding competition and increasing the group's ability to defend territory (Lehmann et al. 2006). This social structure also requires animals to be able to mentally organise group members and their relationships, and to communicate over long distances in order to effectively coordinate group activities (van Schaik 1999; Aureli et al. 2008).

Modern hunter-gatherer humans often form similar fission-fusion groups, known as 'concentration-dispersal' social systems (Dunbar 1993; McComb and Semple 2005). This social system typically arises in environments where food and water availability are unpredictable. During periods of resource abundance, hunter-gatherer humans typically reside in small groups. 
However, during times of resource scarcity, these separate parties reassemble into a larger group, congregating at sites where resources are available for months at a time, such as a waterhole during the dry season (Dunbar 1993). Similar to fission-fusion societies, these highly flexible concentration-dispersal societies require hunter-gathers to be able to reassess relationships upon group reassembly, and maintain group cohesion over long distances (Dunbar 1993). As predicted by the social complexity hypothesis, human and nonhuman hominids also rely heavily on complex visual and auditory communication, including gestures, facial expressions and spoken language (Pika 2008). It thus stands to reason that other primate species with highly complex social systems should exhibit similar styles of complex communication to hominids, and thus may also be able to learn human languages.

A number of primate studies have supported the social complexity hypothesis, finding that group size is an effective predictor of both auditory and tactile modes of communication. A meta-analysis of 42 primate species by McComb and Semple (2005) found that as average group size and time spent allogrooming increases, so too does vocal repertoire size. Because of these relationships, a number of studies have suggested that vocal complexity may have facilitated the evolution of human language, serving as a way of maintaining social bonds and group cohesion between multiple individuals simultaneously when group size became too large for one-on-one allogrooming to serve this purpose (Dunbar 1993; Freeberg et al. 2012). Thus, while primates may not be able to physically speak a human language, this hypothesis still suggests that primates that live in large, complex societies could be good candidates for at least understanding spoken human languages.

Research has also found a positive correlation between visual communication and group complexity. A meta-analysis of 12 haplorrhine primate species by Dobson (2009) found that as group size increases, facial expressions become more complex and occur more frequently. While no research has been conducted on the relationship between gestural communication and social complexity in primates, it could also be predicted that more complex social structures should increase gestural complexity and use. Because ASL and lexigrams are visual and gestural modes of communication, primate species that rely more on these modes of communication as a result of more complex social structures should be ideal candidates for both understanding and communicating using human languages. 


\section{Other primate candidates for learning human languages}

Based on the similarities between social structure and associated modes of communication, there are a number of other primate species that could also be capable of learning human languages. Some of the most likely candidates are Old World monkeys from the Macaca genus, such as barbary macaques (M. sylvanus), pigtailed macaques ( $M$. nemestrina) and rhesus macaques (M. mulatta). All three species live in multimale-multifemale social groups of similar complexity and size to that of chimpanzees, bonobos and humans (McComb and Semple 2005; Burrows et al. 2009; Grueter et al. 2013). Like hominids, facial expression in macaques is highly complex and an integral part of communication (Burrows 2008). Additionally, all three species often use visual gestural communication, which is correlated with socially complex behaviours such as dominance hierarchies and social bonding (Maestripieri 2007).

However, other primate species who do not appear to fit the parameters of the hypothesis are also potential candidates for human language studies, bringing into question the effectiveness of the social complexity hypothesis in predicting language acquisition in nonhuman primates. Spider monkeys (Ateles spp.), for example, live in complex fission-fusion societies, and while there is some evidence of facial expression and gesturing, overall their visual communication is not as complex as that of hominids and macaques (RamosFernández 2005; Schaffner and Aureli 2005). Gibbons (Hylobates spp.), on the other hand, are socially monogamous - an arguably simpler social system than that of hominid and groups of Macaca, according to the social complexity hypothesis (Freeberg et al. 2012). Yet, they display highly complex gestural and facial expression in communication (Liebal et al. 2004; Scheider et al. 2014). Gorillas live in semicomplex polygynous societies but have complex facial expression and gestural communication, and are still able to learn human language (Dobson 2009; Freeberg et al. 2012). This suggests that highly complex social structures may not be the most important contributing factor towards language acquisition. Therefore, it is particularly important to study spider monkeys, gibbons and gorillas to determine whether social complexity and complex communication are both required to learn a human language, or whether close genetic relatedness to humans is the main determinant of a species' ability to learn a human language. 
Using the social complexity hypothesis, it could be predicted that species that are highly socially dissimilar to hominids are unlikely to be able to learn a human language. For instance, nocturnal and solitary strepsirrhines such as the grey mouse lemur (Microcebus murinus; Eberle and Kappeler 2008), the aye-aye (Daubentonia madagascariensis; Sterling and McCreless 2007), and all lorisiformes (Kawamura and Kubotera 2004) rely heavily on olfaction to communicate with other individuals (del Barco-Trillo et al. 2011). In general, strepsirrhines also have far less complex visual communication systems than other primates due to poor visibility at night, limited interaction with other individuals and a fused upper lip disallowing facial expression (Kappeler 2012; Kemp and Kaplan 2013). Within the haplorrhine suborder, nocturnal tarsiformes are more gregarious than most nocturnal strepsirrhines; hence, visual and auditory communication such as facial expressions and vocalisations are somewhat more complex (MacKinnon and MacKinnon 1980). However, these are not as complex as the visual and auditory forms of communication found in hominids or macaques. As humans rely mostly on verbalisation, gestures and facial expressions to communicate, neither strepsirrhines nor tarsiformes would be suitable candidates for learning a human language.

\section{Conclusion}

Research has repeatedly affirmed the social complexity hypothesis, which states that complex social structure is correlated with more complex modes of communication, such as elaborate gestural systems, facial expressions and vocal repertoire. Based on this hypothesis, it can be predicted that nonhuman hominids are able to learn human languages because they share social systems that are similar in complexity and style to humans. However, other nonhominid species with equally complex social systems, such as some species of macaque, could also be excellent candidates for learning human languages. Future research should focus on language acquisition in nonhominid primates living in fission-fusion societies, to determine whether they share the same ability as hominids to learn human languages. In addition, research into species that do not appear to follow the social complexity hypothesis could provide insight into whether human language acquisition requires both social and communicative complexity, just one of these factors, or simply close genetic relatedness to humans. 


\section{Acknowledgements}

I would like to express my sincerest thanks to Dr Alison Behie and Rebecca Hendershott for their continued support, guidance and patience throughout the process of writing this essay. I would also like to thank my partner Chinmoy for his unwavering optimism, encouragement and proofreading efforts; and without whom this essay would not have been possible.

\section{References}

Amrein M, Heistermann M, Weingrill T. 2014. The effect of fission-fusion zoo housing on hormonal and behavioral indicators of stress in Bornean orangutans (Pongo pygmaeus). Int J Primatol. 35(2):509-528. doi.org/ 10.1007/s10764-014-9765-5

Arcadi AC, Robert D, Boesch C. 1998. Buttress drumming by wild chimpanzees: Temporal patterning, phrase integration into loud calls, and preliminary evidence for individual distinctiveness. Primates. 39(4):505-518. doi.org/10.1007/BF02557572

Aureli F, Schaffner CM, Boesch C, Bearder SK, Call J, Chapman CA, Connor R, Di Fiore A, Dunbar RI, Henzi SP. 2008. Fission-fusion dynamics: New research frameworks. Curr Anthropol. 49(4):627-654. doi.org/10.1086/586708

Bergman TJ, Beehner JC. 2015. Measuring social complexity. Anim Behav. 103:203-209. doi.org/10.1016/j.anbehav.2015.02.018

Berwick RC, Friederici AD, Chomsky N, Bolhuis JJ. 2013. Evolution, brain, and the nature of language. Trends Cogn Sci. 17(2):89-98. doi.org/ 10.1016/j.tics.2012.12.002

Bolhuis JJ, Tattersall I, Chomsky N, Berwick RC. 2014. How could language have evolved? PLoS Biol 12(8):e1001934. doi.org/10.1371/journal. pbio. 1001934

Bryan AL. 1963. The essential morphological basis for human culture. Curr Anthropol. 4(3):297-306. doi.org/10.1086/200377 
Burrows AM. 2008. The facial expression musculature in primates and its evolutionary significance. BioEssays. 30(3):212-225. doi.org/10.1002/ bies.20719

Burrows AM, Waller BM, Parr LA. 2009. Facial musculature in the rhesus macaque (Macaca mulatta): Evolutionary and functional contexts with comparisons to chimpanzees and humans. J Anat. 215(3):320-334. doi.org/10.1111/j.1469-7580.2009.01113.x

Classen D, Kiessling S, Mangalam M, Kaumanns W, Singh M. 2016. Fissionfusion species under restricted living conditions: A comparative study of dyadic interactions and physical proximity in captive bonobos and Bornean orangutans. Curr Sci. 110(5):839-850.

del Barco-Trillo J, Burkert B, Goodwin T, Drea C. 2011. Night and day: The comparative study of strepsirrhine primates reveals socioecological and phylogenetic patterns in olfactory signals. J Evol Biol. 24(1):82-98. doi.org/10.1111/j.1420-9101.2010.02145.x

Dobson SD. 2009. Socioecological correlates of facial mobility in nonhuman anthropoids. Am J Phys Anthropol. 139(3):413-420. doi.org/10.1002/ ajpa. 21007

Dunbar RI. 1993. Coevolution of neocortical size, group size and language in humans. Behav Brain Sci. 16(04):681-694. doi.org/10.1017/ S0140525X00032325

Eberle M, Kappeler PM. 2008. Mutualism, reciprocity, or kin selection? Cooperative rescue of a conspecific from a boa in a nocturnal solitary forager the gray mouse lemur. Am J Primatol. 70(4):410-414. doi.org/ 10.1002/ajp.20496

Freeberg TM, Dunbar RI, Ord TJ. 2012. Social complexity as a proximate and ultimate factor in communicative complexity. Philos Trans R Soc Lond B Biol Sci. 367(1597):1785-1801. doi.org/10.1098/rstb.2011.0213

Gardner RA, Gardner BT. 1969. Teaching sign language to a chimpanzee. Science 165(3894):664-672. doi.org/10.1126/science.165.3894.664

Gardner RA, Gardner BT. 1978. Comparative psychology and language acquisition. Ann N Y Acad Sci. 309(1):37-76. doi.org/10.1111/j.17496632.1978.tb29441.x 
Grueter CC, Bissonnette A, Isler K, van Schaik CP. 2013. Grooming and group cohesion in primates: Implications for the evolution of language. Evol Hum Behav. 34(1):61-68. doi.org/10.1016/j.evolhumbehav.2012.09.004

Hagen EH, Hammerstein P. 2009. Did Neanderthals and other early humans sing? Seeking the biological roots of music in the territorial advertisements of primates, lions, hyenas, and wolves. Music Sci. 13(2):291-320. doi. org/10.1177/1029864909013002131

Hauser MD, Chomsky N, Fitch WT. 2002. The faculty of language: What is it, who has it, and how did it evolve? Science. 298(5598):1569-1579. doi.org/10.1126/science.298.5598.1569

Hertenstein MJ, Verkamp JM, Kerestes AM, Holmes RM. 2006. The communicative functions of touch in humans, nonhuman primates, and rats: A review and synthesis of the empirical research. Genet Soc Gen Psychol Monogr. 132(1):5-94. doi.org/10.3200/MONO.132.1.5-94

Heymann EW. 2006. Scent marking strategies of New World primates. Am J Primatol. 68(6):650-661. doi.org/10.1002/ajp.20258

Hobaiter C, Byrne RW. 2011. The gestural repertoire of the wild chimpanzee. Anim Cogn. 14(5):745-767. doi.org/10.1007/s10071-011-0409-2

Kalan AK, Rainey HJ. 2009. Hand-clapping as a communicative gesture by wild female swamp gorillas. Primates. 50(3):273-275. doi.org/10.1007/ s10329-009-0130-9

Kappeler PM. 2012. Behavioral ecology of strepsirrhines and tarsiers. In: JC Mitani, J Call, PM Kappeler, RA Palombit, JB Silk, editors. The evolution of primate societies. Chicago (IL): University of Chicago Press. pp. 17-42.

Kawamura S, Kubotera N. 2004. Ancestral loss of short wave-sensitive cone visual pigment in lorisiform prosimians, contrasting with its strict conservation in other prosimians. J Mol Evol. 58(3):314-321. doi.org/ $10.1007 / \mathrm{s} 00239-003-2553-\mathrm{z}$

Kemp C, Kaplan G. 2013. Facial expressions in common marmosets (Callithrix jacchus) and their use by conspecifics. Anim Cogn. 16(5):773788. doi.org/10.1007/s10071-013-0611-5 
Lehmann J, Korstjens AH, Dunbar R. 2006. Fission-fusion social systems as a strategy for coping with ecological constraints: A primate case. Evol Ecol. 21(5):613-634. doi.org/10.1007/s10682-006-9141-9

Liebal K, Pika S, Tomasello M. 2004. Social communication in siamangs (Symphalangus syndactylus): Use of gestures and facial expressions. Primates. 45(1):41-57. doi.org/10.1007/s10329-003-0063-7

MacKinnon J, MacKinnon K. 1980. The behavior of wild spectral tarsiers. Int J Primatol. 1(4):361-379. doi.org/10.1007/BF02692280

MacLarnon AM, Hewitt GP. 1999. The evolution of human speech: The role of enhanced breathing control. Am J Phys Anthropol. 109(3): 341-363. doi.org/10.1002/(SICI)1096-8644(199907)109:3<341::AIDAJPA5 $>3.0 . C O ; 2-2$

Maestripieri D. 2007. Gestural communication in three species of macaques (Macaca mulatta, M. nemestrina, $M$. arctoides): Use of signals in relation to dominance and social context. In: K Liebal, C Muller, S Pika, editors. Gestural communication in nonhuman and human primates. Amsterdam (Netherlands): John Benjamins Publishing Company. pp. 51-66. doi.org/ 10.1075/bct.10.06mae

McComb K, Semple S. 2005. Coevolution of vocal communication and sociality in primates. Biol Lett. 1(4):381-385. doi.org/10.1098/ rsbl.2005.0366

Micheletta J, Whitehouse J, Parr LA, Waller BM. 2015. Facial expression recognition in crested macaques (Macaca nigra). Anim Cogn. 18(4):985990. doi.org/10.1007/s10071-015-0867-z

Miles H. 1990. The cognitive foundations for reference in a signing orangutan. In: ST Parker, KR Gibson, editors. 'Language' and intelligence in monkeys and apes: Comparative developmental perspectives. New York (NY): Cambridge University Press. pp. 511-539. doi.org/10.1017/ CBO9780511665486.021

Parr LA, Waller BM, Fugate J. 2005. Emotional communication in primates: Implications for neurobiology. Curr Opin Neurobiol. 15(6):716-720. doi.org/10.1016/j.conb.2005.10.017 
Patterson FG. 1978. The gestures of a gorilla: Language acquisition in another pongid. Brain Lang. 5(1):72-97. doi.org/10.1016/0093-934X (78)90008-1

Pika S. 2008. Gestures of apes and pre-linguistic human children: Similar or different? First Lang. 28(2):116-140. doi.org/ $10.1177 / 0142723707080966$

Pika S, Liebal K, Tomasello M. 2003. Gestural communication in young gorillas (Gorilla gorilla): Gestural repertoire, learning, and use. Am J Primatol. 60(3):95-111. doi.org/10.1002/ajp.10097

Pollick AS, de Waal FB. 2007. Ape gestures and language evolution. Proc Natl Acad Sci. 104(19):8184-8189. doi.org/10.1073/pnas.0702624104

Ramos-Fernández G. 2005. Vocal communication in a fission-fusion society: Do spider monkeys stay in touch with close associates? Int J Primatol. 26(5):1077-1092. doi.org/10.1007/s10764-005-6459-z

Remedios R, Logothetis NK, Kayser C. 2009. Monkey drumming reveals common networks for perceiving vocal and nonvocal communication sounds. Proc Natl Acad Sci. 106(42):18010-18015. doi.org/10.1073/ pnas.0909756106

Roberts SC. 2012. On the relationship between scent-marking and territoriality in callitrichid primates. Int J Primatol. 33(4):749-761. doi.org/10.1007/s10764-012-9604-5

Savage-Rumbaugh S, Rumbaugh DM, McDonald K. 1985. Language learning in two species of apes. Neurosci Biobehav Rev. 9(4):653-665. doi.org/10.1016/0149-7634(85)90012-0

Schaffner CM, Aureli F. 2005. Embraces and grooming in captive spider monkeys. Int J Primatol. 26(5):1093-1106. doi.org/10.1007/s10764005-6460-6

Scheider L, Liebal K, Oña L, Burrows A, Waller B. 2014. A comparison of facial expression properties in five hylobatid species. Am J Primatol. 76(7):618-628. doi.org/10.1002/ajp.22255

Scordato ES, Drea CM. 2007. Scents and sensibility: Information content of olfactory signals in the ringtailed lemur, Lemur catta. Anim Behav. 73(2):301-314. doi.org/10.1016/j.anbehav.2006.08.006 
Smith LW, Delgado RA. 2015. Body language: The interplay between positional behavior and gestural signaling in the genus Pan and its implications for language evolution. Am J Phys Anthropol. 157(4):592602. doi.org/10.1002/ajpa.22751

Sterling EJ, McCreless EE. 2007. Adaptations in the aye-aye: A review. In: L Gould, ML Sauther, editors. Lemurs: Ecology and Adaptation. New York (NY): Springer Publishing. pp. 159-184. doi.org/10.1007/978-0387-34586-4_8

Terrace HS, Petitto LA, Sanders RJ, Bever TG. 1979. Can an ape create a sentence. Science. 206(4421):891-902. doi.org/10.1126/science.504995

van Schaik CP. 1999. The socioecology of fission-fusion sociality in orangutans. Primates. 40(1):69-86. doi.org/10.1007/BF02557703

Weber I. 1973. Tactile communication among free-ranging langurs. Am J Phys Anthropol. 38(2):481-486. doi.org/10.1002/ajpa.1330380251

Zhao QK. 1997. Intergroup interactions in Tibetan macaques at Mt. Emei, China. Am J Phys Anthropol. 104(4):459-470. doi.org/10.1002/ (SICI) 1096-8644(199712)104:4<459::AID-AJPA3>3.0.CO;2-N 



\title{
Skeletal evidence of torture: How can the past inform the present?
}

\author{
Victoria Tasker
}

\begin{abstract}
This essay addresses skeletal evidence of torture-an area where the current literature is minimal, and as such this essay will provide an overview that can be used as a background review in the future. Three methods of torture are presented-amputation, hobbling and beatings - and their corresponding skeletal indicators. The skeleton is a useful yet somewhat limited resource for biological and forensic anthropologists. However, it is irrefutable that the past can inform the present as shown through a discussion on the role of bioarchaeology in the development of forensic anthropology practices regarding torture.
\end{abstract}

\section{Keywords}

torture, skeletal evidence, bioarchaeology, trauma

\section{Introduction}

Torture is defined by United Nations General Assembly Resolution 39/46 in Article 27(1) of 'The Convention against Torture and Other Cruel, Inhuman or Degrading Treatment or Punishment' as:

any act by which severe pain or suffering, whether physical or mental, is intentionally inflicted on a person for such purposes as obtaining from him or a third person information or a confession ... when such pain or suffering is inflicted by or at the instigation of or with the consent or acquiescence of a public official or other person acting in an official capacity. 
Methods of inflicting torture have existed for thousands of years-physical remains of which have been seen in the archaeological record-and continue to the present day where they present in forensic anthropology contexts. The methods for employing such torture to the human body may have changed as temporal, spatial and political climates have changed. However, the contribution bioarchaeological studies of torture can provide to forensic anthropology analyses and interpretations of torture from skeletal remains in human right abuse contexts should not be underestimated. Subsequently, this essay will investigate how torture can be inferred from specific skeletal indicators in both bioarchaeological and forensic contexts. Using several ancient cases of human skeletal remains, where torture has been identified, three main skeletal indicators of torture and their forensic application within a human rights context will be examined: amputations, hobbling and beatings. This essay will also address the purpose of torture, the differences between identifying torture from the skeleton and soft tissues, and the contribution of bioarchaeology to forensic anthropology.

\section{Overview of torture methods}

Methods of torture can be categorised into two groups: physical torture and psychological torture. As this essay is exploring skeletal evidence of torture, physical torture will be the main focus. There are several forms of physical torture to consider, including but not limited to: amputation; beatings and other localised blows to the body via torturer's hands, fists or feet using hard objects; phalanga-beating of the soles of the feet or palms of the hands; suspension-hanging the victim by a certain body part such as arms or legs; electric torture-electric shocks to the victim; nail torture-the forcible removal of toe and finger nails, forcing objects under the nails or burning of nails; dental torture - extraction or destruction of healthy teeth; pharmacologicaladministration of unnecessary drugs such as anaesthetics or hallucinogenic drugs; asphyxiation procedures_-anything that obstructs normal breathing (for more exhaustive examples and definitions see Henneberg 1999; Cox and Mays 2000; Rodríguez-Martín 2006; Table 1 for a summary). As can be seen in Table 1, these methods can cause both skeletal and soft tissue damage, but can also leave no detectable trace. 
Table 1: Skeletal evidence of torture

\begin{tabular}{|l|l|l|}
\hline Method of torture & Skeletal evidence & $\begin{array}{l}\text { Evidence in } \\
\text { archaeological record }\end{array}$ \\
\hline beatings & yes & unlikely \\
\hline phalanga & yes & unlikely \\
\hline suspension & yes & unlikely \\
\hline electricity & undetermined secondary & unlikely \\
\hline burns & possible & unlikely \\
\hline asphyxiation procedures & rare & yes \\
\hline nail torture & yes & yes \\
\hline dental torture & primary and secondary & primary and secondary \\
\hline pressure & very likely & unlikely \\
\hline strapping & unlikely & yes \\
\hline forced positions & possible & unlikely \\
\hline hand and feet torture & yes & yes \\
\hline sexual torture & more likely in females & yes \\
\hline bullets and other objects & yes & yes \\
\hline pharmacological & possible & yes \\
\hline
\end{tabular}

Source: Adapted, with permission, from Henneberg (1999:74).

The choice of method of torture is often determined by the desired outcome and often by whether the torture method will leave detectable marks on the victim. An example of this can be seen in a case study of 10 child victims of torture at a refugee camp in Kashmiris (Indian subcontinent), as presented by Petersen and Wandall (1995). The purpose of torture was to pacify the civilian population and to acquire information that would not be released otherwise (Petersen and Wandall 1995). In order to obtain such information, the victim would need to be alive. Hence, the torture inflicted was never aimed to kill. The children in this case revealed torture by the way of amputation of phalanges of the hand, bayonet cuts, beatings, burns by heated wire, dripping hot water, acid, cigarettes and a heated iron (Petersen and Wandall 1995). Amongst the stated methods of torture, amputations, hobbling and beatings are most likely to leave skeletal markers. 


\section{Skeletal evidence of torture}

Skeletal markings can reveal that the human skeleton, despite its protective layer of soft tissues, is vulnerable to its external environment. This includes, but is not limited to, trauma and, more specifically, torture. The importance and validity of these determinations of skeletal indicators of torture can only be realised when the limitations of skeletal remains are acknowledged. The ability of the skeleton to record trauma enables forensic anthropologists to use skeletal markings to identify torture and help bring justice to such abhorrent human rights violations (Hunter and Cox 2005). The skeleton, however, does have its limitations. In most circumstances, the soft tissue, being extremely sensitive to its external environment, is more likely to reveal the occurrence of torture. Soft tissue is clearly an unattainable source of information in skeletal remains. Furthermore, the torturer is more likely to choose torture methods and techniques that do not leave a mark on the victim, either on the skeleton or soft tissue. In cases of clandestine graves where decomposition of the body is extensive, parts of the skeleton are often the only remains left (Powell 2010). When this occurs, postmortem damage is more likely to impact the skeleton. Postmortem damage can include depositional loss or damage of bone, faunal scavenging or postmortem mutilation (Powell 2010). All these aspects of postmortem damage limit the accuracy of the forensic anthropologists' interpretations.

Another limitation is the overlap of skeletal markers between different causes. It is common for the same, or very similar, skeletal markers to result from different mechanisms (Ortner 2003). Several of the skeletal markers discussed above may also present in cases of interpersonal violence in warfare or severe accidents. The interpretation of trauma as either violence or torture has clear social connotations. Therefore, such interpretations, particularly those made in a forensic investigation, must be made with extreme caution. These limitations do not and should not impede a forensic investigation; accuracy of interpretation can only improve as methodologies, and the forensic anthropologists that use them, are rigorously tested and exposed to a range of skeletal markings. 


\section{Bioarchaeological evidence for torture}

Amputation has been one of the most prevalent methods of torture evident in skeletal material (Cox and Mays 2000). Amputation of the phalanges of the hands and feet is most common as it inflicts pain and disability on the victim but will not kill them (Knüsel and Smith 2014). With the amputation of phalanges, the torturer is able to inflict such torture up to 20 times (10 hand phalanges and 10 feet phalanges). Amputations can be revealed in the skeleton not only by the absence of phalanx, but primarily by evidence of sharp force trauma (cut marks) to the surrounding bones and, in some circumstances, evidence of bone remodelling. When a fracture (including amputation) occurs on a bone, the bone slowly remodels, generally with help of medical care (Ortner 2003). However, in some cases, if medical care is not received to treat the traumatised bone, as is assumed in the cases of torture victims, the remodelling could occur in an undesired way. These skeletal markings of an amputation would become more pronounced if the amputation had resulted in an infection that caused complications when the bone started healing (Henneberg 1999). Complications that may present on the bone include avascular necrosis, indicated by the death of bone and consequential crumbling and collapsing, and shortening of the bone (Henneberg 1999). The presence of the discussed skeletal markings is generally more reliable as an indication of amputation rather than solely the absence of a phalanx. Small bones, such as phalanges, are easily subjected to taphonomic and diagenetic processes, and the loss of phalange and other small bones is not uncommon in postmortem deposition and/or recovery (Mann et al. 1990). This means that excavation of a grave must be meticulously carried out. As a disabling and painful method of torture, amputation is effective but, thankfully, does leave forensic anthropologists with osteological insights; as does the equally as disabling and painful method of hobbling.

Hobbling is the crushing and beating of the feet (most commonly the soles) so the individual's mobility is restricted to hobbling, and this renders them disabled. This method is often employed to cause a specific social response (Osterholtz 2012). This type of torture is often employed as a display of violence in order to gain social control over the witnessing population (Fellner and Mariner 1997). Osterholtz (2012) examines the social use of hobbling as well as its skeletal manifestations in human skeletal remains recovered from the prehistoric southwest of America. Tarsals, phalanges and metatarsals were identified from 190 fragments, and were analysed and eventually interpreted 
as subjects of hobbling. One foot was distinguished from these 190 fragments following several identification and conjoining processes. The foot appeared to have suffered damage to three main aspects: the medial and lateral aspects of the calcaneus and talus, the plantar surface and the dorsal surface (see Figure 4 in Osterholtz 2012:152). This damage consisted of perimortem crushing (indicated by fractures), which have led to complications in the healing process, scrape marks, cut marks and chop marks. The plantar aspect of the foot shows crushing and peeling (where the periosteum has broken away from the shafts of the metatarsals), which reflects beating of the soles of the feet. The dorsal aspect shows crushing via two blows to the foot. Chop marks (as indicated by arrows in Figure 4 in Osterholtz 2012:152) indicate attempted disarticulation of the foot and eventual complete disarticulation of the foot. It is clear that this method of torture will leave evidence of skeletal trauma in the form of fractures caused by beatings and, in select extreme cases, skeletal evidence of amputation.

Beatings often result in fracturing to the skeleton in the context of torture. Although the most obvious signs of a beating are to the body's soft tissues, Henneberg (1999) suggests that, as a result of trauma from beatings, secondary abnormalities, such as osteitis (inflammation of bone) and periostitis (inflammation of the periosteum), can form after the bone has healed. Fractures on the bone indicate a traumatic event; however, distinguishing that event as being torture is dependent on the nature of healing on the bone and the location of the fractures.

Petersen and Wandall (1995) presented a case study of 10 children who showed signs of torture. Within their findings one child presented with a neglected fracture of the left foot. The neglected nature of the fracture (arch of the foot accentuated and unstable, and the foot was 2 centimetres shorter than the left), in addition to the soft tissue trauma elsewhere on the body and the social context, led to a conclusion of torture.

Meyer et al. (2015) presented the human skeletal remains of a mass grave from the Early Neolithic in Central Europe (Germany) that revealed mass violence and possible torture. Perimortem trauma to the extremities was extensive amongst the 26 individuals (Meyer et al. 2015). Perimortem injuries to the cranial and upper extremities were prevalent, but the perimortem injuries to the lower extremities were overwhelmingly dominant. Perimortem injuries on the upper extremities presented on 19 per cent of the identified fragments compared to $31-42$ per cent of the fibulae and 53-63 per cent of the tibiae 
(see Figure 2 in Meyer et al. 2015:4). This, combined with the obvious focus on the lower extremities, and repeated blows to the lower legs, rendering the victims disabled and immobilised, suggests that the intent was not to kill. Several individuals also presented with healed rib and long-bone fractures, which may suggest that beatings had occurred previously, but they could be an archaeological case of interpersonal violence and not torture. This case revealed that the quantity and nature of the skeletal trauma, as well as its location on the skeleton, can suggest torture as the cause of trauma.

\section{Informing forensic anthropology practice}

The insights that bioarchaeologists can gain from skeletal remains of ancient lifeways are an immense contribution to our knowledge of the past. The historical importance of these insights should not be underestimated. Although the context in which the skeletal analysis is different, the same osteological approach is applicable for forensic anthropology. As is apparent from this essay, there are specific patterns of trauma to the skeleton and specific morphologies of trauma that have been identified to be indicative of evidence of torture in ancient cases. Martin and Harrod (2015) explore how bioarchaeology has contributed to the evolution and practice of forensic anthropology. Biological anthropologists have been able to contribute their arsenal of human skeletal analyses and indicators to the field of forensic anthropology because of the wide and long history of violence by societies. Furthermore, the contribution of archaeology to forensic anthropological methods, such as body excavation and recovery of evidence at burial sites, has shaped forensic anthropology to what is seen today (Dirkmaat et al. 2008). As many torture methods have persisted over many centuries, forensic anthropologists are able to use bioarchaeological studies to understand what skeletal indicators to look for in cases of torture. For example, Kimmerle and Baraybar (2008) discuss how blunt force trauma and the resulting fracturing is often an indication of torture consistent with beatings in modern-day forensic cases. With the large variability in what the modern human mind can conceive, there is no way of ruling out the use of similar methods of torture in today's society. Hence, the forensic anthropologist must be aware of key skeletal indicators of torture (Haglund and Sorg 2002).

Although bioarchaeology contributes to forensic anthropology considerably, it does not always complement it because there are torture methods that do not exhibit skeletal damage. Anaesthetics, hallucinogens, tranquillizers and 
addictive drugs are four examples of pharmacological abuse and torture (Henneberg 1999). If hair is present on a body, it can sometimes reveal traces of pharmaceuticals; however, the forensic anthropologist would be interested in the pharmaceuticals that leave traces in bone. McGrath and Jenkins (2009) test the possibility of bone and bone marrow revealing drugs that were taken (either by choice or force) by the individual when they were alive. They conclude that as drug concentrations in bone were generally higher than those found in corresponding blood specimens, the study reveals a viable way of revealing drugs in the postmortem stage (McGrath and Jenkins 2009). It is clear that the wide range of methods of torture provide a series of challenges for the forensic anthropologist.

As torture is fundamentally a denial of basic human rights, forensic anthropologists must be well learned in the skill of identifying it. The identification of torture found on skeletal remains can have different political ramifications for different political climates (Hunter and Cox 2005). Within these political climates are often differing procedures and protocols the forensic anthropologist must follow. The forensic anthropologist plays a fundamental role in identifying torture in skeletal remains, and hence is influential in its subsequent documentation and place in judicial and legal systems.

The act of torturing another human being has been embedded in the physical core of the human societies for many centuries. The skeletal markings of torture from archaeological contexts, as highlighted in this essay, do inform forensic anthropology practice to some extent. Bioarchaeological cases provide forensic anthropology the tools to understand the history of torture, the expected skeletal evidence, and the societal roll it fills. However, it does not assist in identifying pharmaceuticals and other modern methods of torture.

\section{Acknowledgements}

I would like to thank course tutors Felicity Gilbert and Alyce Cameron for their guidance and support in my forensic anthropology class. I would also like to thank my classmates in forensic anthropology and archaeology for their support and friendship. 


\section{References}

Cox M, Mays S. 2000. Human osteology in archaeology and forensic science. New York (NY): Cambridge University Press.

Dirkmaat D, Cabo L, Ousley S, Symes S. 2008. New perspectives in forensic anthropology. Am J Phys Anthropol. 137(S47):33-52. doi.org/10.1002/ ajpa. 20948

Fellner J, Mariner J. 1997. Cold storage: Super-maximum security confinement in Indiana. New York (NY): Human Rights Watch.

Haglund WD, Sorg MC. 2002. Advancing forensic taphonomy: Purpose, theory, and process. In: WD Haglund, MC Sorg, editors. Advances in forensic taphonomy: Method, theory, and archaeological perspectives. Boca Raton (FL): CRC Press. pp. 3-29.

Henneberg ML. 1999. Forensic evidence of torture: Investigations into human rights violations [Master's thesis]. University of Birmingham.

Hunter J, Cox M. 2005. Forensic archaeology: Advances in theory and practice. London (UK): Routledge.

Kimmerle E, Baraybar J. 2008. Skeletal trauma: Identification of injuries resulting from human rights abuse and armed conflict. 1st ed. Boca Raton (FL): CRC Press. doi.org/10.1201/9781420009118

Knüsel C, Smith M. 2014. The osteology of conflict: What does it all mean? In: C Knüsel, M Smith, editors. The Routledge handbook of the bioarchaeology of human conflict. London(UK): Routledge. pp. 656-694.

Mann RW, Bass WM, Meadows L. 1990. Time since death and decomposition of the human body: Variables and observations in case and experimental field studies. J Forensic Sci. 35(1):103-111. doi.org/10.1520/JFS12806J

Martin D, Harrod R. 2015. Bioarchaeological contributions to the study of violence. Am J Phys Anthropol. 156(S59):116-145. doi.org/10.1002/ ajpa. 22662

McGrath K, Jenkins A. 2009. Detection of drugs of forensic importance in postmortem bone. Am J Forensic Med Pathol. 30(1):40-44. doi.org/ 10.1097/PAF.0b013e31818738c9 
Meyer C, Lohr C, Gronenborn D, Alt K. 2015. The massacre mass grave of Schöneck-Kilianstädten reveals new insights into collective violence in Early Neolithic Central Europe. Proc Natl Acad Sci. 112(36):1121711222. doi.org/10.1073/pnas. 1504365112

Ortner D. 2003. Identification of pathological disorders in human skeletal remains. 2nd ed. London (UK): Academic Press.

Osterholtz A. 2012. The social role of hobbling and torture: Violence in the prehistoric Southwest. Int J Paleopathol. 2(2-3):148-155. doi.org/ 10.1016/j.ijpp.2012.09.011

Petersen H, Wandall J. 1995. Evidence of physical torture in a series of children. Forensic Sci Int. 75(1):45-55. doi.org/10.1016/0379-0738(95)01766-C

Powell K. 2010. Grave concerns: Locating and unearthing human bodies. Bowen Hills (QLD): Australian Academic Press.

Rodríguez-Martín C. 2006. Identification and differential diagnosis of traumatic lesions of the skeleton. In: A Schmitt, E Cunha, J Pinheiro, editors. Forensic anthropology and medicine: Complementary sciences from recovery to cause of death. Totowa (NJ): Humana Press pp. 197221. doi.org/10.1007/978-1-59745-099-7_8

United Nations, General Assembly. The United Nations convention against torture: A handbook on the convention against torture and other cruel, inhuman or degrading treatment or punishment, A/39/46 (26 June 1987). Available from www.ohchr.org/EN/ProfessionalInterest/Pages/CAT.aspx 


\title{
When the forest calls: My experience on the Primate Behavioural Ecology Field School in Cambodia ${ }^{1}$
}

\section{Cynthia Parayiwa}

\begin{abstract}
Biological anthropology is deeply rooted in developing a better understanding of the behaviour and biology of humans and nonhuman primates. Though the classroom remains an effective tool for sharing theories and discussing concepts, behavioural studies continue to be enriched by the opportunity to enter the field and make real world observations. This essay shares how the Primate Behavioural Ecology Field School in Cambodia provided the opportunity for undergraduate and postgraduate students to observe and report on nonhuman primates within their natural forest habitat. Based at the Veun Sai-Siem Pang Conservation Area in northeast Cambodia, the field school allowed students to not only collect and report on behavioural and ecological data, but simultaneously experience local environmental conservation efforts in practice.
\end{abstract}

\section{Keywords}

field, methodology, Cambodia, nonhuman primate

1 An undergraduate course offered by the School of Archaeology and Anthropology (BIAN3018/6018): programsandcourses.anu.edu.au/course/BIAN3018. 


\section{Introduction}

Over three weeks in early January 2014, I had the opportunity to travel to northeast Cambodia and study local nonhuman primate species. Getting involved in field research at the end of my three-year science degree was an experience that exceeded my expectations; not only by giving me invaluable research experience beyond lectures and laboratories, but also broadening my interests and future study prospects. Through this field school, I was able to garner expertise in the collection and analysis of qualitative and quantitative behavioural, ecological and biological data. Being able to grasp and apply these skills in a practical setting and in an unpredictable environment was something I am grateful for when reflecting back on my undergraduate studies.

\section{Field site}

The course itself ran over three weeks at Veun Sai-Siem Pang Conservation Area (VSSPCA) in Virachey National Park, Cambodia (Figures 1 and 2). VSSPCA is one of the few protected areas that lie within the Indo-Burma biodiversity hotspot, which is home to about 130 mammalian species (King et al. 2016). The site also plays host to several vulnerable and endangered species, which include a variety of nonhuman primates I had the opportunity to observe in varying capacities. Before entering the field, we received training to cover necessary research methodologies in order to 'hit the ground running'. During my time on site, I was fortunate enough to observe the brightly marked and rare redshanked doucs (Pygathrix nemaeus), the newly described northern buff-cheeked crested gibbons (Nomascus annamensis) and the endangered silvered langurs (Trachypithecus margarita). Fieldwork involved the collection of behavioural data from a habituated group of gibbons, doing ad libitum observations on unhabituated langur groups and conducting ecological transacts to collect data on local vegetation. 


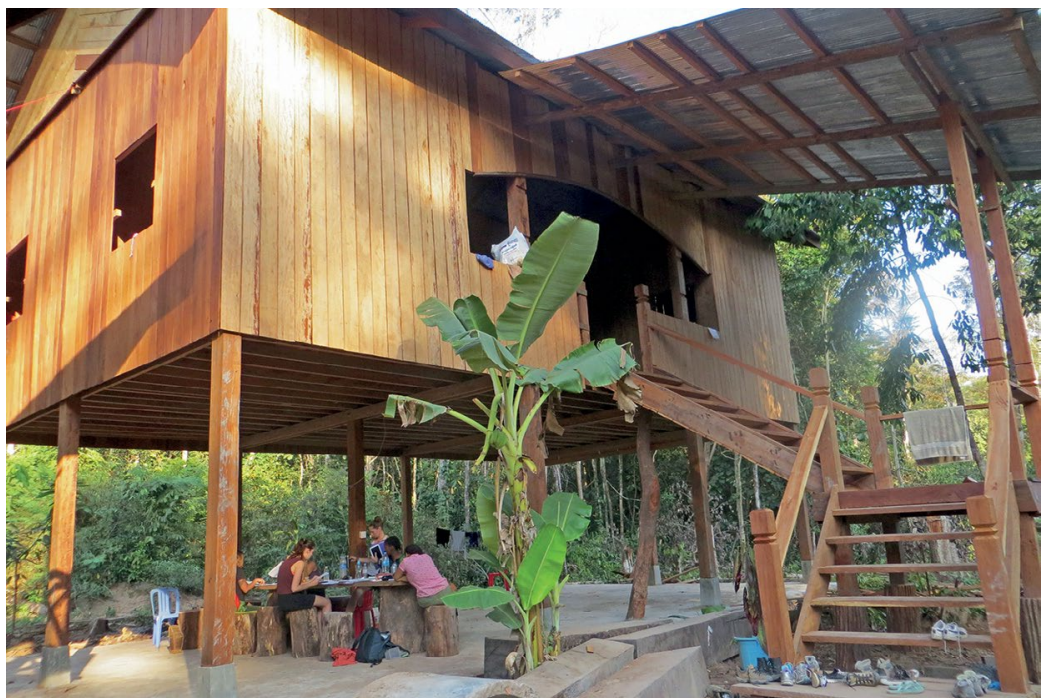

Figure 1: Raised student share house at Veun Sai-Siem Pang Conservation Area base camp with open-air study area below Source: Author.

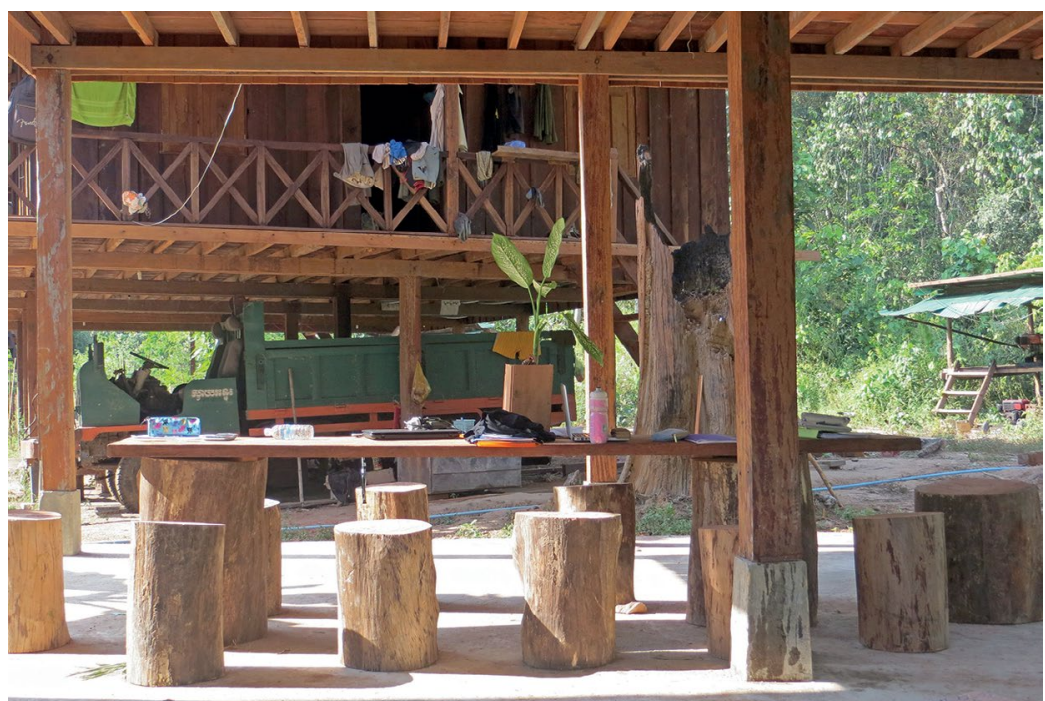

Figure 2: Student study space at Veun Sai-Siem Pang Conservation Area Source: Author. 


\section{Behavioural data collection}

Gibbon observation days were definitely some of my favourite, but they could also be some of the most challenging and frustrating. Days would start before sunrise with a group of half-awake students blindly following the local guide through the park's semidense forest to a designated calling bench located roughly 30 minutes from base camp. Male gibbons (Figure 3) started the morning with a mournful call they hoped would be reciprocated by their female mate (Figure 4) or a potential mate. Juvenile gibbons occasionally joined in with fainter calls. Groups were located by listening to these eerie calls echo across the park from a strategically placed calling bench. Once they started, we would take note of calling times, an estimated caller location, weather conditions and whether a male call would receive a response. When the habituated study group called, we would hurriedly follow our guide until the group was located and begin our behavioural data collection. Observing habituated animals was an experience beyond words. Habituation removes the confines of captivity and allows detailed behavioural data to be collected within the animal's natural habitat. Beyond observing habituated nonhuman primates, the opportunity to be observing a newly discovered species, like the gibbons studied during this field school, added a surreal feeling to the experience.

Being at the mercy of wild animals and factoring this into research was something that was also experienced first-hand. The gibbon calls played a crucial part in locating our habituated group to carry out the day's behavioural data collection; if the group did not call, we could not study them that day. This was resultantly the source of many frustrations. As a gibbon's call is not guaranteed, I soon learnt it was crucial to make smart use of the time we had with the gibbons when we did find them. Maintaining effective group relationships was an easily transferrable skill I also learnt from this experience, as group moral could easily be affected by rising temperatures or the disappointment of a sudden change in plans. This presented a very different group environment to pipetting with a lab partner or chasing up slides for a group presentation.

In addition to tracking through the bush, we also spent a portion of our time writing up field reports and analysing collected samples, such as faecal matter we collected for later hormone analysis. 


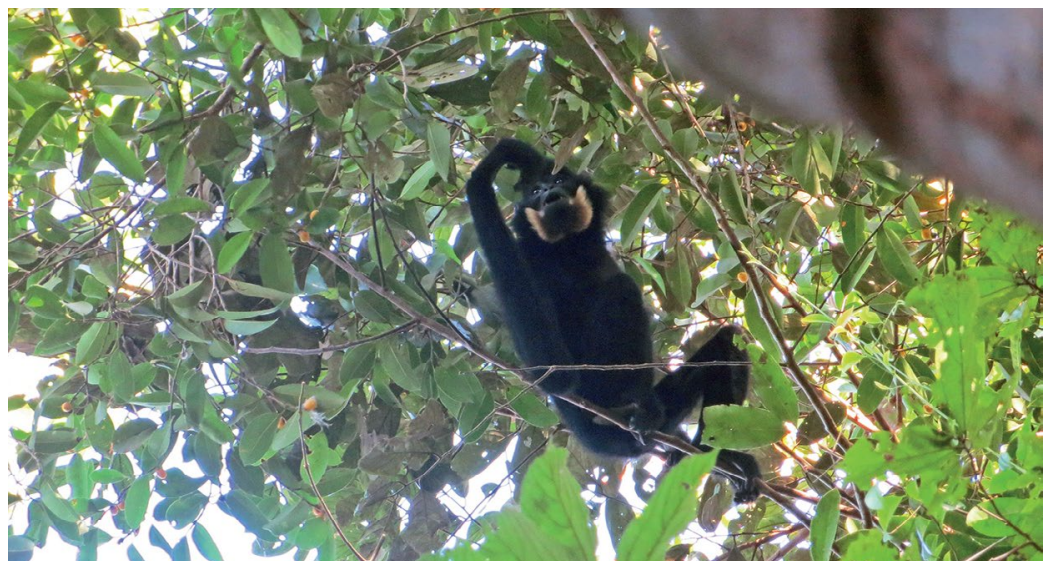

Figure 3: Habituated adult male northern buff-cheeked crested gibbon eats fruit of local gibbon feeding tree

Source: Author.

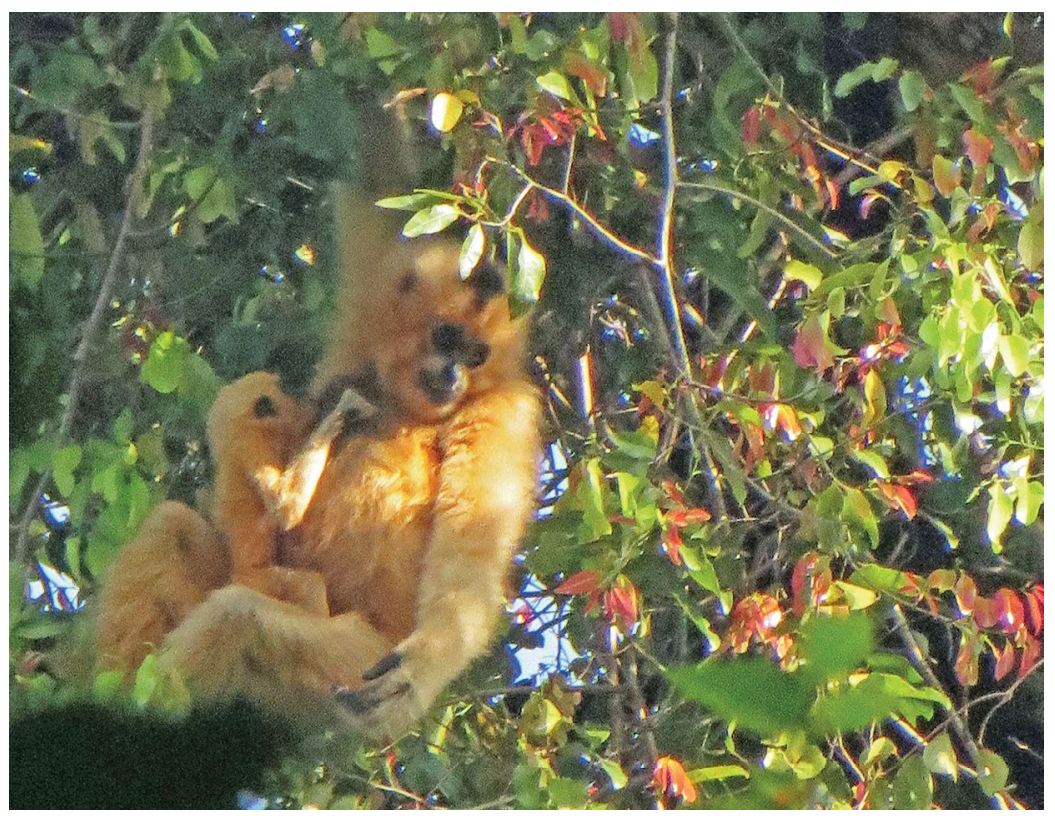

Figure 4: Adult female and infant northern buff-cheeked crested gibbons Source: Author. 


\section{Ecological analysis}

Transact analysis of the evergreen and semi-evergreen, mixed deciduous, riverine and gallery forests that made up the VSSPCA involved not only effectively applying methodologies learnt before entering the field, but also working together with local field guides to correctly identify local tree species. I was able to use some of the skills gained from this exercise-working in a group to collect data despite time constraints, being in an unpredictable environment and navigating cultural or language barriers-not only throughout my Honours year but also when I began my career in data research.

Though our main aim had been to record local vegetation and its use by our study species, we had to consider additional factors such as the impact of local human settlements on available feeding trees. Widespread deforestation was an obvious issue during our stay; we frequently heard logging as we tracked through the forests each day. Additional evidence of human impact on local vegetation included tree tapping for sap, which left gapping burnt-out holes on the sides of older trees. We were confronted by the real-life challenges of doing primate research amidst current threats, and this gave us a more holistic approach and understanding about what it is like to collect data in the fieldgoing far beyond points learnt from a textbook or hour-long lectures. The opportunity to have conversations with locals about how VSSPCA affected their lives further added another valuable component to the research.

\section{Take-home message}

Following three years of a biological science degree that heavily focused on covering scientific theory with an emphasis on laboratory-based practice, completing my studies with an opportunity such as this allowed me to come full circle. Exposure to all forms of learning, I feel, has better equipped me for both further study opportunities and the workforce. I have gained skills in effectively working in unpredictable environments with a diverse group of people, and under unexpected pressures, to produce quality results. I would recommend an experience such as this to all students, regardless of career path, as it presents a once-in-a-lifetime opportunity to learn about the practicalities of field research and to develop problem-solving skills in a way that a classroom does not provide. 


\section{Acknowledgements}

The author thanks Dr Alison Behie for coordinating and providing research guidance during the 2014 Primate Behavioural Ecology Field School. The author would further like to thank the research and ranger teams at VSSPCA for their on-site support.

\section{References}

King A, Behie AM, Hon N, Rawson BM. 2016. Patterns of salt lick use by mammals and birds in northeastern Cambodia. Cambodian J Nat Hist. $1: 40-50$. 



\title{
So that their graves overlooked the sea: Student experience of the Philippines International Archaeological Field School ${ }^{1}$
}

\section{Melandri Vlok}

\begin{abstract}
Practical archaeological experience is essential in the training of future bioarchaeologists. This essay recounts the experience received by the author during undergraduate studies at a field school held in the Philippines. The site in Catanauan, central Philippines, provides the opportunity for students to receive training in survey, excavation, heritage work, artefact analysis and research design on real archaeological material. Furthermore, the experience encouraged independent archaeological thought and true scope in relation to the theoretical aspects of the discipline that were taught in class.
\end{abstract}

Keywords

field school, Philippines, archaeology, practical experience

1 An undergraduate course offered by the School of Archaeology and Anthropology, International Archaeological Field School (ARCH2059): programsandcourses.anu.edu.au/ course/ARCH2059. 


\section{Introduction}

To be responsible for the recovery of someone's burial, to be a part of the retelling of the story of one who came before us, is both a privilege and a rare moment of human connection where the past and present blurs into one. It is a moment that cannot be described in any way, yet it is the very reason why archaeologists and biological anthropologists excavate; I have had the opportunity to experience this very early on in my career. I attended the Philippines International Archaeological Field School in January 2013, following my first year at The Australian National University, and have been back twice since. In that time, I have grown as an excavator and a researcher; yet I attribute much of my confidence in archaeological interpretation in my undergraduate work to the practical experience I received in the field school. If nothing else, the field school placed things into perspective. When you have excavated at a real archaeological site, concepts learnt in class feel less foreign. The skills I had acquired in the Philippines field school then became foundational to my further learning.

\section{Napa site, Catanauan}

The Philippines field school, known as the Catanauan Archaeology and Heritage Project, is held at Napa site in Catanauan, on the southern border of Luzon Island. Overlooking the beach, the site is from the Metal Period dating from the 1st to 10th century CE (Vlok et al. 2017). The burials uncovered at Catanauan were predominantly placed in large earthenware jars. However, a number of extended supine burials have also been uncovered (Paz et al. 2016; Figure 1). There are eight localities present at the site, with extensive archaeological material retrieved from Localities 1 and 4 . The position of the ocean in relation to the burial site, and the presence of a shell midden overlaying the burials in Locality 1 , suggest that the ocean was important for the life-way practices of the people buried at Napa site. The 2018 season will be the 10th year of excavation at the site, indicating the extensive archaeological potential, and, along with the presence of artefacts entirely unique to the site, makes Napa a site of importance for understanding the prehistory of the Philippines and the greater Southeast Asian region in this time period. 


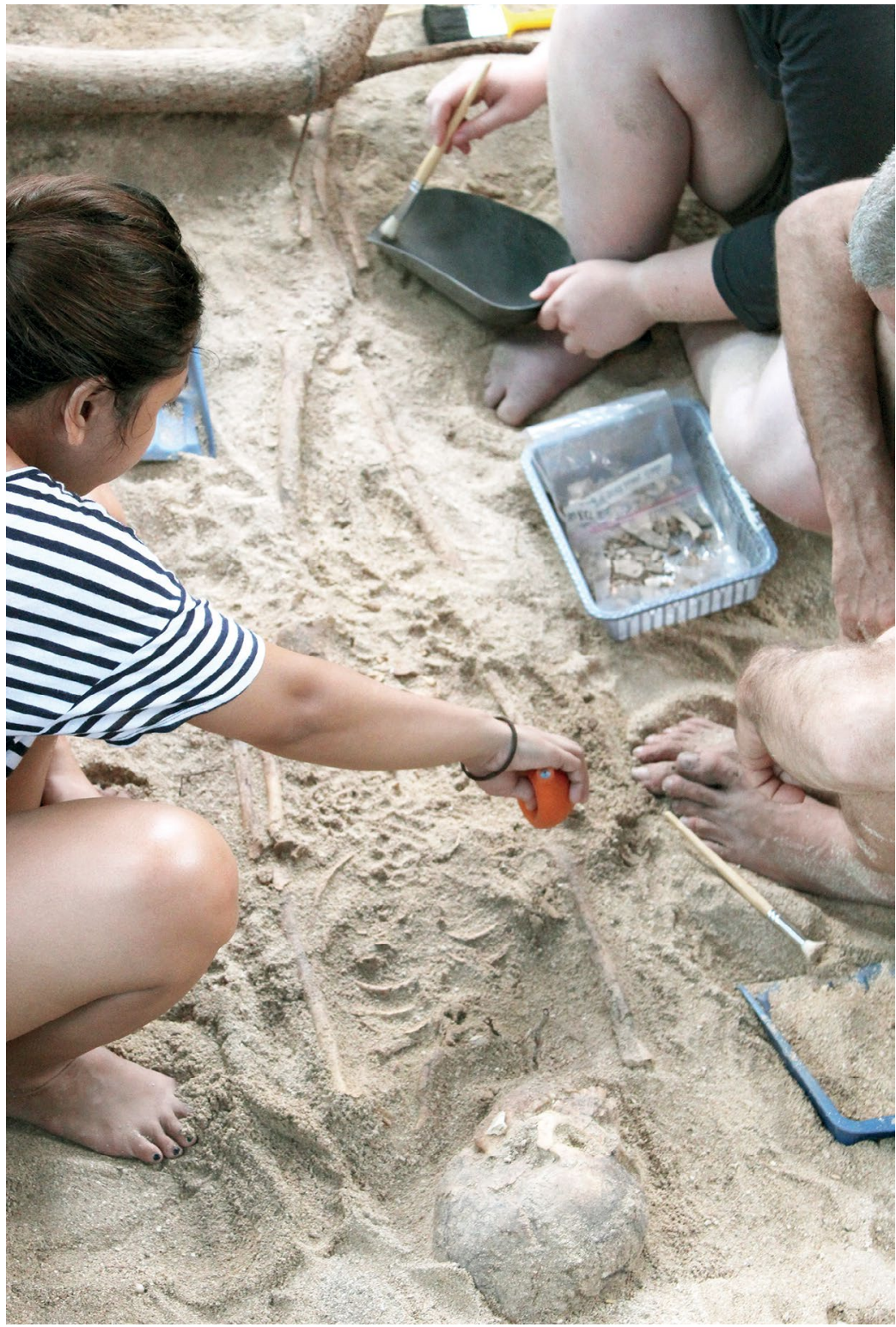

Figure 1: One of extended burials being excavated at Napa site Source: Author. 


\section{Excavation}

The excavation period of the field school runs over the course of two to three weeks, and allows all participants in the course to be involved in every aspect of the excavation. Within one field season, I experienced field walking surveys, dumpy level surveys, artefact recording, soil type identification and excavation of bone, shell, pottery and metal implements. Furthermore, I had the opportunity to engage with the local community in relation to the ongoing heritage work at the site, as well as complete museum inventory of artefacts. These aspects of excavation are often not available on field schools, yet are very important in research access and impact.

The excavation ran every day with breakfast beginning at $6 \mathrm{am}$, and everyone in the field by 7 am to beat the midday sun. By lunchtime, a midday break was taken where many caught a quick siesta in a hammock, bought snacks at the local mart called a 'sari sari store', or had a quick dip in the picturesque ocean mere metres away from the site (Figure 2). Following this, it was back to the trenches until 4 pm, where 'rounds' were held across the site and the day's happenings in the trenches were recounted so that everyone was aware of what was happening in the excavation beyond their small area.

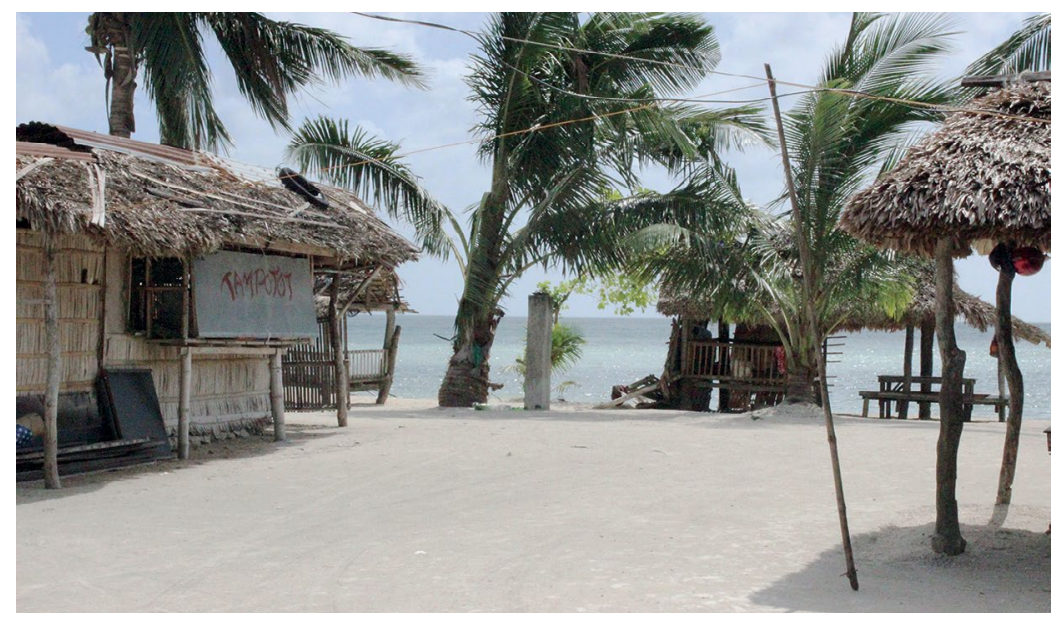

Figure 2: The site overlooks the ocean, suggesting coastal influence on the life ways of the Napa people; it is also nice for a dip during the lunch break or at the end of the day

Source: Author. 
The excavation was run in a flexible way that made it possible for us to receive more training in any aspect of excavation if we felt the need to. In this way, students were able to receive training catered to their wants and needs while also receiving general training in all areas of excavation. The nature of the cultural material at the site is diverse, and therefore attracted students with a number of different interests.

At the end of each excavation day, night-time lectures were scheduled and were aimed at expanding our knowledge of the archaeology of the greater region, as well as providing theoretical background for what was being put into practice during the day. This allowed our work to be put into the bigger context of biological anthropology and archaeology.

\section{Postexcavation artefact analysis}

Following the excavation, analysis of shell and pottery was undertaken to give us further research skills in identifying earthenware types and shell species. Once the excavation was complete, this field school offered the option of taking an extension course run during the first semester of the year. This course uses postexcavation analysis to further interpret the material and data collected. This enabled us to advance our interpretative skills and overall contributed to the narrative of the people we uncovered who had lived almost 2,000 years ago.

\section{Acquired experience}

The benefits of the field experience in the Philippines went well beyond just learning excavation skills (Figure 3). The opportunity to work alongside professionals in the field-including bioarchaeologists, archeobotanists, ceramic analysts, and geographic information system (GIS) and mapping specialists-meant I learnt from some of the best in the field. Furthermore, as the Napa excavation is a joint collaboration between The Australian National University and the University of the Philippines, the excavation provided an opportunity to work with students from a different academic upbringing, and therefore different perspectives and strengths. This only served to further expand my knowledge and skill in the field of archaeology. 


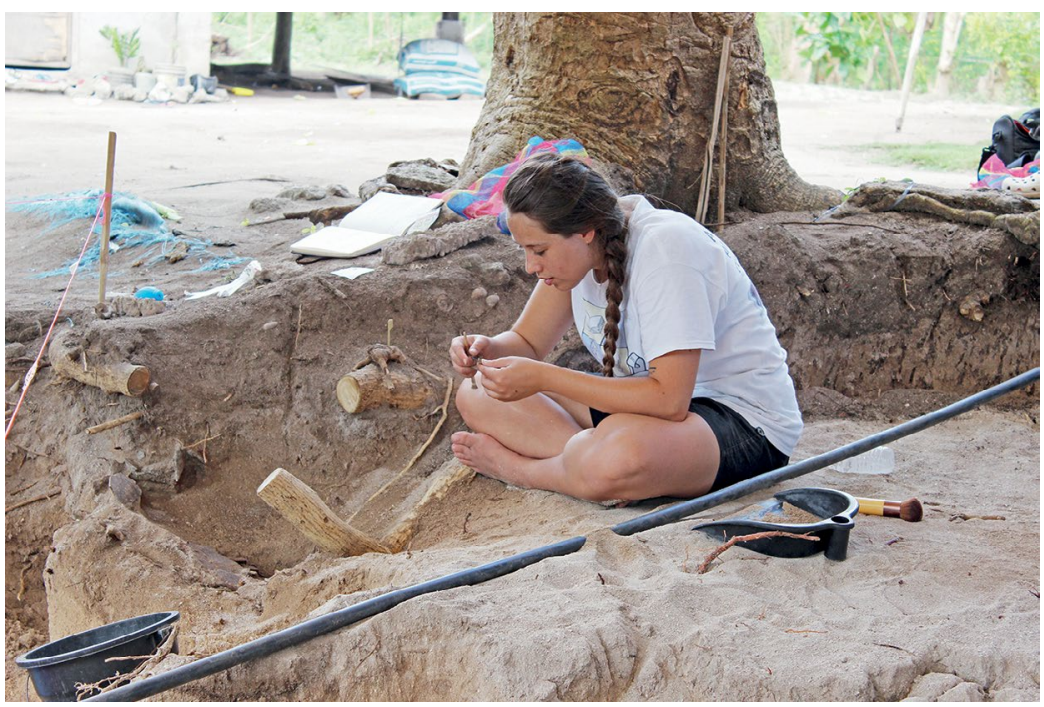

Figure 3: Melandri Vlok excavating at Napa site

Source: Bonnie Taylor.

I was always encouraged during the excavation to explore interpretations of the site, and my opinions were always considered valid. Such an environment assisted in the development of independent thought and encouraged me to think beyond the material finds and to consider the true implications of these artefacts for our understanding of the people of the past. This served to assist me in becoming a better bioarchaeologist.

Given the broad range of activities in the Philippines field school-which included surveying, excavation, heritage work, artefact analysis and research design-I was well equipped with practical experience and theoretical foundation going into my second year at university. More importantly, I approached my archaeology and biological anthropology studies with more confidence as I had a sound frame of reference given my real archaeological experience. 


\section{Acknowledgements}

I would like to thank Professor Marc Oxenham, Professor Victor Paz, Dr Rebecca Crozier, Christine Cave and Don Matthews for their continued efforts in nurturing the minds of future archaeologists at the field school. I would also like to acknowledge Ermilando Napa, Captain Leopoldo Quindoza and other members of the Barangay council of Tuhian, and the people of Tuhian, for their support of this ongoing field school.

\section{References}

Paz V, Oxenham M, Ramos J, De Castro L, Matthews D, James H, Cave C, Claravall F, Rider C, Reasonda N, Vergel D, Palconit T, Vlok M, Orizar I, Sheehan S, Katigbak G, McKenzie G, Walker M, Baker N, O’Brien D. 2016. Catanauan archaeology and Heritage Project, report on the 8th field season. University of the Philippines (Diliman): Archaeological Studies Program.

Vlok M, Paz V, Crozier R, Oxenham M. 2017. A new application of the bioarchaeology of care approach: A case study from the metal period, Philippines. Int J Osteoarchaeol. doi.org/10.1002/oa.2588 



\section{Author biographies}

\section{Terri Fisher}

Terri is an Honours student at The Australian National University (ANU). She is currently studying biological anthropology after completing her Bachelor's degree majoring in biological anthropology and history in 2016.

\section{Tess Johnson}

Tess is a fourth-year flexible double degree student, majoring in biological anthropology, linguistics and biology. She takes a particular interest in demography, an area she only had exposure to later in her degree. It is for this reason she has produced the essay contained in this journal on birth seasonality-to her, a fascinating phenomenon due to its great diversity of causes and differing trends across the world.

\section{Sarah Martin}

Sarah has completed a double undergraduate degree in arts and science, with majors in biological anthropology and biology. She is currently doing her Honours in the division of ecology and evolution, looking at sodium availability for koalas in high-altitude areas. Once this is complete, she is hoping to do a postgraduate veterinary science degree as she loves working with animals and being able to apply her scientific knowledge.

\section{Cynthia Parayiwa}

Cynthia Parayiwa, Bachelor of Science/Arts (Honours), is currently employed as a data research analyst reporting on Australia's community services sector. Her interests broadly include researching and exploring innovative approaches to reporting on human health and welfare. Her studies have more specifically 
fed her interest in nonhuman primate conservation and more passionately her interest in researching the development of human perinatal health outcomes following stressful events such as environmental disasters.

\section{Phoebe Raff}

In 2015, Phoebe graduated from the School of Archaeology and Anthropology, ANU, with Bachelor of Arts degrees in archaeology and biological anthropology. Her interests are in primates and the environment, and it was for a primate ecology and behaviour course in her third year that she originally wrote this essay. Currently, Phoebe is doing a Master of Environment at the Fenner School, ANU, hoping to specialise in biodiversity conservation and management.

\section{Rebecca Jade Sullivan}

Rebecca Sullivan is a recent graduate from a Bachelor of Science (majoring in biology and biological anthropology) and a Bachelor of Science (Psychology). Her main research interests are in animal cognition and behaviour, particularly tool use, culture, consciousness, language, problem solving and personality in nonhuman primates and birds. She is also interested in research methodologies and statistics, and is currently employed as a researcher and data analyst within the federal government. In July 2017, she begins researching the impact of sublethal high temperatures on foraging behaviours and chick provisioning in birds for her Honours year.

\section{Victoria Tasker}

Victoria has a Bachelor of Archaeological Practice from ANU with a specialisation in forensic anthropology and archaeology. In July 2017, she completes a Masters in Museum and Heritage Studies from ANU.

\section{Melandri Vlok}

Melandri Vlok completed her Bachelor of Science/Bachelor of Arts (Honours), majoring in biological anthropology, with the School of Archaeology and Anthropology, ANU, in 2016. Her research focus includes bioarchaeology and palaeopathology, which she plans to pursue further in her $\mathrm{PhD}$. Melandri has a particular interest in studying ancient health and disease in the Southeast Asian region. 


\section{Jessica Williams}

Jessica graduated from ANU with a Bachelor of Arts, a Bachelor of Science (Honours) and no desire to settle into an adult job but rather to adventure. She enjoys seeing, experiencing and learning from the natural world, which is diminishing at a scarily fast rate and would like to contribute to conservation efforts. Jessica's PhD research will see her head off into the jungles of Asia and produce best practice guidelines for tourism involving wild gibbons, which, if managed correctly, can support local communities and conservation initiatives while ensuring the welfare of the animals. 
